\title{
The transition towards circular economy and waste within accounting and accountability models: a systematic literature review and conceptual framework
}

\author{
Assunta Di Vaio' ${ }^{1}$ - Sohail Hasan ${ }^{1}$ (D) $\cdot$ Rosa Palladino $^{2}\left(\mathbb{D} \cdot\right.$ Rohail Hassan $^{3}(\mathbb{D}$
}

Received: 13 December 2021 / Accepted: 18 December 2021 / Published online: 7 January 2022

(c) The Author(s), under exclusive licence to Springer Nature B.V. 2022

\begin{abstract}
A transition towards a circular economy is a challenge. It is vital to know that circularity and sustainability are two different segments. So, circular economy can only be achieved in the long-term perspective. This study investigates accounting and accountability for circular economy and waste. Considering these principles and based on a critical review of the literature, economic gains from the transition toward a circular economy are measurable; the problems for corporations and governments are diverse; the way to handle the stakeholders who are losing control in the circular economy is considerable. Diffusion of innovation theory is used to conduct this study. It is essential that an organisational design built should help implement the circular model. Targeted questions responded by adopting a systematic literature review approach by applying PRISMA protocol. This study examines 78 publications in English between 2012 and 2021, which present a map of the circular economy-related knowledge published in web of science and Scopus. Besides, this study includes 03 European Commission reports, 01 Ellen Macarthur Foundation report, 01 Council for the Environment and Infrastructure report, 01 report from SUN IZA, 01 UN Global Compact and 01 the Brundtland Commission report. The results highlight how circular economy, waste management, sustainability, accountability, and management accounting practices help to develop an ecosystem and achieve sustainable development goals of the United Nations 2030 Agenda. Theoretical and practical implications are discussed.
\end{abstract}

Keywords Circular economy and waste $\cdot$ Sustainable development goals $\cdot$ Digital transformation $\cdot$ Accounting practices $\cdot$ Accountability practices

\section{Introduction}

Developmental waste management that facilitates new business models, design thinking, and a more productive approach for consumption and production are all the circular economy (CE) concepts as per recent literature. We have existed in a linear economy since the

Assunta Di Vaio

susy.divaio@uniparthenope.it

Extended author information available on the last page of the article 
industrial revolution. Our consumption and habits for "special use" make the planet a world of "taking, creating, and disposing of" (Esposito et al., 2018). Due to institutional voidnesses, packaging waste management in poorly institutionalised nations, such as emerging nations, is challenging. Large MNEs for fast-moving consumer goods (FMCG) have to reconsider how they see their products. Consumers are becoming increasingly inclusive where packaging forms part of their product (Ajwani-Ramchandani et al., 2020). The findings show that the pillars of institutional quality (such as voice and accountability, the rule of law, and regulatory quality), the value created per capita, and participation in ecological associations are all important variables for a successful waste separation process. These factors are particularly significant for collecting organic waste, paper, glass, and plastic (Agovino et al., 2020). The extent to which the study can alter that addresses the people who do it is doubtful. This issue motivated some researchers to devise strategies to mobilise social and environmental accounting research to advocate organisational change inside the capitalist system (Adams \& Larrinaga-González, 2007). There is a growing availability of information about environmental management accounting in municipal waste management (Qianet et al., 2011).

A burgeoning accounting literature is emerging, the circular economy, and the COVID19 epidemic, testing some concepts to inform an ecological criticism of accounting that might help us fight off "dreams of escape" the ecological disaster (Latour, 2018). Investors, creditors, consumers, and the government are all potential users of accounting data. These users are uninvolved in the day-to-day operations and administration of the firm. The branch of accounting that gives information to non-accountants is known as financial accounting (Warren et al., 2012). The incorporation of CE into professional practice accountability frameworks has been one of the most significant improvements in the last 20 years. As regulatory bodies tried to develop accountability mechanisms, participation in CE was typically the method of choice. On the other hand, these new criteria have been chastised for ostensibly encouraging accountability while doing little or nothing to address the fundamental issue of competency (Queeny, 2000). The term "accountability" has become a buzzword in modern government. Each two-year cycle between 2001 and 2006, the phrase "accountability" featured in the title of between 50 and 70 bills filed to the US Congress (Dubnick, 2007, 8). The concept of accountability is very complex but have a core meaning. "Accountability is the quality or state of being accountable; especially an obligation or willingness to accept responsibility or to account for one's actions (Merriam -Webster, 2004)".

In the background of a CE viewpoint, Bohringer and Rutherford (2015) presented and evaluated a model that analyses and examines the economic implications of a technical transition and regulator policies, emphasising how to improve finite resources' assignment efficiency. According to Tuladhar et al. (2016), the authors developed a computer model that simulated and evaluated $\mathrm{CE}$ scenarios to reduce new resources and produce waste not reused in output. On the other hand, the concepts of $\mathrm{CE}$ are (a) the equilibrium between stock and sustainable flows is controlled; (b) inventory, commodity, or part usage is circulated as far as possible; and (c) the application of modern models reduces negative externalities of output and consumption processes (Jabbour et al., 2019).

In a $\mathrm{CE}$, the focus is on waste, a constantly circulating resource in any economy. Unchecked waste generation and building up inappropriate material in waste disposal sites challenge and industrial growth globally, making it difficult to reach the sustainable development goals (SDGs) adopted by the United Nations (UN) general assembly formally in 2015 under Agenda 2030 (Elgie et al., 2021). Three pillars of sustainable development are directly or indirectly linked to waste management: economic growth, environmental health, 
and social health (Lenkiewicz, 2016; Schroeder et al., 2019). Material flow accounting (MFA) is an accounts tool that proposes a system-based solution relating to importing, consuming, and recycling of goods. MFA helped find issues and prospects for waste management of different economies (Eckelman et al., 2014; Millette et al., 2019). It is significant to identify and quantify factors that help to measure and control waste. Furthermore, it is concluded that quantitative measurement and assessment of waste management processes are essential because decision-makers cannot control what they cannot quantify. Sound data are vital in leading the transition to sustainable, circular waste management systems (Imoniana et al., 2020; Elgie et al., 2021).

It is found that companies attempt to counter rapid technological development, significant environmental challenges (WCED, 1987; Murray et al., 2017), and national and international directives that are much more draconian (European Commission, 2011, 2017; Mathews \& Tan, 2011, 2016) also evidence by Rosa et al. (2019). According to Ciulli et al. (2019), the company intermediary network association has become a new organisation that takes an innovative approach to waste recycling thanks to the surge of digitalisation. Digital innovations offer these organisations the possibility of creating a market model to recover waste from the site. It is puzzling that the missing concern of the market-intermediate platforms based on food waste recovery, primarily because of its legal, environmental, and social value. Furthermore, Pagoropoulos et al. (2017) found that the literature analysis determines it; the application of the digital technologies indicated in the transition to the circular economy is significant. There has been no apparent demarcation between multiple layers of technology in several areas of study and practice, such as distributed headlines, blockchains, and smart contracts (Casino et al., 2019; Crosby et al., 2016). Otherwise, this methodology is suitable for generating modern, practice-based theoretical perspectives (Langley \& Abdallah, 2011).

Reporting practical CE implementation activities will help researchers and enterprises develop awareness about sustainable circular economic business models and businesses to hear about the circular ecological economy business models (Upward \& Jones, 2016; Arjaliès \& Mundy, 2013; Cho et al., 2020; Kirchherr et al., 2017; Michelon et al., 2019). Moreover, scientists can demonstrate the relevant results (Reike et al., 2018).

There is a considerable research gap in fresh ideas about converting a linear business model (BM) into a circular one in practice. Indeed, there is still a clear line supporting a BM shift from a linear economy to CE (Rosa et al., 2019). It is important to remember that circularity is not always synonymous with sustainability and that CE should only be pursued in the context of long-term sustainability. Unfortunately, despite numerous attempts and advancements in many areas, the remnants of earlier and current linear approaches continue to haunt and obstruct our efforts to reform our resource recovery systems (Iacovidou et al., 2021). On one side, theories of science principles are given mainly to corporations and policymakers. On the other hand, the best practice is too difficult for small- and medium-sized firms to implement. This study investigates the accounting and accountability for circular economy and waste $(C E \& W)$, considering these principles and building on a critical literature review. Furthermore, it emphasises and clarifies the aim of this study on how CE, waste management, accounting, and accountability models by implementing digitalisation to develop an ecosystem that ultimately provides firm grounds to achieve the UN 2030 Agenda. It is concluded by Carmona and Ezzamel (2007), historical accountability worked in three spheres: the individual state, the state, and the individual. The spheres were managed by canals that make hierarchically, horizontally, and automatically. These degrees of accountability were based on religious and societal rules and beliefs, but accounting played an important part. According to Immoniana et al. (2021), technological 
maturity might be related to CE uptake. The link between auditing and the circular economy is based on sustainable technology, which is still developing in different organisational aspects. The harmful impacts of unsustainable and environmental consumption and production pattern are hard to regulate. It is vital to investigate to increase resource performance across the world economy significantly. This phenomenon enhances social sustainability, ecology, and economy, leading to a new paradigm shift (Rajput \& Singh, 2019a, 2019b). Indeed, these newly growing criteria are promising but strongly criticised for their willingness and worthy focus (Jamali, 2010). Mainly, this study investigates how digital transformation influences accountability and accounting models to achieve the CE\&W. Data collection provides ample evidence that previously no rigorous systematic literature review was conducted while using appropriate theory and bibliometric analysis using VOSviewer. Moreover, there is a dire need to address this current paradigm shift because these terminologies and keywords have passed through the evolution stage. It ensures the novelty of why an SLR is novel to demonstrate harmony and synergy among accounting, accountability, and CE\&W. Which suggests an appropriate mode to address this paradigm shift and define measures to adopt (actions) under the pinning theory of diffusion of innovation. A systematic literature review approach is adopted to respond to targeted questions (Massaro et al., 2016). However, quantitative and qualitative methods can both be modified in accounting analysis. This study will address the following research questions (RQ):

RQ1 What is the role of accounting and accountability for the circular economy and waste?

RQ2 How do accounting and accountability models achieve the circular economy and waste towards the UN 2030 Agenda?

RQ3 What is the role of digital transformation in the accounting and accountability models for a circular economy and waste?

Under the lens of "diffusion of innovation (DOI) theory", this study would illuminate the new position of the circular economy and waste accounting and accountability. It further outlined the emerging deficiencies in CE\&W literature and reflects the effect of digital transformation and accountability models in the UN 2030 Agenda, bibliometric and literature studies, and a systems analysis on the accounting and waste circle economy. This study answers the following questions by a bibliometric analysis of 78 articles.

The arrangements of this study outline are as follows. Section 2 introduces the theoretical background. Section 3 details the methodology. Section 4 highlights the data analysis and results. Then, Sects. 5 and 6 will provide an in-depth discussion on the results; the development of research propositions, theoretical and practical implications, policy recommendation, limitations of the study and conclusions.

\section{Theoretical background}

\subsection{Background theories and theory in action}

There are additional possibilities for study in these areas as theoretical inter-pollinations of directly used ideas at the same research stage. It can be generalised and related to big data and IT organisations and technology theories in one area, such as economic and policy theory (CE) (Jabbour et al., 2017). Two institutional theories, New institutional sociology and old institutional economics have evaluated the findings. In order to develop an analytic approach to give a more contextual one and in the words of Creswell, "real" and "alive" 
insights have been taken from these two theories (Contrafatto, 2014). Neo-institutional theory gives scientists a practical and informative toolkit to create ethical living and ecological thinking commitments and encourage a sustainable future route (Ball \& Craig, 2010). The power shift with dedicated funds has allowed shared interests between accountable and those engaged in technical work, research shows (Collier, 2001).

MNCs in underdeveloped nations are often accused of using weak rules, authoritarian regimes, and inadequate environmental rules, avoiding calls for transparency and accountable profitability and short-term advantages (Kolk et al., 1999; Shamir, 2004; Waddock, 2004). The challenge of controlling MNCs' free space and influence is not new: the introduction of International CSR Accountability Norms seems to give fresh perspectives and promise for improved transparency by fostering good behaviour and convergence around shared values (Williams, 2004). 'Power circuits' might be beneficial to provide a more vibrant description of how institutional forces influence organisations and provide a more extensive explanation of changes/reproductions, particularly in organisational contexts, of the rules followed by the institutions (Ribeiro \& Scapens, 2006). One of the first theories in social sciences is DOI theory, founded by E.M. Rogers in 1962; in a given demographic or social structure, an idea or a commodity gains popularity and diffuses (or spreads) over time. An in-depth literature review shows that large- and small-scale organisations adopt digitalisation, enabling DOI theory functions. The key to achieving an ecosystem that allows accounting and accountability models, sustainability, waste management practices ultimately leads to achieving the UN 2030 Agenda.

There is no doubt that legitimacy, and institutional theories played a significant role during the evolution of SDGs benchmarking (D'Adamo, 2019). The crossing of functional integration is vital nowadays for the correct declaration of innovative processes, harmonising engineering and economic ventures (Koksharov et al., 2019). According to Boons et al. (2013), radical creativity and innovative market models have to develop the CE paradigm. Bocken et al. (2014) argued that the surplus sources for businesses could be considered lost, ruined, or wasteful. On the contrary, waste sources will deliver value innovation opportunities by new practices and partnerships through catching lost value. Gregson et al. (2015) stated that a recent study has also been undertaken in the EU with conflicting $\mathrm{CE}$ social and physical scales to promote creativity to save factory jobs. Comments show a favourable role in linking sustainable development to $\mathrm{CE}$ by renewable resources (D’Adamo, 2019).

\subsection{Circular economy and waste, accounting, and accountability}

The definite dates of 2021 and 2012 raised the urgency, ambition because the CE does not strictly describe what it means; however, this uncertainty and wide range seem to have increased this appeal to date. According to the DOI theory, it gives space to creativity and strengthens dedication to extending, challenging, and disrupting the situation. In conclusion, all the objectives are highlighted by CE programs, which reveal their roots in current activities. Digitalisation will play a key role in harmonising accounting and accountability models, sustainable development, which collectively as an ecosystem will contribute to achieving SDGs adopted under the UN 2030 Agenda. According to Rajput and Singh (2019a, 2019b), The integrated industry 4.0 CE can improve sustainability, reuse and remanufacture goods to evolve technologically, and is more suited to automation and process innovation. 
According to The Ellen MacArthur Foundation (2013), CE transformation cannot use only to overlay the linear economic model "take, create, and dispose of", and three concepts are described in this regard by the Ellen MacArthur Foundation; (a) "design out waste and pollution" (b) "keep products and materials in use" (c) "regenerate natural systems". The European Union (EU) approved the 2015 CE Action Plan (European Commission [EC], 2015); in January 2018, there was a "Circular Economy Package" (EC, 2019). In the Implementation Plan, the program itself will be in operation by 2030, "instrumental in achieving the SDGs and objective twelve (12) to achieve sustainable consumption and production patterns" (EC, 2015, p. 3). Accountants who aid organisations through the intricacies of the era and scholarly viewpoints need information. The strong impact of climate change on the world is enormous as food production systems are moving, water strain, biodiversity, and the human population globally are disturbing (Vallero, 2019; Bouten \& Hoozée, 2021).

A document entitled "Platform for Accelerating the Circular Economy" (PACE) was issued by the World Economic Forum in 2017, in partnership with many organisations, including the Ellen MacArthur Foundation and the World Resource Institute, to implement CE values on a global scale (Sikdar, 2019). It is observed that a linear economy's pollution harms the environment and human health. Instead, waste introduced into a circular economy that emerges from various processes offers "beneficial artefacts". According to Kirchherr et al. (2017), multiple studies contribute to the conceptualisation of CE. Several contributors have made the following remarks. The first is that $\mathrm{CE}$ is not often related to $3 \mathrm{R}$ (reduction, reuse, reuse) and waste hierarchy in general but is usually only referred to within the recycling environment. Second, $\mathrm{CE}$ is a shift in the status quo and a change to the framework. The third indicates that $\mathrm{CE}$ and sustainability are poor because economic growth is considered environmental quality. However, impacts on social justice are not evaluated. Finally, the challenge is the close synchronisation of social and technical characteristics. The end performance will be creating appropriate technologies to process this waste. According to D'Adamo (2019) the CE model is essential to build a close loop cycle as a linear model substitute, argues the author. For this reason, the meaning concept for both the atmosphere and the economy must be illustrated.

\subsection{Circular economy and waste, digitalisation and SDG's}

According to Mayer et al. (2019), a mass balance approach refers to a broad-filed accounting system for resource transfer. A full range of metrics, calculating size and circularity and closing socioeconomic and environmental loops between the overall material and waste streams are proposed. Jacobi et al. (2018) concluded that it is methodologically possible to integrate multiple data sources into the single CE reporting system, even though it involves technical difficulties in data aggregation and data coverage, and derivative metrics.

According to Okoli and Schabram (2010), today, the information systems (IS) study has virtually unknown the systematic, structured technique for performing an SLR, evolving in health sciences and other areas. CE model can be an advantage for small businesses if they can intervene with the production/sale of green goods while at the same time demonstrating an increasing interest in the brand (De-Juan-Vigaray \& Seguí, 2019). Each year, onethird of food provided for human consumption is discarded, mentioned by the UN Food and Agriculture Organisation. The analytical method highlights that the transformation to CE may respond to the local business problem (FAO, 2017). The irony is that one billion people worldwide are still suffering from food scarcity is a cause of immense ethical waste, as scholars and practitioners stress (Ribeiro et al., 2018; World Bank, 2014). Ciulli et al. (2019) 
mentioned that sustainability literature has highlighted how to blame emissions and spread food waste across the supply chain. Digital transformation-based platforms enable users to register and share food periodically (Bockel et al., 2020). Six brokerage functions established on food waste platforms: connecting, informing, protecting, mobilising, integrating, and measuring. It is concluded that a new development recently seen in the food and other supply chains of the digital marketplace has helped the recovery of waste by bridging the vacuum of circularity (Ciulli et al., 2019). In terms of measurement and implementation of CE, there are numerous challenges. For instance, Littengerger (2020) concluded that Croatia is the country's paradigm where it must comply considering the EU legislative structure. The application of the waste hierarchy is incomplete, and the handling of waste is over-emphasised.

According to RLI (2015), resource shortage and efficient use are essential concerns for the twenty-first century. One of the challenges is the economic value-creation method, which generally follows the linear economy: the extraction of resources, manufacturing the product, utilising the product, and waste disposal (Andrews, 2015). Although the Dutch Government accepted the 2012 CE transition (Tweede, 2012), circular companies are inconvenienced by liner economy firms, some of which relate to the accounting environment (SER, 2016).

Accounting standards and recommendations must bring, and the accounting experts need to know how to integrate CE into their operations (SER, 2016). There is still a tremendous gap in waste resource quantification in the global economies and tracking these waste resources from scratch to consumable goods with verifiable digital technologies as far as management is concerned. On the other hand, where accounting and accountability play their role, there is still a lack of implantation of accounting standards and low expertise of accountants in these areas, leading to inferior accountability measures. This vicious cycle evolves due to the limitations of linear economies and the slow pace towards the transition of CE. This vicious cycle is the key hurdle in developing an optimised ecosystem to achieve the UN 2030 Agenda. DOI theory reinforces digitalisation with all its segments will open new horizons of innovation to develop an ecosystem where accounting, accountability, sustainable development, and CE\&W will be optimised to achieve the goals included in the UN 2030 Agenda (see Fig. 1). It is evident from the reports of international organisations, European institutions, and industry (see Table 1) that it is essential to adapt and implement accounting and accountability models for the smooth transition towards a circular economy and waste.

\section{Methodology}

A quantitative analysis system is used in this article. Between 2012 and 2021, seventy-eight (78) articles from Scopus and Web of Science (WoS) were gathered for analysis based on research and technique offered in previously published bibliometric studies (Bonilla et al., 2015). In addition, eight (08) reports from international organisations and institutions are also considered to conduct this study. It evaluates articles related to CE, accounting, waste management, digitalisation, and the UN 2030 Agenda. The Scopus and WoS databases were picked as sources based on different abstracts, references, and scientific summaries following established processes (Fink, 2010, 2014, 2019). Content analysis is an investigative technique that uses software to organise comparative samples of multiple documents on the same subject (Krippendorff, 2004; Massaro et al., 2016). According to Elsevier (2020), Scopus is the biggest curated and reviewed abstract and indexing database 


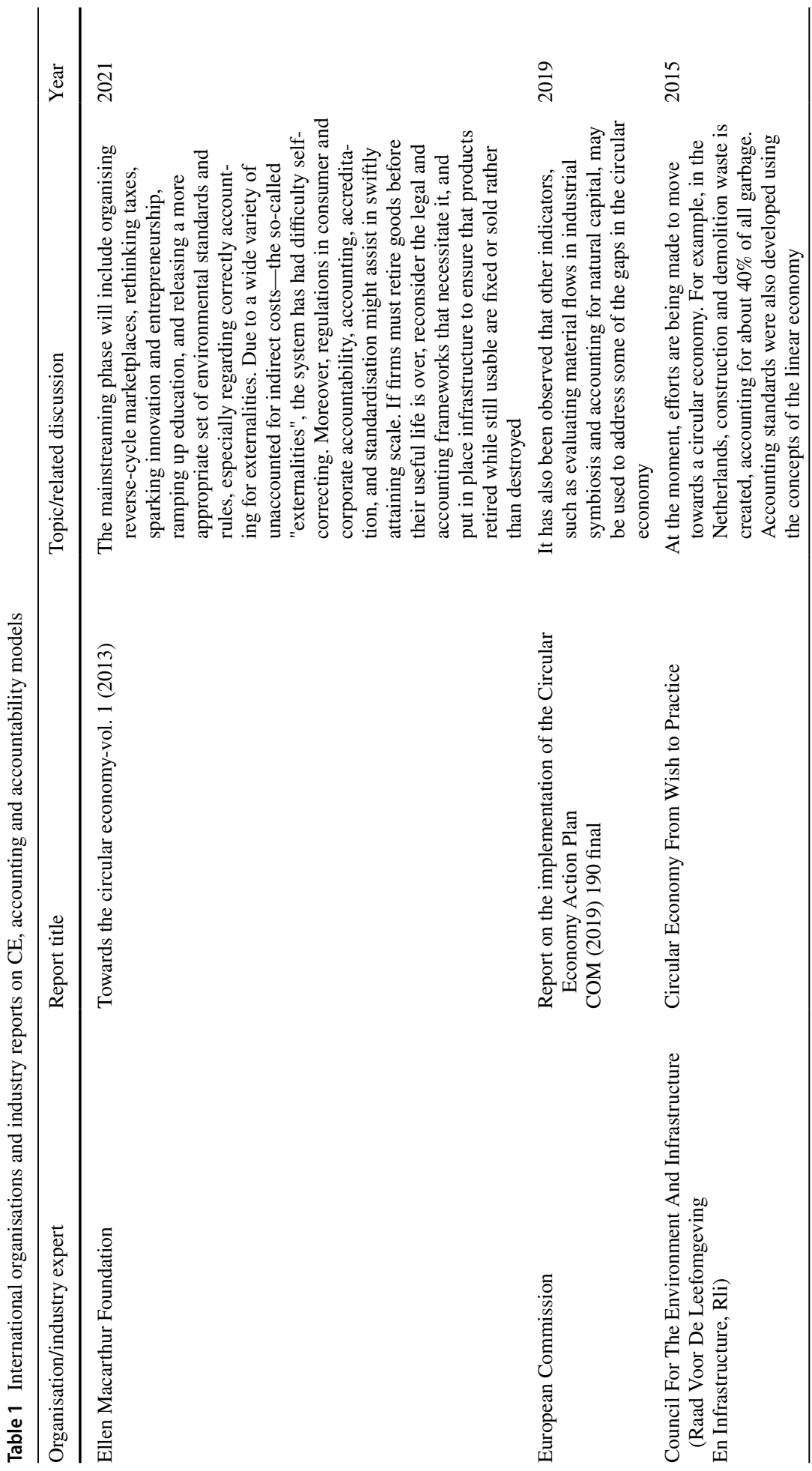




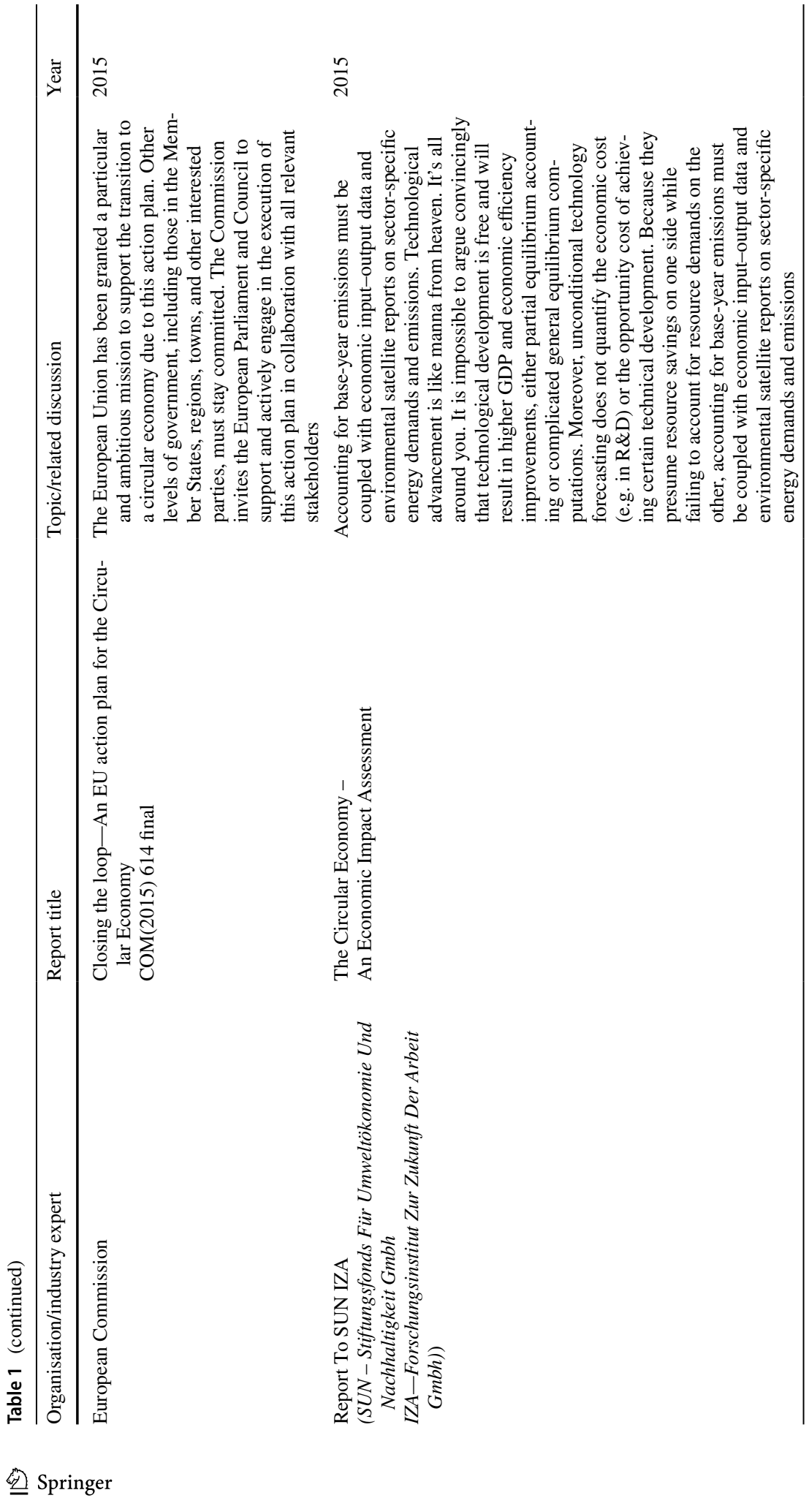




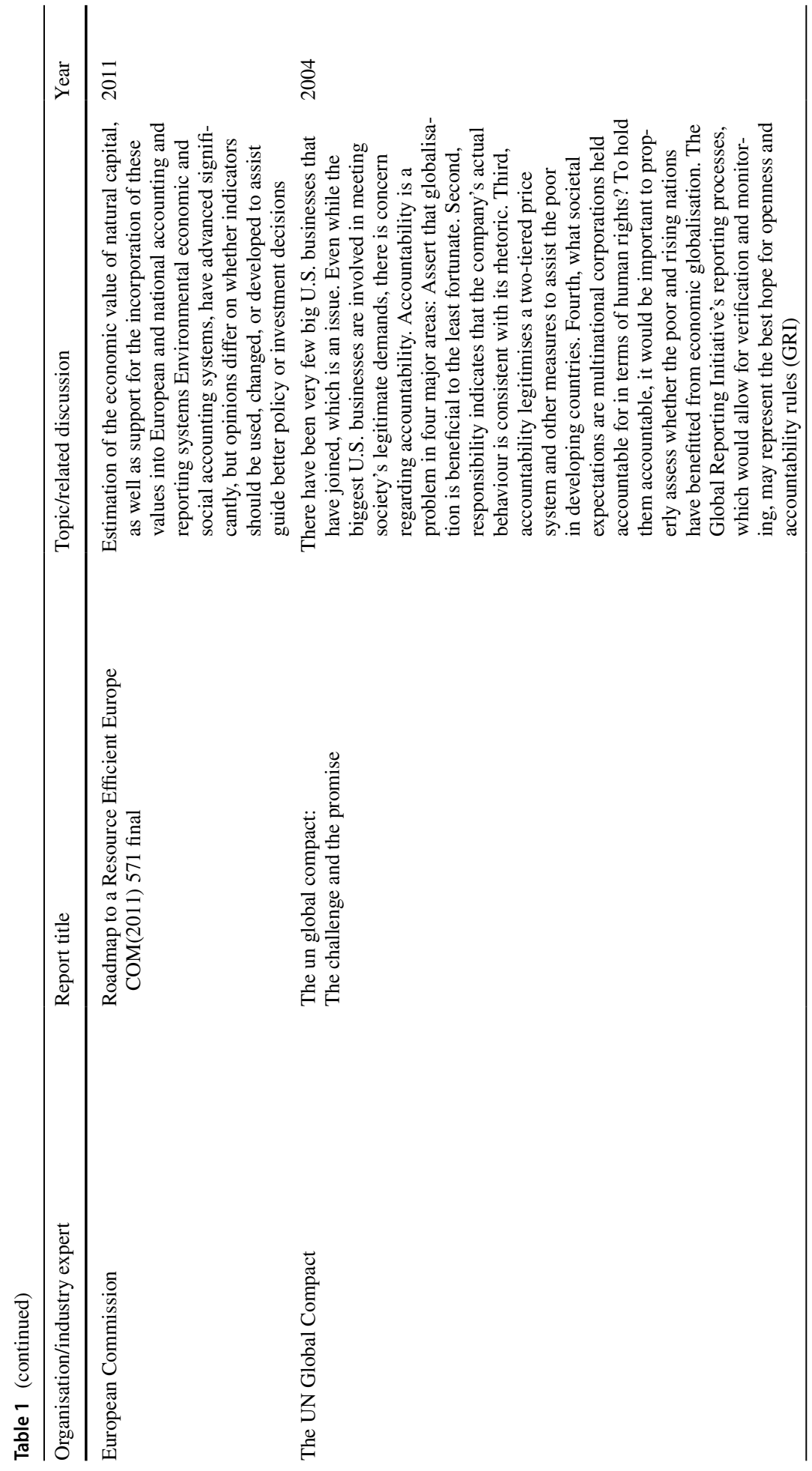




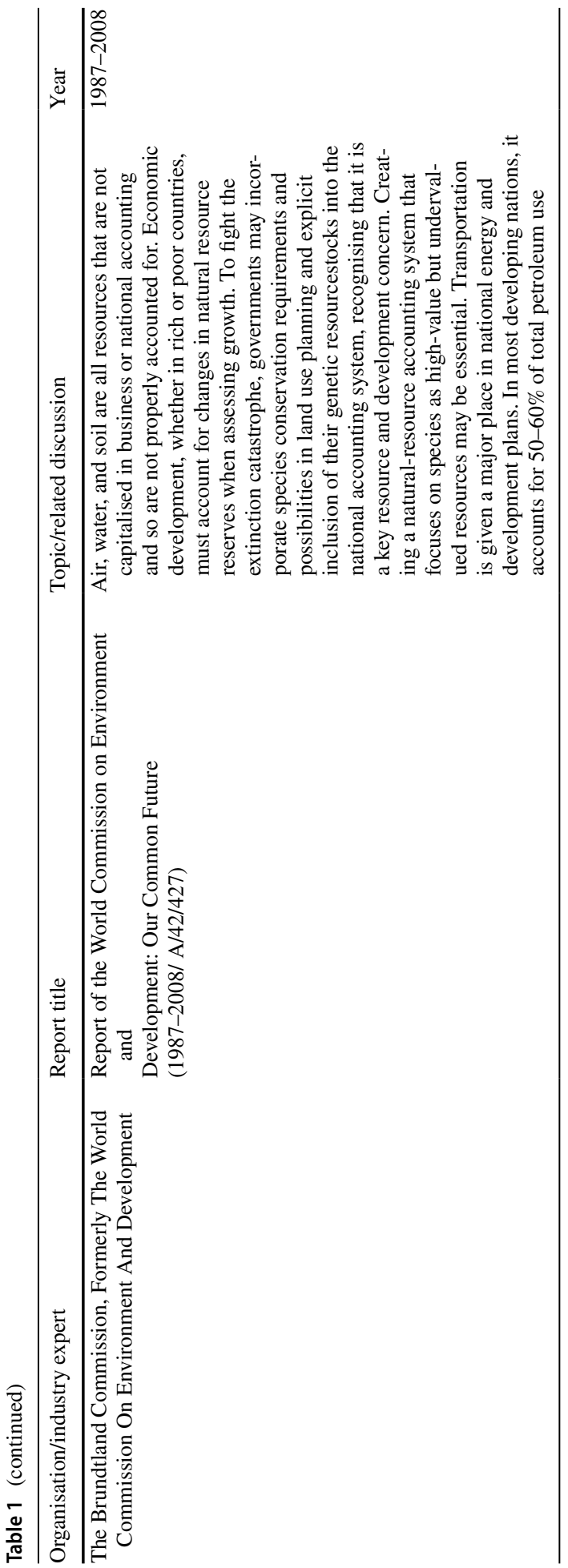

Springer 
for academics, government, and business organisations since 2020. In this context, Scopus has over 24.000 current titles indexed. Scopus has added 820 new publications last year $(+3.5 \%$ title growth). In addition, 225,000 books and book goods have also been added $(+11.7 \%$ increase). Scopus added 3.29 million new records $(+4.15 \%)$ between August 2019 and August 2020. As of August 2020, 79.8 million records are currently in use (Scopus, 2020). The h-index utility that displays an article, author, or journal's quality is also impossible to overlook (Hirsch, 2005). Li et al. (2018) conducted pioneering research on the web of science with the critical focus on database, a scientific study conducted in 1997 and 2017 to uncover the WoS academic usage characteristics in countries/regions. Eugene Garfield's most incredible legacy (Li et al., 2018; Jacso, 2018), WoS Core database specifically includes three classical citation indexes: Expanded Science Citation Index (SCIE), SSCI, and the Arts and Humanities Citation Index Collection (A\&HCI). These citation indexes are globally famous and widely preached in academia (Hu et al., 2018; Liu et al., 2020; Tang \& Shapira, 2011).

It is necessary to distinguish the shortcomings of architecture for a particular reason from Google Scholar (GS) and the different types of errors made by the search engine (GS) when processing the data. Errors are anomalies from the tool's standard or intended working. On the other hand, limits apply to features that may jeopardise the suitability of an instrument for a specific reason. The list was then processed using VOSviewer softwareversion 1.6.15 for generating a document with the required networking structure and format (www.vosviewer.com; Van Eck \& Waltman, 2014). It is an open-source software used in bibliometric network design and development. A mapping representation of bibliographic data was developed to provide a broader and more precise understanding of the effects of research questions. Moreover, a text-mining feature is supported by VOSviewer. It is used for building networks connected in a body of scientific literature to meaningful terms.

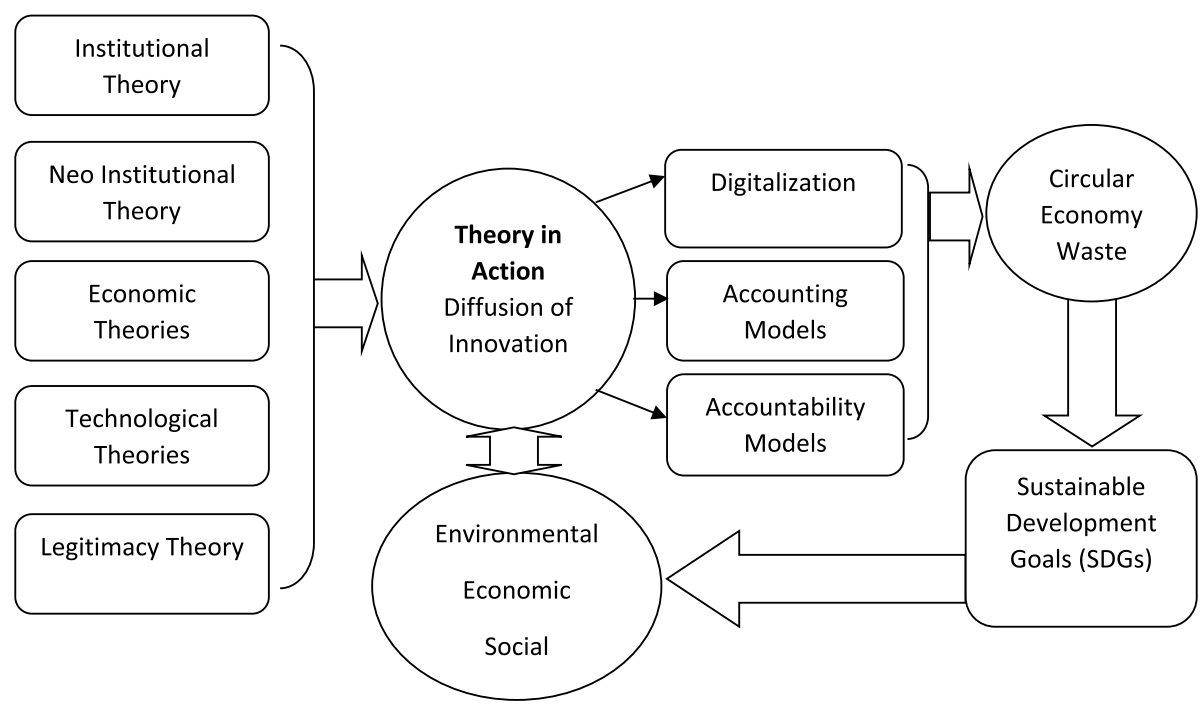

Fig. 1 Theoretical framework on CE\&W by adopting digitalisation, accounting and accountability models to achieve SDG'S 
The mode of study was split into two phases: first, the extraction and review of the relevant documents and bibliometric analysis. First, the retrieved papers were reviewed based on these parameters: (i) search identification, (ii) data screening, (iii) data eligibility, and (iv) data inclusion. A systematic approach to data collection was provided in Fig. 2; these measures were adopted to ensure that the method was firm. According to Selçuk (2019), a review article analyses, synthesises, and assesses scientific publications and research published in peer-reviewed journals. A systematic approach to a review will eliminate bias and maximise its usefulness since Preferred Reporting Items for Systematic Reviews and MetaAnalyses (PRISMA) is employed.

During the first component of the research, the two central databases, e.g. Web of Science or Scopus, the principal research recommendations for researchers in the area have been addressed using these tools. At this stage, the timelines were not explicitly applied to gather all the comments on this subject from 2012 to 2021 (default years of WoS and Scopus databases). Instead, the search was carried out with the aid of a truncated combination of nine separate search string classes to classify the related articles:

Group 1 Accounting practices AND circular economy.

Group 2 Accounting practices AND circular economy AND waste.

Group 3 Accountability AND waste management AND circular economy.

Group 4 Accounting practices OR waste management OR circular economy.

Group 5 Waste management AND circular economy AND sustainability AND accounting.

Group 6 Accounting practices AND accountability practices AND circular economy AND waste.

Group 7 Accounting practices OR accountability practices OR circular economy AND waste.

Group 8 Circular economy AND waste AND sustainable development goals AND digital transformation.

Group 9 Digital transformation AND circular economy AND waste.
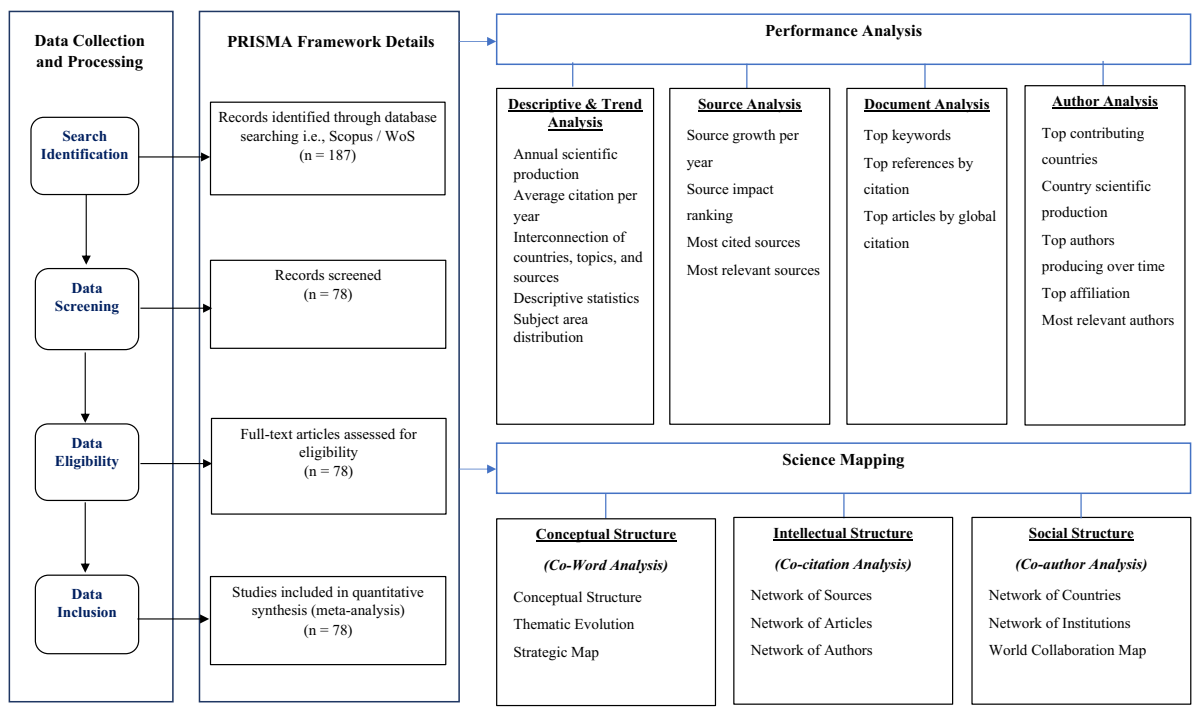

Fig. 2 Research design and methodology 
The number of articles selected from Scopus is one hundred and eighty-seven (187). The second step was to classify the articles involved. After reading the abstracts, we decided on the content of each article to ensure the consistency of the research purpose, emphasised their unique importance in our research. All study authors evaluated and highlighted their essential aspects in the final phase and worked separately. Finally, after extracting outdated publications and duplicates, the writers compared the results and split them into sections to update the literature. Seventy-eight (78) articles were produced in the final list and analysed.

These (78) articles are divided into nine (9) groups named Group 1, Group 2, Group 3, Group 4, Group 5, Group 6, Group 7, Group 8, Group 9, and each group holds a specific number of shortlisted articles respectively (9), (4), (1), (6), (10), (35), (4), (7), (2). The first four (4) groups are focused on answering research question one (RQ1), groups (5), (6), (7) deal with research question two (RQ2), and the last two (2) groups respond to the research question (RQ3). Nine variations are designed to get as many publications on the subject as possible and validate the similarities between the articles analysed in the different study categories. This study is extended to include all CE, accounting, and waste management analyses.

Section 4 explains the bibliometric analysis. The fourth and last phase reviewed each article and highlighted its essential aspects separately from the present authors.

\section{Data analysis and results}

The quantitative analysis of the selected articles is comprehensive in sub-sections. The number of articles is centred on year, journal, publishing country, business organisations, and authors' contributions; we analysed several publications on the CE interface, accounting, and waste management trends. We used bibliographical information from the databases Scopus, ISI and WoS.

\subsection{Bibliometric Aspects of the selected articles}

\subsubsection{Keyword analysis}

After presenting methods, we led to an overview of the keywords. Using the VOS viewer 1.6.15 text-mining routine (Van Eck \& Waltman, 2014), the research streams created by this large number of articles are helping us to imagine. In existing bibliometric research, this approach has been checked (Marzi et al., 2017). The text mining process generates a map where the distance between terms is interpreted as a relation between keywords. In conclusion, the shorter the gap between two or more keywords, the more effective the terms associated with each other are. The co-occurrences in the publications were examined to judge the words' relatedness (Van Eck et al., 2014). In particular, the Author Keywords review, comprising those keywords which appear at least twice in the database, was undertaken for this bibliometric study. In addition, we relied on a human selection to verify data dependability, which led to 24 of the 242 keywords considered appropriate for the study. The keywords that could not explain anything on their own (e.g. literature, evaluation, content analysis) were filtered out in Fig. 3. The author's keywords network overview map for the headings is shown the most often used terms for the headlines are highlighted. The word size depends on its presence exclusively in the selected articles in the photo. 


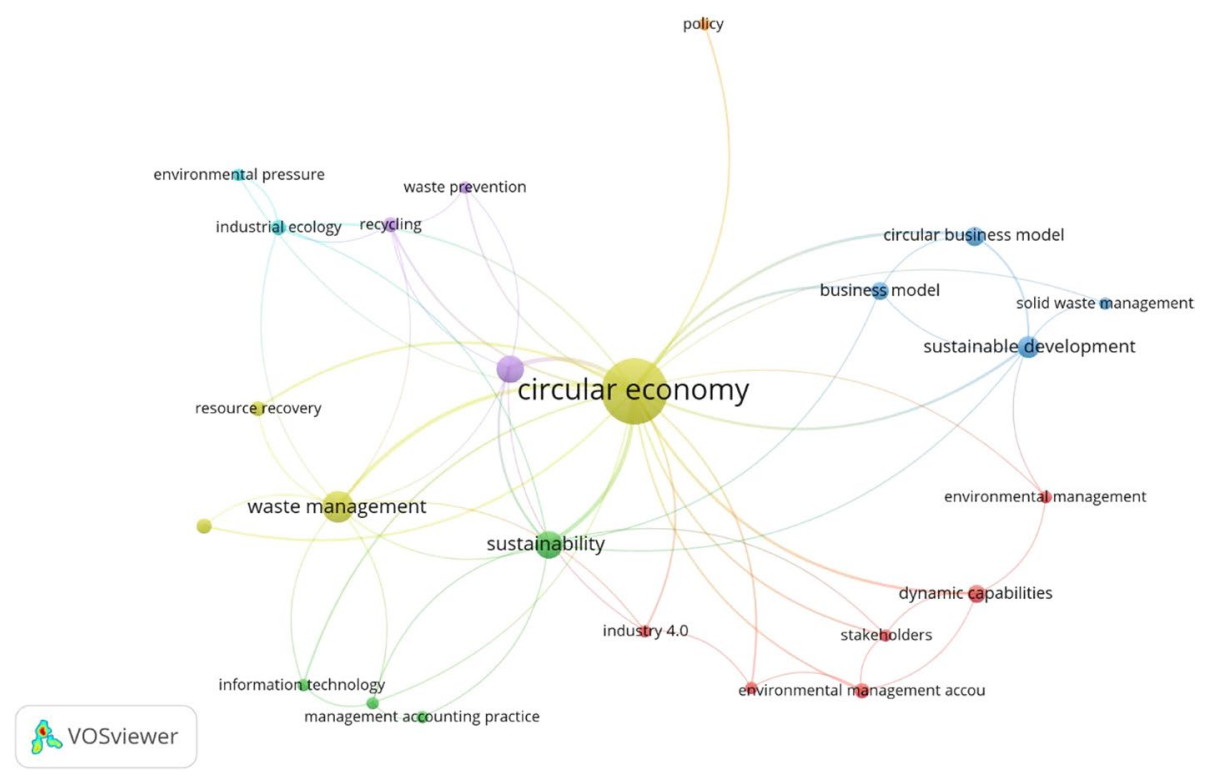

Fig. 3 Network visualisation map of the author keywords

As Fig. 3 shows, "CE", "Waste Management", and "Management Accounting Practices", which are at the core of the map, were our study's keywords. These keywords have been used as a constant throughout the research period of our data collection (Zhong, 2012; Olukanni et al., 2013; Wu X., 2014; Corsini, 2015; Iacovidou et al., 2017; Jacobi et al., 2018; Helander et al., 2019; Abraham et al., 2020; Aranda-Usón et al., 2020; Bari et al., 2020; Lin et al., 2020; Mirzaie et al., 2020; Scarpellini, Valero-Gil, et al., 2020; Scarpellini, Marín-Vinuesa, et al., 2020; Taleb and Al Farooque, 2021). The terms CE, waste management, and management accounting practices appeared (Table 2 and Appendix 1).

Based on the bibliometric analysis, the conceptual diagram demonstrated the relationship between keywords (Van Eck \& Waltman, 2014). The keywords and the calculation of co-occurrence or co-words are shown in Fig. 3; they also offer some well-known themes in the $\mathrm{CE}$, accounting practices, and sustainable development literature. It is essential to note ex multis in colour matching that, in addition to the words "creativity, employee creativity, and organisational culture", the terms CE, waste management, sustainability, management accounting practices, and sustainable development have a relation. This index of co-occurrences shows how strongly CE is associated with waste management by spreading CE, enhancing CE's understanding. Table 2 shows the top keywords used by several researchers.

\subsubsection{Documents and source types}

There were $(67.95 \%)$ article papers containing the most various types of documents in the 78 -record sample. This is surprising, followed by conference papers (16.67\%). The descriptions of the various kinds of papers can be seen in Table 3 .

The most numerous journals were written concerning the source of documents $(80.77 \%)$. Table 4 includes a comprehensive description of the sources. 
Table 2 Top keywords

\begin{tabular}{|c|c|c|}
\hline Author keywords & Frequency & Percent \\
\hline Circular economy & 52 & 21.49 \\
\hline Waste management & 12 & 4.96 \\
\hline Business models & 9 & 3.72 \\
\hline Sustainability & 9 & 3.72 \\
\hline Sustainable development & 6 & 2.48 \\
\hline Circular business model & 5 & 2.07 \\
\hline Business model & 4 & 1.65 \\
\hline Dynamic capabilities & 4 & 1.65 \\
\hline Environmental management Accounting & 3 & 1.24 \\
\hline Industrial ecology & 3 & 1.24 \\
\hline Recycling & 3 & 1.24 \\
\hline Resource recovery & 3 & 1.24 \\
\hline Sustainable development goals & 3 & 1.24 \\
\hline Cleaner production & 2 & 0.83 \\
\hline Environmental management & 2 & 0.83 \\
\hline Environmental pressure & 2 & 0.83 \\
\hline Industry 4.0 & 2 & 0.83 \\
\hline Information technology & 2 & 0.83 \\
\hline Innovation & 2 & 0.83 \\
\hline Management accounting practices & 2 & 0.83 \\
\hline Policy & 2 & 0.83 \\
\hline Solid waste management & 2 & 0.83 \\
\hline Stakeholders & 2 & 0.83 \\
\hline Waste prevention & 2 & 0.83 \\
\hline
\end{tabular}

Total key words $=242$

Table 3 Document type

\begin{tabular}{llr}
\hline Document type & Frequency & $\%(\mathrm{~N}=78)$ \\
\hline Conference paper & 13 & 16.67 \\
Article & 53 & 67.95 \\
Book chapter & 02 & 2.56 \\
Review & 04 & 5.13 \\
Editorial & 0 & 0.00 \\
Article in press & 06 & 7.69 \\
Conference review & 0 & 0.00 \\
Note & 0 & 0.00 \\
Book & 0 & 0.00 \\
Letter & 0 & 0.00 \\
Short survey & 0 & 0.00 \\
Erratum & 0 & 0.00 \\
Total & 78 & 100.00 \\
\hline
\end{tabular}


Table 4 Source Type

\begin{tabular}{llr}
\hline Source type & Frequency & $\%(N=78)$ \\
\hline Journals & 63 & 80.77 \\
Conference proceedings & 13 & 16.67 \\
Book series & 0 & 0.00 \\
Books & 02 & 2.56 \\
Trade publications & 0 & 0.00 \\
Total & 78 & 100.00 \\
\hline
\end{tabular}

\subsubsection{Year of publications: evolution of published studies}

Figure 4 illustrates the evolution of publications on the current subject from 2012 to 2021. $\mathrm{CE}$, waste management, sustainability, and accountability publications have been gradually expanded. In 2012 and 2014, the lowest number of publications was observed, with a persistent rise to 2020 and a sharp increase in 2021. The reason for a sharp decrease in 2021 is the beginning of the year 2021. Trends in the data collected and from the figure suggest the increasing interest of researchers in CE, waste management, sustainability, and management accounting practices. A maximum interest in these topics is observed from 2018, 2019, and 2020, the maximum interest shown. Table 5 shows a detailed list of numerous years in which articles were published.

Fig. 4 Document by year

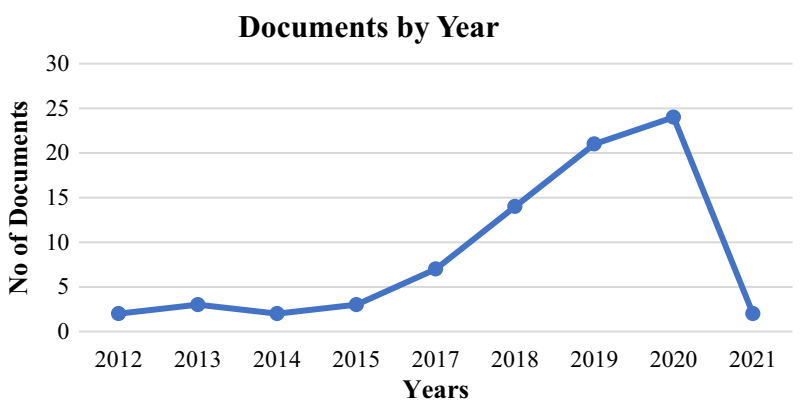

Table 5 Year of publications

\begin{tabular}{llrc}
\hline Year & Frequency & $\%(N=78)$ & Cumulative percent \\
\hline 2012 & 2 & 2.56 & 2.56 \\
2013 & 3 & 3.85 & 6.41 \\
2014 & 2 & 2.56 & 8.97 \\
2015 & 3 & 3.85 & 12.82 \\
2017 & 7 & 8.97 & 21.79 \\
2018 & 14 & 17.95 & 39.74 \\
2019 & 21 & 26.92 & 66.66 \\
2020 & 24 & 30.77 & 97.43 \\
2021 & 2 & 2.56 & 100.00 \\
Total & 78 & 100.00 & \\
\hline
\end{tabular}




\subsubsection{Most active source titles}

The most popular and vital journals are mentioned in Table 6, publishing CE, waste management, sustainability, and management accounting practices articles. Journal of Cleaner Production (JCP) and Business Strategy and the Environment are examples. It presents articles especially important to $\mathrm{CE}$, waste management, sustainability, and management accounting practices. It explores the contributions of CE, waste management, sustainability, and management accounting practices in achieving SDGs of the UN 2030 Agenda (Scarpellini, 2020).

\subsubsection{Geographical distribution of publications: the most influential countries}

Table 7 presents the percentage of contributions by the top 20 countries in publications written in various countries. Italy $(15.38 \%)$ is the leading country to publish in the journal, followed by the UK (14.10\%) and Germany (11.54\%). This data validates that the initial nerve centre was in Italy, the UK, and Germany for CE, waste management, sustainability, and management accounting practices studies. Interestingly, Spain (8.97\%) places fourth and fifth China $(6.41 \%)$ on the table. Italy records a high growth rate and promotes CE, waste management, sustainability, and management accounting practices. That has given rise to many studies focused on $\mathrm{CE}$, waste management, sustainability, and management accounting practices in the context of Italy to determine the causes of the country's continuous growth. At the bottom of the table are Australia, Canada, Finland, France, and Greece, contributing $2.56 \%$ to the overall publications. Another important aspect is that fewer studies are available for $\mathrm{CE}$, waste management, sustainability, and management accounting practices from the best countries, such as Canada, the USA, Switzerland, etc. Therefore, the article focused on CE, waste management, sustainability, and management accounting

Table 6 Most active source title

\begin{tabular}{llr}
\hline Source title & No. of documents & $\%$ \\
\hline Journal of Cleaner Production & 14 & 36.84 \\
Business Strategy and the Environment & 8 & 21.05 \\
Proceedings of the 26th International Business Information Management & 7 & 18.42 \\
$\quad$ Association Conference-Innovation Management and Sustainable Eco- & & 10.53 \\
nomic Competitive Advantage: From Regional Development to Global & & 10.53 \\
Growth, IBIMA 2015 & 4 & 5.26 \\
Journal of Industrial Ecology & 4 & 5.26 \\
Resources, Conservation and Recycling & 2 & 5.26 \\
California Management Review & 2 & 5.26 \\
Corporate Social Responsibility and Environmental Management & 2 & 5.26 \\
Economics and Policy of Energy and the Environment & 2 & 5.26 \\
Energy Policy & 2 & 5.26 \\
Environmental Monitoring and Assessment & 2 & 5.26 \\
Journal of Fashion Marketing and Management & 2 & 2.63 \\
Shengtai Xuebao/ Acta Ecologica Sinica & 2 & 1 \\
WIT Transactions on Information and Communication Technologies & & \\
Central European Business Review & 2 & \\
\hline
\end{tabular}

Total source titles $=38$ 
Table 7 Top 20 Countries contributed to the publications

\begin{tabular}{lll}
\hline Country & Frequency & $\%(N=78)$ \\
\hline Italy & 12 & 15.38 \\
United Kingdom & 11 & 14.10 \\
Germany & 9 & 11.54 \\
Spain & 7 & 8.97 \\
China & 5 & 6.41 \\
Sweden & 5 & 6.41 \\
Denmark & 4 & 5.13 \\
Japan & 4 & 5.13 \\
United States & 4 & 5.13 \\
Austria & 3 & 3.85 \\
Brazil & 3 & 3.85 \\
Malaysia & 3 & 3.85 \\
Poland & 3 & 3.85 \\
Russian Federation & 3 & 3.85 \\
Thailand & 3 & 3.85 \\
Australia & 2 & 2.56 \\
Canada & 2 & 2.56 \\
Finland & 2 & 2.56 \\
France & 2 & 2.56 \\
Greece & 2 & 2.56 \\
\hline
\end{tabular}

Total countries $=40$

practices that are more common in countries with current needs in waste management to develop an ecosystem for CE to achieve SDGs optimally as the UN 2030 Agenda.

\subsubsection{Authorship}

Table 8 indicates the number of authors per article. This segment represents the social structure of science mapping, including the conceptual and intellectual structure. It is imperative that more than one author/researcher/scientist is responsible for creating this idea, so this section explains mathematically in percentage contribution of each group

Table 8 Number of author(s) per document

\begin{tabular}{llc}
\hline Author count & Frequency & $\%(N=78)$ \\
\hline 1 & 07 & 8.97 \\
2 & 20 & 25.64 \\
3 & 15 & 19.23 \\
4 & 20 & 25.64 \\
5 & 07 & 8.97 \\
6 & 06 & 7.69 \\
8 & 01 & 1.28 \\
9 & 02 & 2.56 \\
Total & 78 & 100.00 \\
\hline
\end{tabular}


of authors. The maximum number of articles have been written by two and four authors (25.64\%), followed by three (19.23\%), one and five (8.97\%), and six (7.69\%), and so on. It can be safely stated that published articles with more than one author appeared to be of higher quality than those written by one author.

Table 9 shows the most productive authors in CE, waste management, sustainability, and management accounting practices. Scarpellini S. (Spain) dominates the table with three documents, followed by Aranda-Usón A. (Spain), Corsini F. (Brazil), Leipold S. (Germany), and till the end with two articles. Interestingly, all these authors are of mixed gender, and all are from developed countries.

Collaboration among diverse researchers is vital for developing any area; consequently, greater cross-national cooperation is essential (Turner \& Baker, 2020). Figures 5I, ii and Fig. 6 exhibit the degree of collaboration between researchers with an analytical unit as countries and authors. It is more clearly visible in Fig. 5ii, in which authors have collaborated actively in the past five (5) years. The influential countries in collaborative efforts are Italy, Spain, Germany, and the UK. It offers a powerful network of collaboration across many regions, predominantly European countries, Brazil, the US, China, UAE, and Australia. Scarpellini S., Aranda-Usón A., and Mayer A., Haas W. and Frey M., Corsini F. are the most illustrious. Scarpellini S., Aranda-Usón A. Increased cooperation in research with researchers from various countries. Co-authorship's preference is decided by cultural relationships, geopolitical position, or language (Schubert \& Schubert, 2020). This analysis reveals that linguistic and geopolitical similarities are essential to co-authorship decisionmaking across nations. However, Italy's research articles are the highest, and its scholars are more open to cooperating with their counterparts in other countries.

Table 9 Most productive authors

\begin{tabular}{lll}
\hline Author's name & No. of documents & Percentage (\%) \\
\hline Scarpellini S & 3 & 1.28 \\
Aranda-Usón A & 2 & 0.85 \\
Corsini F & 2 & 0.85 \\
Esposito M & 2 & 0.85 \\
Frey M & 2 & 0.85 \\
Gusmerotti N.M & 2 & 0.85 \\
Haas W & 2 & 0.85 \\
Leipold S & 2 & 0.85 \\
Mayer A & 2 & 0.85 \\
Millward-Hopkins J & 2 & 0.85 \\
Pedersen E.R.G & 2 & 0.85 \\
Petit-Boix A & 2 & 0.85 \\
Portillo-Tarragona P & 2 & 0.85 \\
Purnell P & 2 & 0.85 \\
Soufani K & 2 & 0.85 \\
Wiedenhofer D & 2 & 0.85 \\
\hline
\end{tabular}

Total Authors $=234$ 
(i)

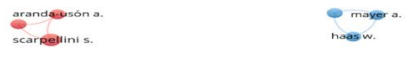

millwardehopkins,
purnell p.

petitboix a.
leipolds.
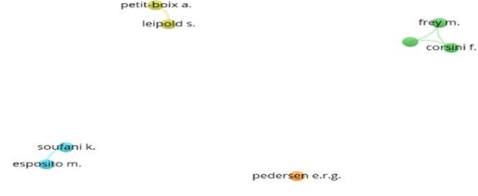

\section{fos vosviewer}

(ii)

pedersen e.r.g.

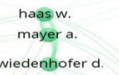

purnell $\mathrm{p}$.

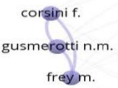

scarpellinis.

portillo-tarragona $\mathrm{p}$

aranda-usón a.

Fig. 5 i Network visualisation map of the co-authorship. Unit of analysis=Authors. Counting method: Fractional counting. Minimum number of documents of an author $=2$. Minimum number of citations of an author $=5$. II Network visualisation map of the bibliographic coupling. Unit of analysis = Authors. Counting method: fractional counting. Minimum number of documents of an author $=2$. Minimum number of citations of an author $=13$

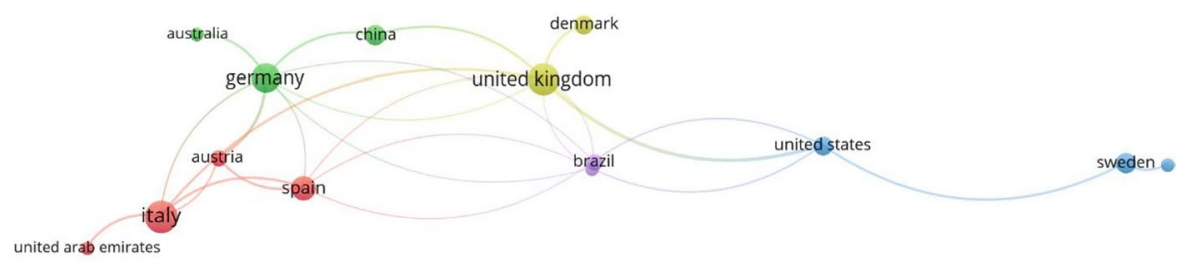

\& vosviewer

Fig. 6 Network visualisation map of the co-authorship. Unit of analysis=countries. counting method: fractional counting. Minimum number of documents of a country $=2$. Minimum number of citations of a coun$\operatorname{try}=5$ 


\subsubsection{Most influential institutions}

Table 10 shows the top influential institutions within CE, waste management, sustainability, accountability, and management accounting practices to achieve a smooth CE transition. With a maximum of two publications. "Hult International Business School, Cambridge, Ma, United States" contributed the maximum number of articles (02)" on second, third, fourth. Till end number "Chair of Societal Transition and Circular Economy, University of Freiburg, Tennenbacher, Germany" "Department of Management Engineering, Division for Quantitative Sustainability Assessment, Technical University of Denmark, Lyngby, Denmark" "Department of Management, Economics and Industrial Engineering, Politecnico Di Milano, Italy" and "Economics Division, Leeds University Business School, University of Leeds, Leeds, UK" produces an equal number of articles (01). Most of the institutions contributed a minimum number of articles (01). However, the most popular article in citations is from "Economics Division, Leeds University Business School, University of Leeds, Leeds, UK". Though, articles from "Economics Division, Leeds University Business School, University of Leeds, Leeds, UK" are not top of the most popular articles.

\subsubsection{Citation analysis}

A study's influence is beneficial for other researchers (Bornmann et al., 2008). Table 11 presents the citation metrics of the 78 records from the year 2012 to 2021 . Approximately ten years, the total number of citations is 717, resulting in 79.67 citations per year and 9.19 citations per article. Citations are intended to indicate that a publication has utilised the contents of several other publications (in the form of others' ideas, research results, etc.); thus, the number of citations applied in research assessment serves as a determiner of the influence of the research (Bornmann \& Daniel, 2007).

The most cited authors are shown in Table 12. As can be observed, Iacovidou E., Millward-Hopkins J., Busch J., Purnell P., Velis C.A., Hahladakis J.N., Zwirner O., Brown A. are top the list, with their widely cited article "A pathway to a circular economy: developing a conceptual framework for complex value assessment of resources recovered from waste", which identifies and analyses the $\mathrm{CE}$, waste management, sustainability and management accounting practices in achieving SDGs of UN 2030 Agenda.

\subsubsection{Textual exploration}

An organised approach was adopted to investigate and display keywords with VOSviewer. A map is developed on the details from the bibliography. The "association strength" is used to standardise the association principles relating to the keywords (Van Eck \& Waltman, 2007, p. 2). The Visualisation of Similarities (VoS) approach positions each word on the map graphically (Van Eck \& Waltman, 2014). Finally, the VOSviewer algorithm provides different resolution parameters to detect the various clusters. In this case, we nullified and picked 24 keywords. The entire power correlated with co-occurrence correlations with other keywords was determined. Then four distinct clusters of colours (green, red, light brown, and blue) were distinguished.

The co-words or keywords coincidence graphics are seen in Figs. 7I, ii and 8. The structure of ideas or information from the earlier literature is described in the main in Fig. 7I, ii (Hughes et al., 2019). The discovery of words is seen in circles in varying colours and sizes. The circle's size corresponds to the frequency of an apparent term; the greater the 


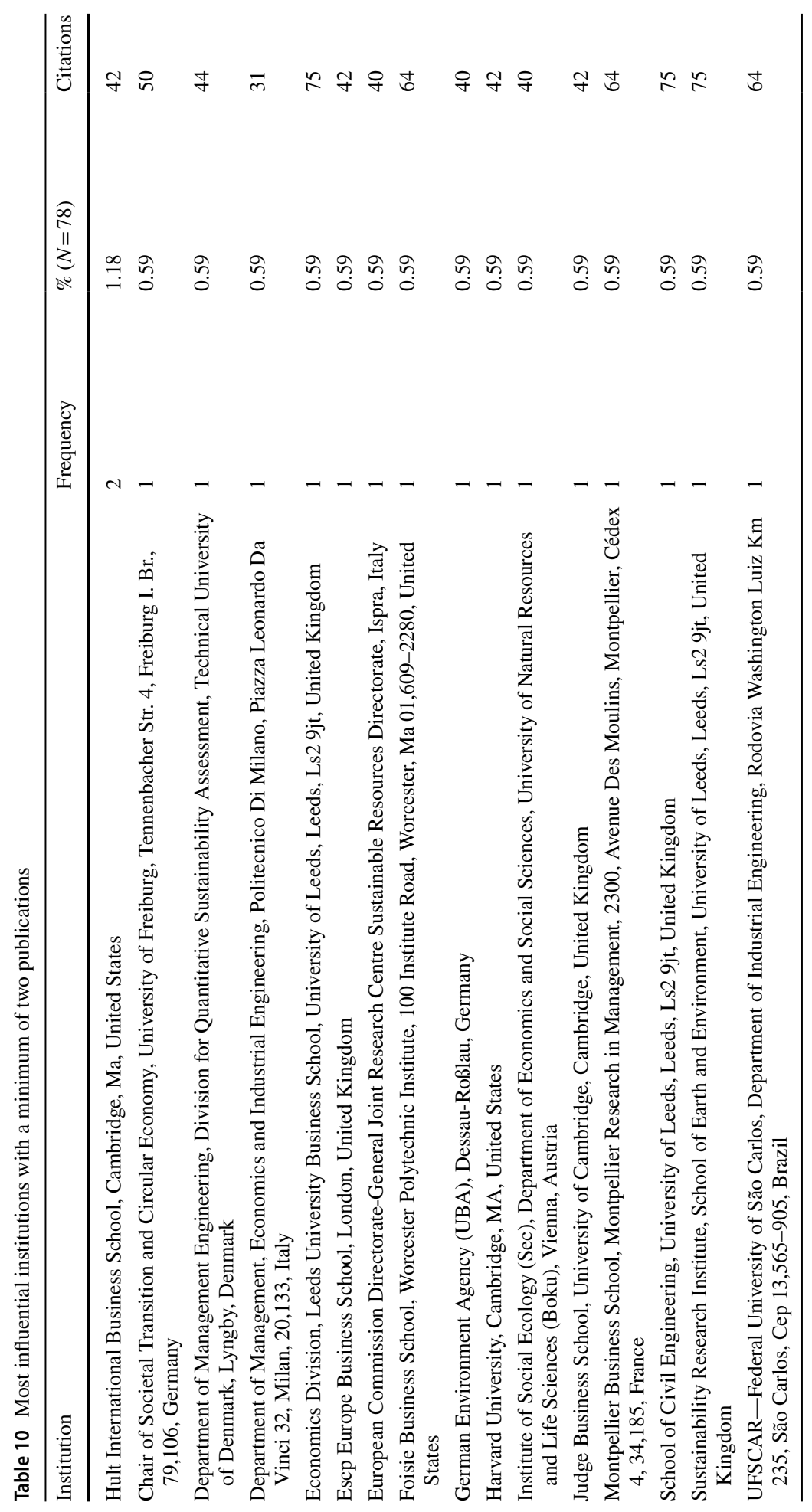


Table 11 Citations metrics

\begin{tabular}{ll}
\hline Metrics & Data \\
\hline Publication years & $2012-2021$ \\
Citation years & $09(2012-2021)$ \\
Papers & 78 \\
Citations & 717 \\
Citations/year & 79.67 \\
Citations/paper & 9.19 \\
Citations/author & 3.06 \\
Papers/author & 0.33 \\
Authors/paper & 3.00 \\
\hline
\end{tabular}

frequency of summaries and titles (Van Eck et al., 2014). The colours of the circles in the hunt were observed parallel to the numerous clusters. The distance between the circles (i.e. the keywords) is informative: the narrower the distance, the stronger the relation. The combination of the terms and conditions in abstracts and title publications (Van Eck \& Waltman, 2014) depends on the number of results. Figure 7i clearly shows a solid relationship between waste management, management, and technology under digital transformation. Figure 3 gave obvious insights into a strong relationship between management accounting practices, waste management, and information technology. This ultimately concludes that digital transformation in all its segments helps achieve the broader outcomes of accounting and accountability of circular economy (Figs. 9, 10).

The description of the articles holds in the table of the appendix, using the subtitles' schematic and the brief intent explanation of each article, by separate columns including policy recommendations, academic and managerial implications. In general, most scientists have examined the consequences for $\mathrm{CE}$, accounting, accountability waste management, sustainability, and management accounting practices in achieving the SDGs of the UN 2030 Agenda (Zhong, 2012; Olukanni et al., 2013; Wu, 2014; Corsini, 2015; Iacovidou et al., 2017; Jacobi et al., 2018; Helander et al., 2019; Abraham et al., 2020; Aranda-Usón et al., 2020; Bari et al., 2020; Lin et al., 2020; Mirzaie et al., 2020; Scarpellini, Valero-Gil, et al., 2020; Scarpellini, Marín-Vinuesa, et al., 2020; Taleb and Al Farooque, 2021).

\section{Discussion of results}

In response to RQ1, this study found that improved accounting practices can play an essential role in quantification and accountability during the analysis. Accounting and accountability frames tend to align with low carbon or circular economy ideologies due to recirculating capital and preserving their technological importance (Iacovidou et al., 2017, 2018). The need for such decisions to be taken will, by extension, begin to escalate (Guinée et al., 2009), and increase consumer "residues" mechanisms will expand the ties between sectors even more frequently. Furthermore, concerning RQ2, it is highlighted that once CE achieves its optimum level, it will contribute massively to fulfilling the UN 2030 Agenda. According to the results, there are a few studies for the quantification and regulation of CE. It is essential to gain the CE's real benefits by putting tariffs on undesired industries and subsidising those useful for CE. Applying new regulations and digital transformation will yield long-run benefits for society and the environment and contribute to the UN 2030 Agenda. 


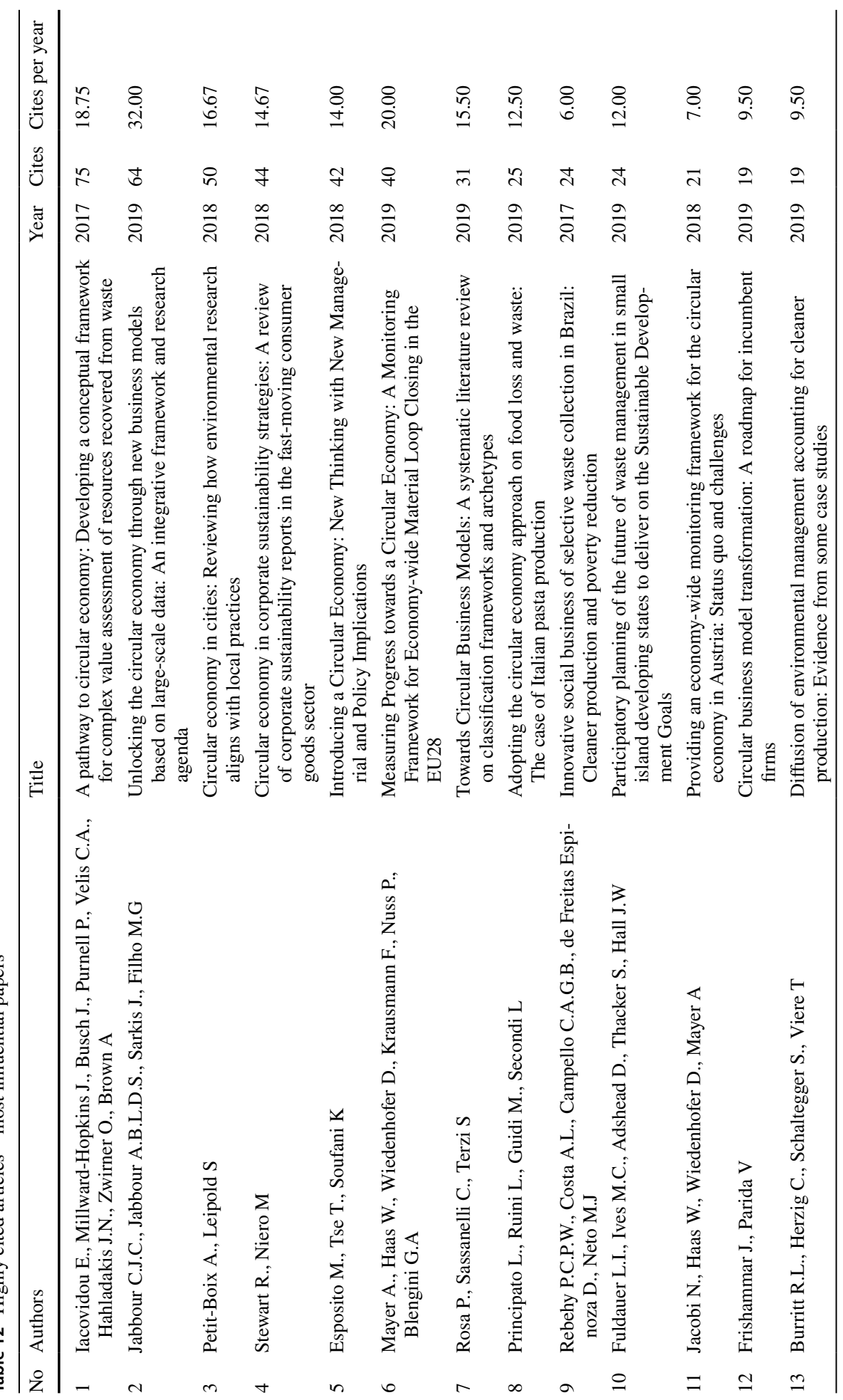




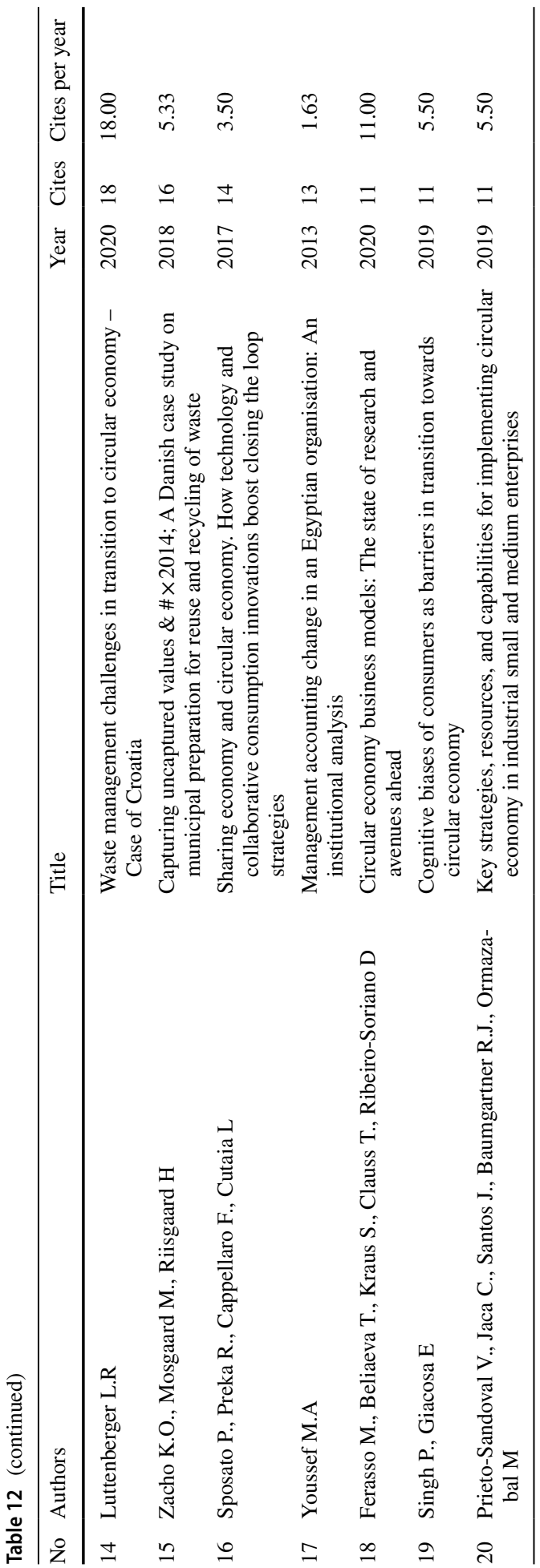


(i)

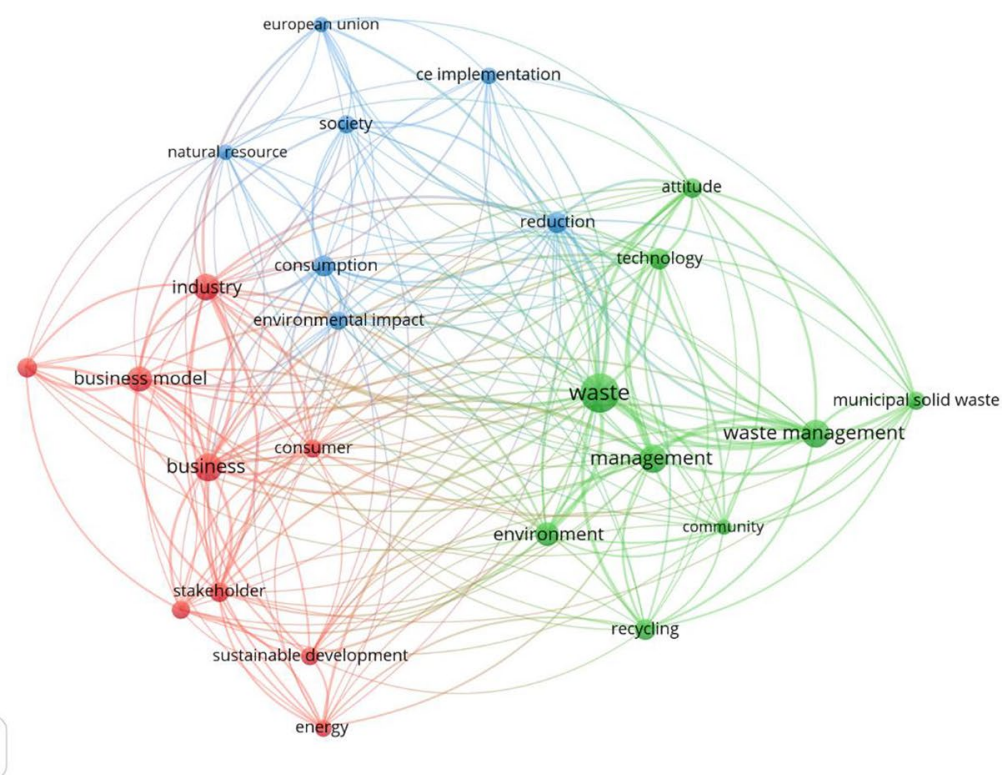

(ii)

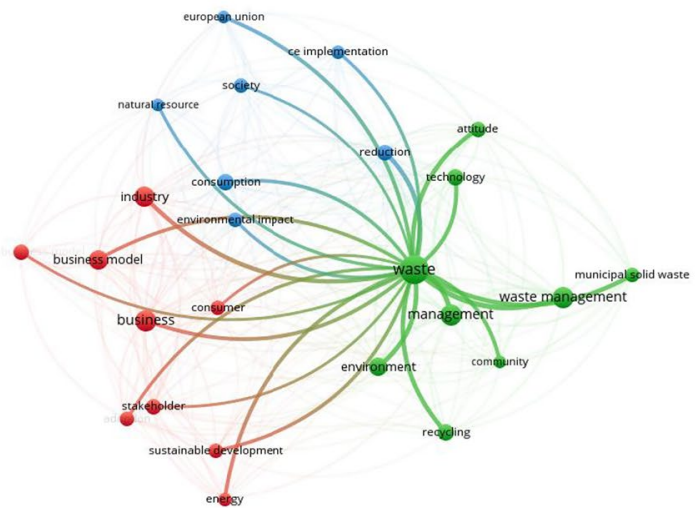

Fig. 7 i, ii VOSviewer visualisation of a term co-occurrence network based on title and abstract fields (binary counting)

CE's jurisdiction is vast; therefore, to respond to RQ3, the only adoption of technological change, innovation, and digitalisation can help smooth CE transition and optimum outcomes. According to the DOI theory (Rogers, 2003), adapting digital transformation will help support the accounting and accountability models and play a vital role in achieving a smooth transition towards a CE. This interconnected system will put checks and balances on the incentivised industries and collectively help the UN 2030 Agenda globally.

In Germany, Siemns Inc.'s experience highlights that essential organisation have implemented critical technology improvements and have initiated an inventive approach to cope with dynamic business developments. However, small and medium-sized organisations are unavailable to adjust themselves to technological development. Zaco et al. (2018) explored and suggested that the new demand for a transition to the $\mathrm{CE}$ is projected to catch opportunities for generating capital and developing infrastructure. This study seeks to provide 


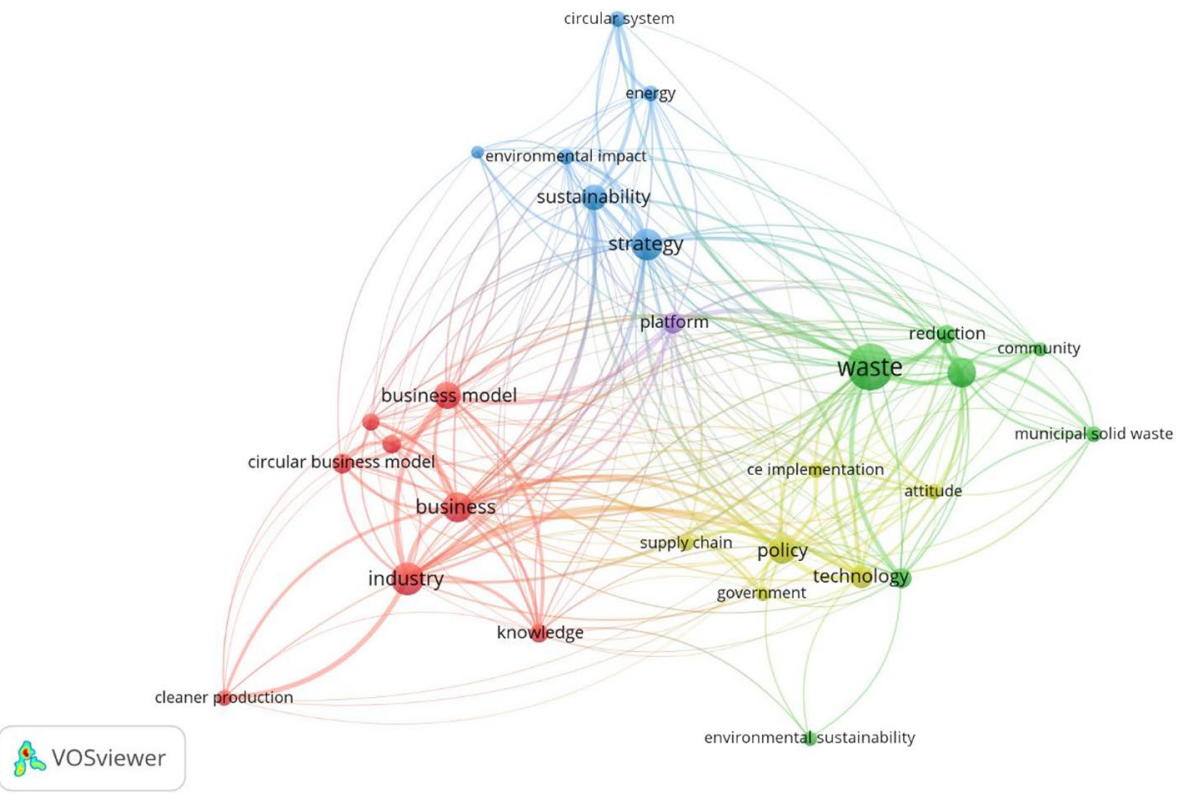

Fig. 8 VOSviewer visualisation of a term co-occurrence network based on title and abstract fields (full counting)

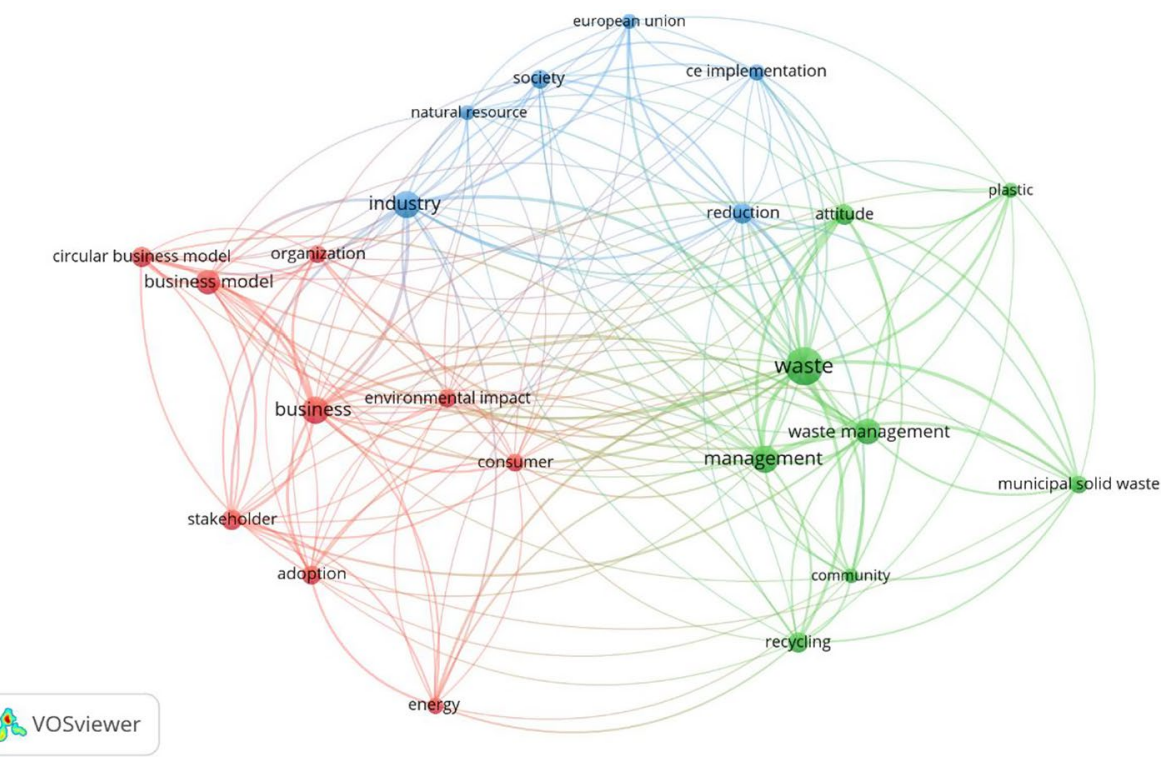

Fig. 9 VOSviewer visualisation of a term co-occurrence network based on abstract fields (binary counting)

further information about waste resources' potential benefits and characteristics. The findings highlight that the current law on waste business would not sufficiently transition to a circular economy. In addition, waste management has to concentrate on value creation and 


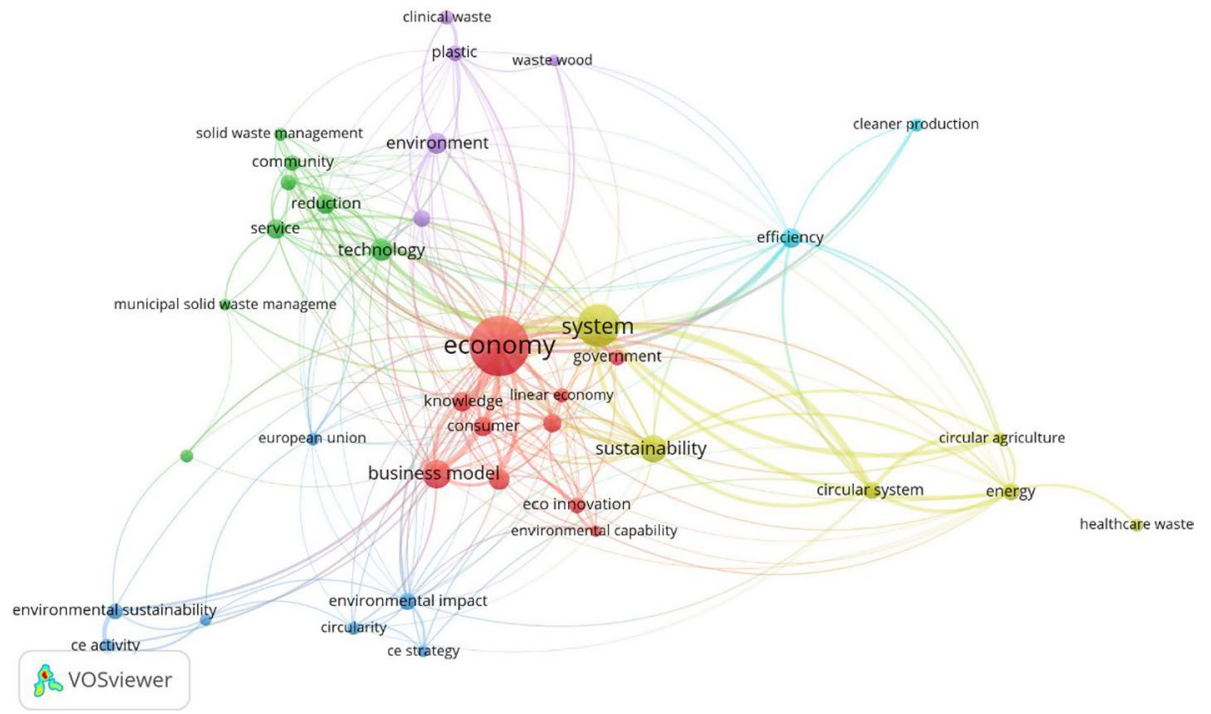

Fig. 10 VOSviewer visualisation of a term co-occurrence network based on abstract fields (full counting)

better re-utilisation activities focusing on cost-performance. According to innovation and technology theories, there must be incentives for small and medium-sized organisations to adopt new regulations for the successful transition of CE.

Extensive dependence on economic growth has led to numerous environmental issues, including pollution, global warming, and ozone layer loss. Most contend that the root reason for these environmental problems lies in commercial activities (Schaltegger et al., 2016). According to Imperatives (1987), an increasing number of existing organisations are putting environmental issues at the top of the organisation's agenda. According to Kauflin (2017), Siemens is one of the most energy-efficient organisations globally, including US firms Cisco and Johnson \& Johnson. These examples depict that it is easier for large-scale organisations to adapt and implement innovations through digitalisation than small-scale organisations. It enables developing an optimised accounting, accountability, and waste management ecosystem to achieve the UN 2030 Agenda.

The existing expansive economic system offers an alternative to rising global environmental pressure, and the CE has gained much attention (Korhonen et al., 2018; Maina et al., 2017). However, others see inconsistencies in the sustainability link (Geissdoerfer et al., 2017). Helander et al. (2019) argued that it is essential to analyse the relationship between environmental pressures and CE. Further, they emphasised CE's necessity and urgency because it is generally established in political and science discussions and is closely related to the SDGs' accomplishment by scientists and politicians. Helander et al. (2019) recommended that CE operations' environmental viability be measured—but not adequately—by a resource-based footprint approach considering significant ecological inputs and outputs. The CE is of academic importance as a transformative and creative economic paradigm concerning government policy, corporations, and customers. (Esposito et al., 2018).

An environmental agenda has driven a waste hierarchy focused on regulation and the taxation of waste and incineration. These taxes make energy disposal cost-effective with most waste forms (with a few exceptions). Ferronato et al. (2019), Good answers are supplied by waste recycling in packaging that overcomes the EU aim of a $55 \%$ recycling rate, 
where legislation and regulations are passed due to accepting standards from high-income nations that might not be financially feasible.

Frishammar and Parida (2019) found that circular economic theory can provide enormous economic, environmental, and social advantages. Many businesses struggle to transition from linear to circular business models. According to Principato (2018), very few studies adopted the CE viewpoint to analyse food loss and waste (FLW). It is one of the critical social, economic, and environmental challenges eroding the planet's sustainability. Indeed, CE's quantification is crucial and can only be achieved by strict accountability measures.

Stewart and Niero (2018) revealed that the correlation between CE and sustainable growth remains largely ambiguous. The partnership with corporations is the most identifiable. It concludes that accounting frames that endorse market practices and industrial transformations would quickly be established (Millward-Hopkins \& Purnell, 2019). As the effects of sustainability strategy on market outcomes become more pronounced over time, comparability between CSR engaged firms and observationally equivalent firms will likely account for CSR matching criteria more systematically than just industry and financial criteria (Durand et al., 2019). This approach will benefit from doing more for less, working quicker, thinking creatively, and incorporating acceptable practices in other branches (Espositio et al., 2018). The CE model will inspire and draw interest among politicians, academics, and practitioners, promoting sustainable growth (Ghisellini et al., 2016).

As a result of a comprehensive literature examination throughout 2012-2021, the three unique issues attempted to identify and explain CE, waste management, and sustainability components. Academic writing benefits from the recognition of these components. It will allow them to speak of intangible aspects, assess their contributions properly to the UN 2030 Agenda, and, ultimately, identify them as part of a seamless transition to CE\&W measurable practices.

Hence, three research questions are discussed based on results acquired after analysis. According to Martens et al. (2013), the theoretical framework's scope is based on content analysis, which includes the following key tasks: universe definition and sampling and coding and interpreting findings. Nadae and Carvalho (2019) presented a conceptual model linking the key components, variables, and their interactions are provided to understand better the function of IMS as a driver for sustainability. This study's findings help develop a conceptual framework to understand the smooth transition towards CE while adopting accounting and accountability models. These propositions are developed based on the content analysis of this study and the conceptual framework presented in Fig. 11I, ii. These figures describe the relationship of key variables adopted in this article regarding direct and indirect relationships. Moreover, the width of connecting lines shows how strongly these variables are correlated.

Hence, in the light of RQ1, four propositions suggested based on the relevant literature reviewed.

Proposition (P1) describes the direct relationship between CE and accounting models; Businesses are adopting standardised procedures and controls as part of the transition to a circular economy, which includes eco-innovative operations and, as a result, a circular business model. When used in a circular model, eco-innovation entails changes to an organisation's environmental management and accounting systems for natural resource management. The theoretical framework's dynamic capabilities propose certification 

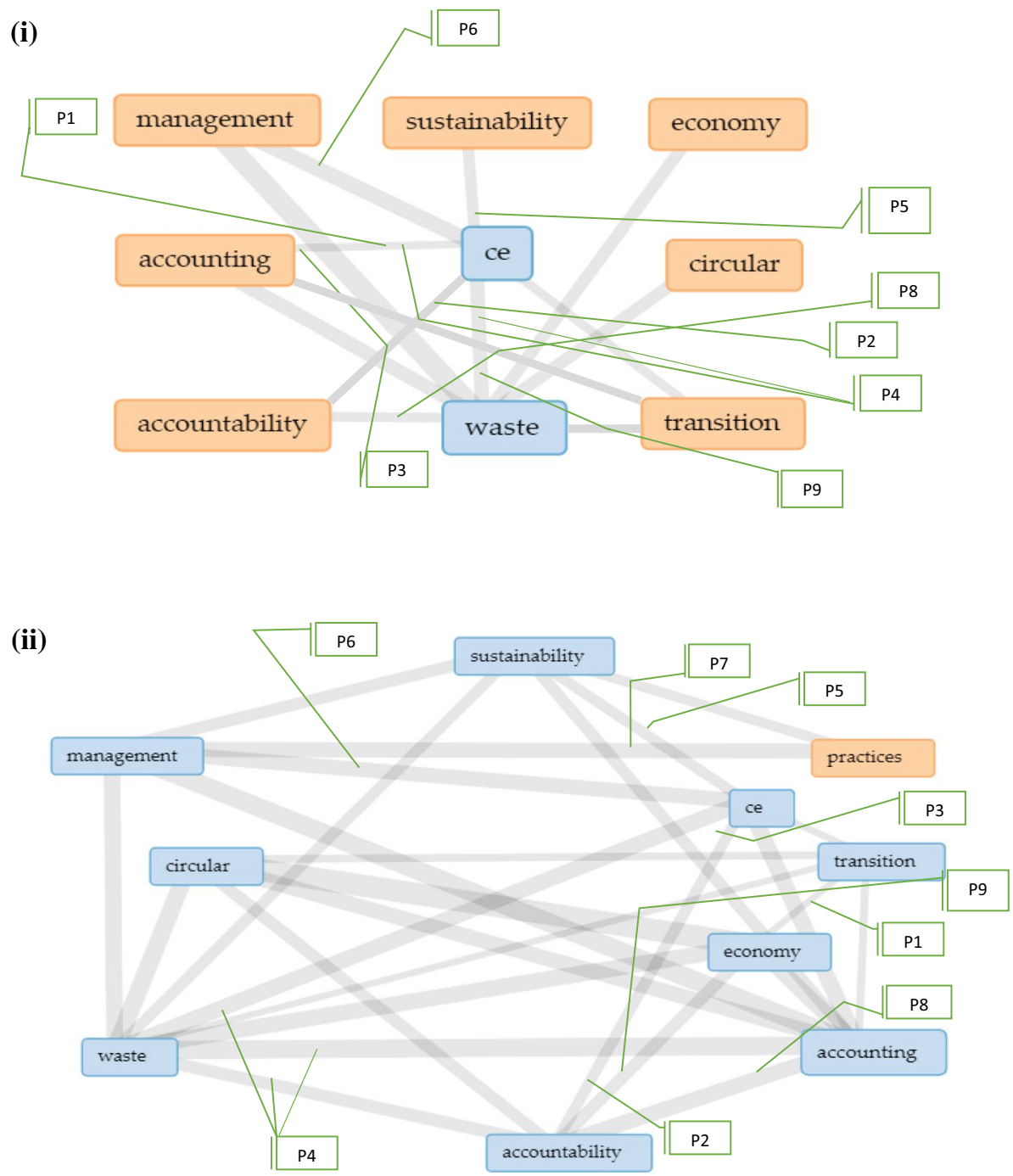

Fig. 11 i, ii A conceptual framework for a smooth transition towards CE by implementing accounting and accountability models

standards and other management and environmental accounting methodologies used in eco-innovation and CE (Scarpellini, Valero-Gil, et al., 2020).

Proposition (P2) is evidence of a direct relationship between CE and accountability models; Based on the dynamic capabilities theoretical approach, various environmental competencies that firms use during this process are investigated. Environmental management systems, corporate social responsibility, reporting and accountability, and other environmental accounting practices are analysed using the same analytical methodology as environmental capabilities influencing a firm's circular scope (CS). The findings suggest 
a connection between a company's CS, environmental accounting procedures, corporate social responsibility (CSR), and accountability. Stakeholder pressure has a mediating effect on a firm's CS (Scarpellini, Marín-Vinuesa, et al., 2020).

Proposition (P3) suggests that CE, accounting, and accountability models are correlated; The environmental capabilities of the CE are linked to its financial performance. The findings support the validity of the investigated concept by giving empirical support for the positive relationships between CS and the variables EMS (Environmental Management System), environmental accounting practices, and other management competencies. Establishing a positive link between ECA (CE environmental capabilities) and CS, as well as demonstrating that when ECA is included in the model as a mediation variable, the positive relationship between ST (Stakeholders) and CS weakens or becomes insignificant (Scarpellini, Marín-Vinuesa, et al., 2020).

Proposition (P4) depicts that waste is directly related to key variables CE, accounting and accountability models. A significant conclusion is that the examined skills impact the CErelated activities taken by enterprises, which enhances organisations' environmental and financial performance in a CE framework. Furthermore, because this connection has not been well investigated for the CE, the function of stakeholders in mediating the CE's introduction into enterprises is a little-explored topic of investigation. Because the criteria that may be used for enterprises are still being developed, measuring an organisation's level of $C E$ is a research area. Firms' $C S$ is established by examining the actions and investments presently being conducted by businesses and are deemed relevant in terms of the CE (Scarpellini, Marín-Vinuesa, et al., 2020).

In the light of RQ2, there are three propositions suggested based on research conducted.

Proposition (P5) suggests a direct relationship between CE and sustainability; different economies often face a slew of sustainability challenges due to their distance, size, reliance on imports, and limited waste absorption capacity. At the end of their useful life, most imported items end up as garbage in dumpsites, resulting in a one-way material flow. The "circular economy" (CE) idea is a potential resource management method for island governments to enhance solid waste management. In a CE, trash is a resource that is constantly cycled through the economy. According to the study, small economies may reduce waste output using circularity measures. Its mission is to push for improved data collection, the adoption of the polluter pays principle, the prohibition of substitutable, problematic materials, and the development of waste management strategies for unsuitable materials (Elgie et al., 2021).

Proposition (P6) suggests a direct link between CE and management; practitioners from various sectors fast recognise circular economy business models as feasible for addressing long-standing ecological challenges such as climate change, biodiversity loss, and rising natural resource scarcity. However, despite increased interest in the potential of circular business models, little is known about the relationships between organisational characteristics and business model generation processes. The model also highlights organisational conditions and management practices that hinder linear BM (business model) replication and, as a result, allow for early CBM (circular-based model) innovation. A collection of assumptions about how organisational transition management should be managed and 
what incumbents require to traverse circular business model innovation successfully. The findings serve as a foundation for the current understanding of circular business model transition management and an impetus for further study (Hofmann \& Jaeger-Erben 2020).

Proposition (P7) demonstrate a direct relationship of practices with management and sustainability. Business intelligence (BI) solutions are constantly being created to assist decision-makers at all company levels. These technologies simplify compiling, aggregating, and summarising massive amounts of data. As a result, the business value supplied by these systems grows as they enable increasingly complex analytics, ranging from descriptive analytics to predictive analytics to prescriptive analytics. On the other hand, internal data are frequently used by the majority of businesses. Nevertheless, despite countless references to the value buried in external data in the literature, there are few ways to leverage it. When paired with an operational BI system, the findings show how external data from several external data sources may be used collaboratively to provide descriptive, predictive, and prescriptive analytics (Strand \& Syberfeldt, 2020).

Finally, considering the RQ3, two propositions that are suggested as per the literature shortlisted.

Proposition (P8) suggests that the transition towards CE is directly related to accounting models but indirectly to accountability models; Small island developing states (SIDS) have unique waste management challenges due to their high per capita infrastructure investment, remoteness, and limited resources resource bases, and reliance on tourism. The lack of comprehensive planning frameworks that take these SIDS components into account has impeded progress towards sustainable waste management. To address this issue, SIDS should develop an integrated system for long-term waste management planning to achieve the United Nations Sustainable Development Goals (SDGs). The modelling of waste infrastructure is linked with multi-level participatory SDGs visioning and back-casting. SDG fulfilment is calculated using a national accounting model for three island-specific waste management portfolios (inaction, circular economy, and technology-led) built through stakeholder back-casting. The findings emphasise the need for waste reduction and reuse strategies that involve island people. Furthermore, participatory techniques based on evidence-based waste management plan design and evaluation may help achieve the aim (Fuldauer et al., 2019).

Proposition (P9) suggests a direct relationship between the transition and waste but an indirect relationship with sustainability. During the transition period, the corporation will confront several challenges, including financial, organisational, technological, social, policy-related, market-based, and logistical obstacles. A method was developed to identify policy-related barriers for a supply chain transition to CE and analyse possible consequences for improving a company's corporate environmental performance. The absence of adequate recycling processes to achieve quality in waste management has been the least essential element. In contrast, a lack of attitude and awareness about CE in government institutions has been the most influential. As ways for businesses to improve their corporate environmental performance, the government's perception of $C E$ and the current linear economy, cooperation with nongovernmental organisations (NGOs) and civil actions, the government's vision towards circular principles, circular public procurement, local 
governments in circular policymaking, and awareness of bureaucracy and government were all suggested (Kazancoglu et al., 2021).

Moreover, a cloud of words is presented in Fig. 12 by using Zipf Law to support above mentioned propositions.

\subsection{Holistic comparison with past studies}

A comparison with other studies of our results is already explained a unique pattern in our findings for the quantification and accountability measures through accounting practices while adopting digital channels (Arjaliès \& Mundy, 2013; Cho et al., 2020; Kirchherr et al., 2017; Michelon et al., 2019). There is ample evidence already partially discussed by different scholars; some focused-on technology and quantification, while others concentrated on accountability and regulations. For instance, Tuladhar et al. (2016) designed a model computer for simulating and analysing scenarios of CE; Kauflin (2017) mentioned Simens is the most energy-efficient company; Elgie et al. (2021) stressed quantitative measurement and assessment of waste management processes; Ciulli et al., (2019) focused on digitalisation. This article provides a unique blend of accounting and accountability for the smooth transition of CE, which ultimately contributes to achieving SDG's 2030. There are numerous articles available for each keyword for different fields of study with a specific set of issues but broader. However, this mix of keywords is unique and difficult to find articles with the same blend. The diversity of topics covered and discussed in this document makes this study unique, with a broader overview of keywords and an optimal portfolio for the keywords used. This study will provide firm grounding to scholars, practitioners, and policymakers to consider the deep linkages of the accounting and accountability model for

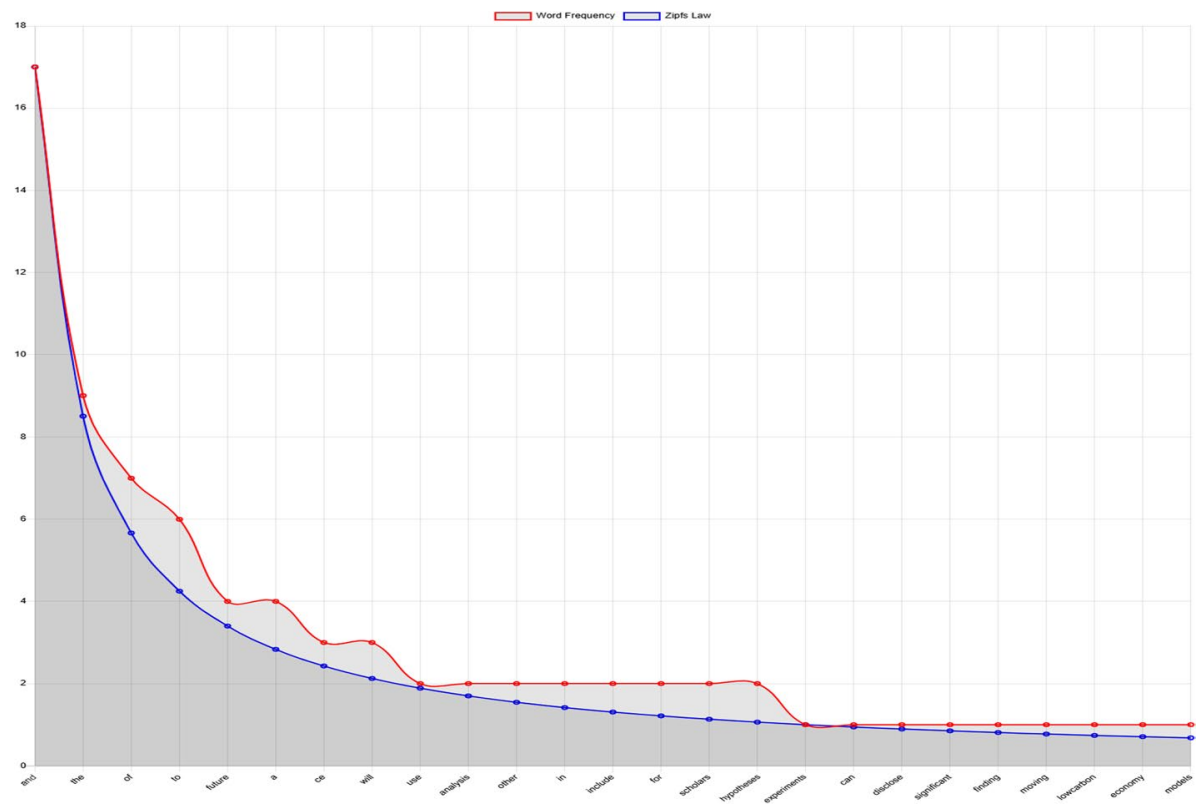

Fig. 12 Zipf Law (Cloud of Words) 
a smooth transition of CE, ultimately pursuing SDGs. In addition to that, it will open more wide horizons for scholars to think on this initial effort, leading to the development of a new dimension of research.

\subsection{Theoretical and practical implications}

This study provides a distinctive trend important to a smooth transition to CE and contributes to the UN 2030 Agenda in quantification and transparency in accounting practice. Enhanced organisational, creative, and technical improvements have been introduced to large businesses. On the other hand, SMEs are slow to introduce innovative, systemic, and technical reforms because of lower standards of transparency. The possible start-up costs associated with applying blockchain technology are recognised, while we see that the advantages are likely to surpass the hurdles. It is essential to coordinate the system fitted to customers with industrial businesses to execute the technologies properly. The seamless transformation of $\mathrm{CE}$ is generally acknowledged to provide enormous advantages. It can be accomplished using a holistic and collective strategy on an organisation, global, and individual level. Will it be necessary to support preferred approaches and initiatives if unwanted processes are a disincentive to tariffs? The use aspects of CE literature remain under-represented, despite the growing literature on $\mathrm{CE}$. It is necessary to alter the $\mathrm{CE}$ framework so that individuals and behaviours become equal and lead to a broader and more sophisticated dialogue on the consumer's role. In terms of cognitive impairment, consumers currently have a small presence in CE literature. Waste perceived as a burden inside the system was regarded as a resource as it became a new revenue stream. Companies recognised new agents or goods as a helpful resource in their production and consumption systems. Corporate leaders must work effectively and quickly on eliminating hurdles to sustainable waste management via the circular use of presently wasteful resources. It is crucial to address the current status of garbage and recycling adequately. The main drivers for this rise are SME's, large corporations, corporate leaders, legal advisors, global leaders, consultants, legislative, public, and non-governmental authorities, non-governmental organisations, and consulting companies.

\subsection{Policy recommendation}

This study proposes discounts and incentives for those sectors that can contribute to a smooth CE transition and enforce tariffs where possible. It is crucial to quantify the CE and achieve transparency through accounting methods. Training for the phenomena of CE can take place in companies, small to medium-sized organisations. The leadership must interact and guide its subordinates to improve. Digital transformation can provide excellent outcomes for CE quantification and the application of accounting rules. However, the EU and the UN have already established the competence and dynamics of the CE. These giant entities will determine the future of CE and its dynamics by the commitment to CE. Researchers should acknowledge and initiate intelligent discussions, further comprehend, develop, promote and amend the plan via involvement with organisations: improved accountability processes and absence of social and environmental responsibility. Researchers can explore the organisational senses, procedures, components, speeches, and values leading to a lack of accountability for social concerns and ecological challenges by involvement with organisations. A legislative standard for circularity would be the first step in setting the government's circular accounting policy. The construction of a legislative framework for the 
circular economy must continue to be encouraged, and society must progressively reach "zero waste". The government can regularly publicise the projected expenditures for environmental damage and waste disposal. It allows tax lawmakers to evaluate whether sectors require additional taxes. It also demands accountants to integrate environmental value factors into their duties.

\subsection{Limitations of the study}

Various technology and service progress sectors have revealed that reasonable improvements, despite their demonstrated value, take longer than anticipated to attain broad-based adoption. This study explores CE's transition, quantification, and sustainability through digitalisation, accountability, and accounting to establish an ecosystem. Moreover, it is essential to note that the information in Scopus and WoS is updated every day, leading to a variation in the number of quotations and articles (Valenzuela-Fernandez et al., 2019). One of Scopus/WoS restrictions is for articles to be uploaded only if writers or journals (including those in Scopus and WoS) ask. As a result, the accuracy of the datasets from Scopus and WoS is disputed on a specific day.

\subsection{Avenues for future research and recommendations}

Future experiments can disclose a significant finding of moving to a low-carbon economy and the CE model's correlation with renewable energy use. Moreover, manufacturing shipments (e.g. company creativity, efficiency, and performance) and market shifts (consumer preferences, conduct, and practices), rethinking the concept of waste, conditions, and possibilities, CE strategy analysis, the position of subsidies, and penalties and taxes. Future research will improve understanding of the relationship between circulatory and sustainable economies conceptually, empirically, and through a quantitative assessment of circular practices. Other study topics to address will be whether and how the transition to circularity increases the competitiveness of the industry and its supply chains and the context in which organisations incorporate environmental targets into their agendas. In certain instances, this essay will include a radical contribution for scholars to promote the exploration and extension of CE to future analysis and hypotheses development. Scholars may also use other data and theories to evaluate hypotheses and include different insights and findings for future studies. For example, future studies will investigate how innovations affect circular business dynamics and how the circular economy will adopt disruptive technologies. Other study subjects include integrating industrial 4.0 processing technologies (e.g. $3 \mathrm{D}$ printing) into sustainable growth and how companies can integrate intelligent manufacturing with their circular operating models. Additional investigation is necessary when other examples of waste design are explored. Future research should incorporate the generation of professional designers utilising garbage. In addition, researchers and practitioners should further research and promote the institutional component of $\mathrm{CE}$ and its relationship to the measurement of sustainable outcomes. 


\section{Conclusion}

This article explores the field of study on accounting and accountability functions for the $\mathrm{CE}$ of waste through practices of responsibility and transparency, analysing the contribution of digital transformation to achieving the UN 2030 Agenda. The findings revealed that $\mathrm{CE}$ is undoubtedly at the centre of world political discussions because it relates to the SDGs achievement. However, it still sends a solid policy design to support accounting frameworks to measure and quantify operations' environmental feasibility. International financial institutions (IFIs) can be a significant driver in the absence of solid local drivers, e.g. by legislation or by popular public opinion. In this sense, digital transformation's role can foster better reporting of resources, considering ecological inputs and outputs significantly for sustainable growth. Using ICT and IoT enhances waste management systems effectiveness and efficiency, despite technical constraints such as restricted sensors, system complexity, and restricted mechanical technology, which must all be resolved before product creation. According to Adams and Larrinaga (2019), it is crucial to recognise what conservatives use well-established theories and concentrate on criticism rather than tackling environmental issues.

A wide variety of evidence has been examined partly by various researchers, some of whom centred on technologies and quantification. This article will include a specific trend that will be important for a smooth CE transition and lead to the UN 2030 Agenda by quantifying and rendering accounting practice accountable. The circular economy's maximum capacity and advantages must be re-designed under circular economic model development processes, an excellent scenario to support working environments and ambitions in the face of increased demand and natural capital. Material cycle management or new business models in product design are not particularly widespread and come under strategies for large-scale resource-saving. Yet, these techniques are crucial to the strategic revision of a circular economy. This article aligns with Jabour et al. (2019) findings; by 2030, European GDP could rise by $11 \%$ if the CE principles extend to various economic sectors (The Ellen MacArthur Foundation, 2015). This analysis aimed to summarise business model patterns and the $\mathrm{CE}$ and broaden their current knowledge base by establishing a research objective. We analysed the relations between the key terms using a bibliometric network analysis performed with VOSviewer. It extends beyond the usage of traditional libraries to examine network authors, individuals, and quotes. Using the VOSviewer as a tool for data mining, selected articles, good gaps in a future study may be investigated, and articles identify the key phrases chosen. This process variates from the study of the qualitative and quantitative literature. With additional thorough qualitative literary analysis, it enables the identification of the major groups and their relationship.

\section{Appendix 1: additional data}

The supplementary details in this article are as follows:

See Table 13. 


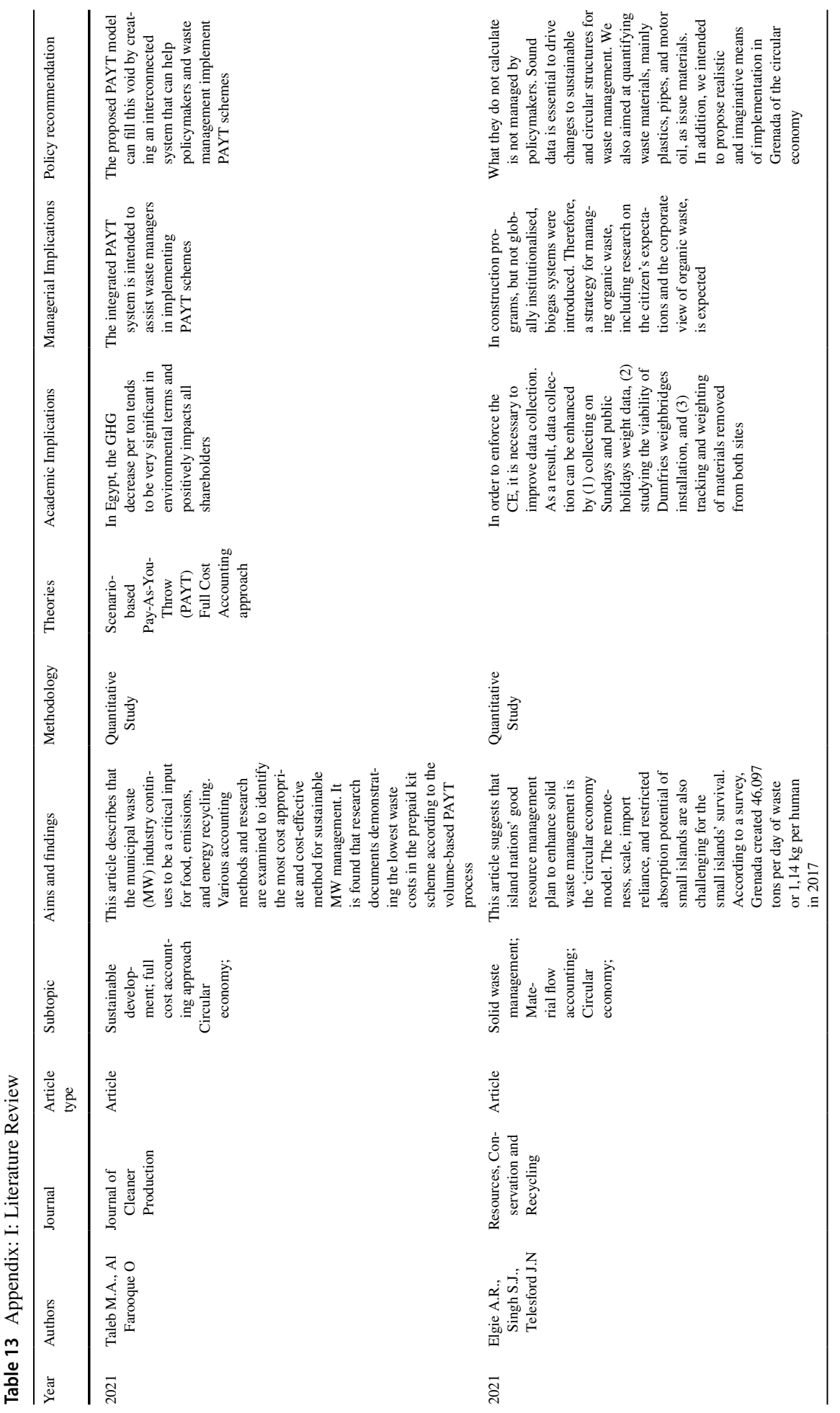




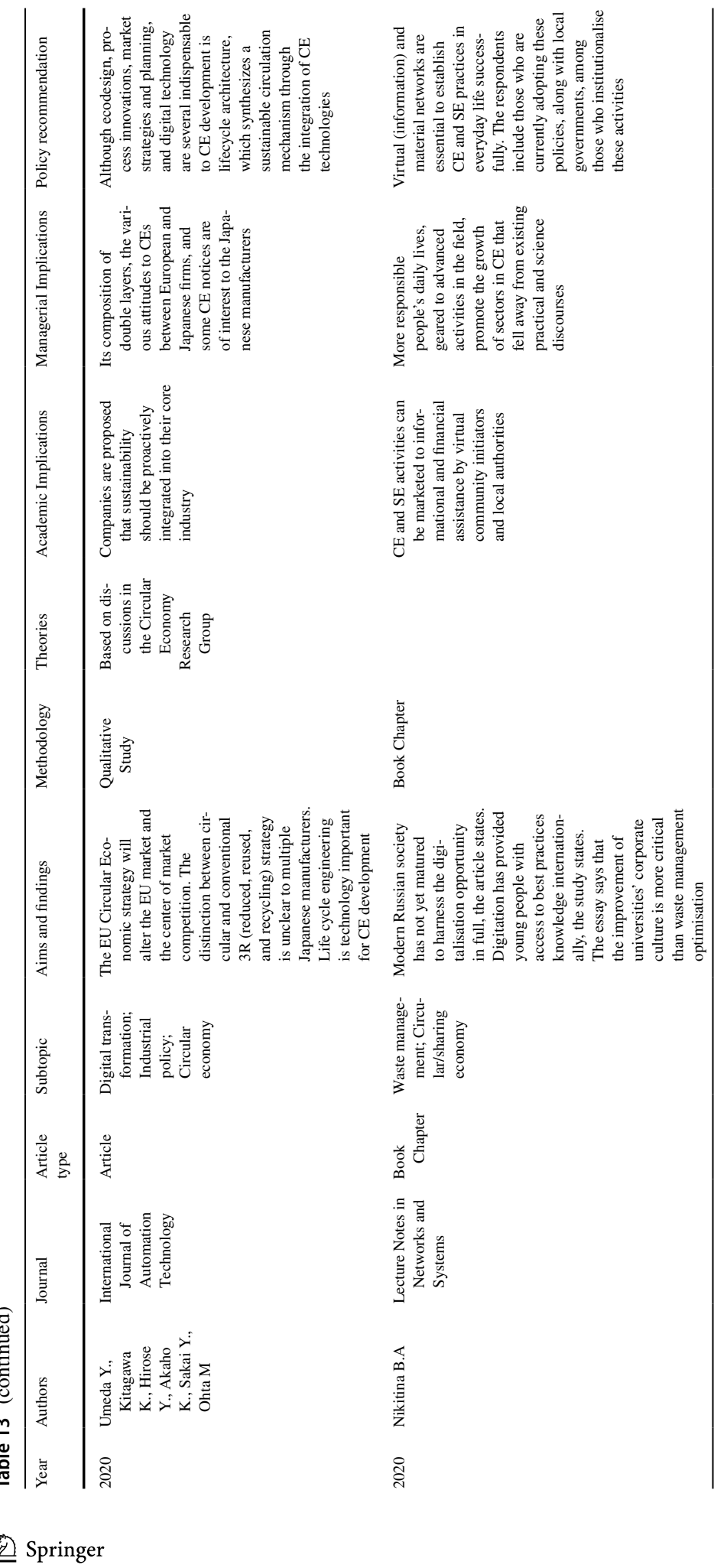




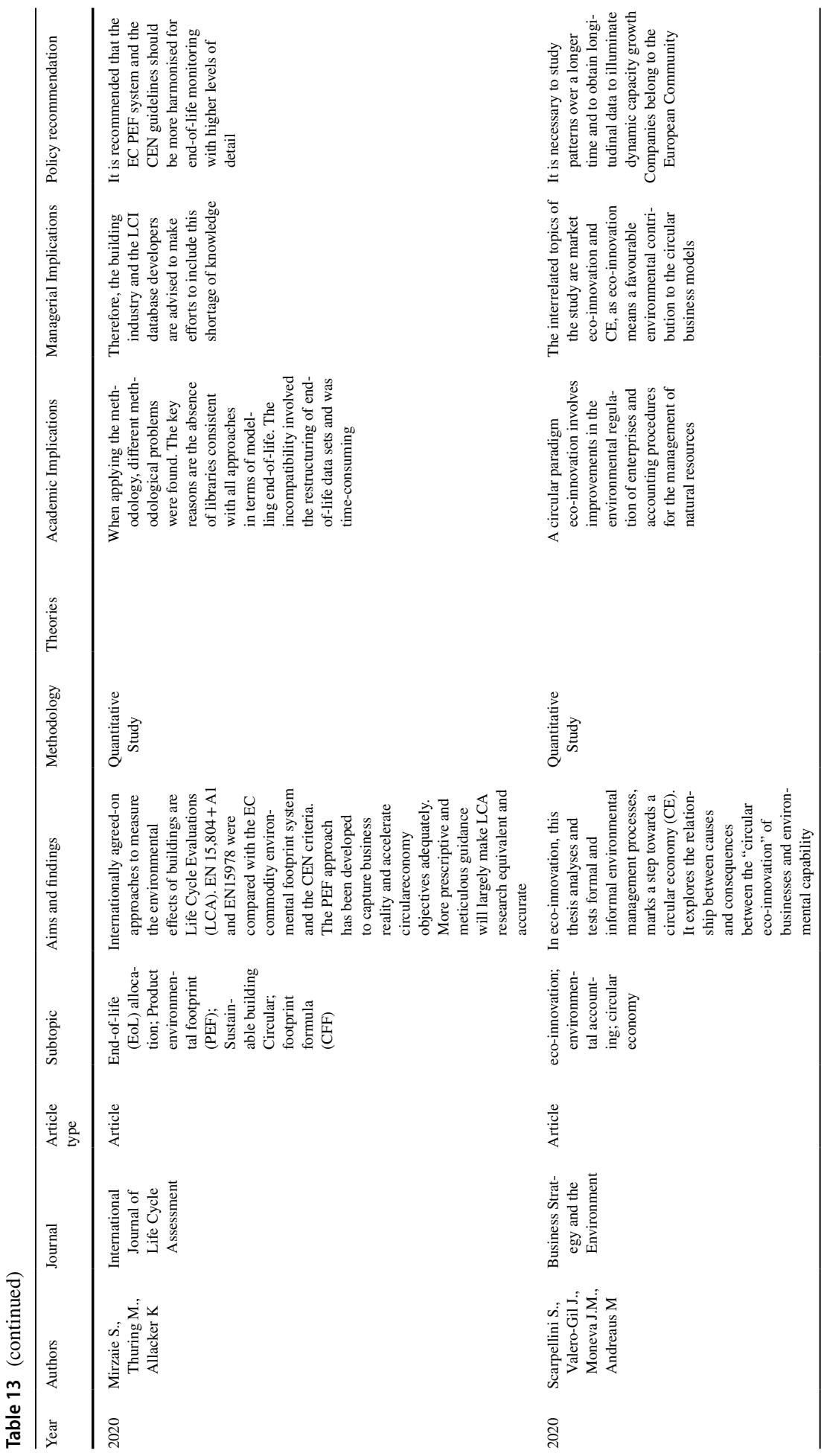




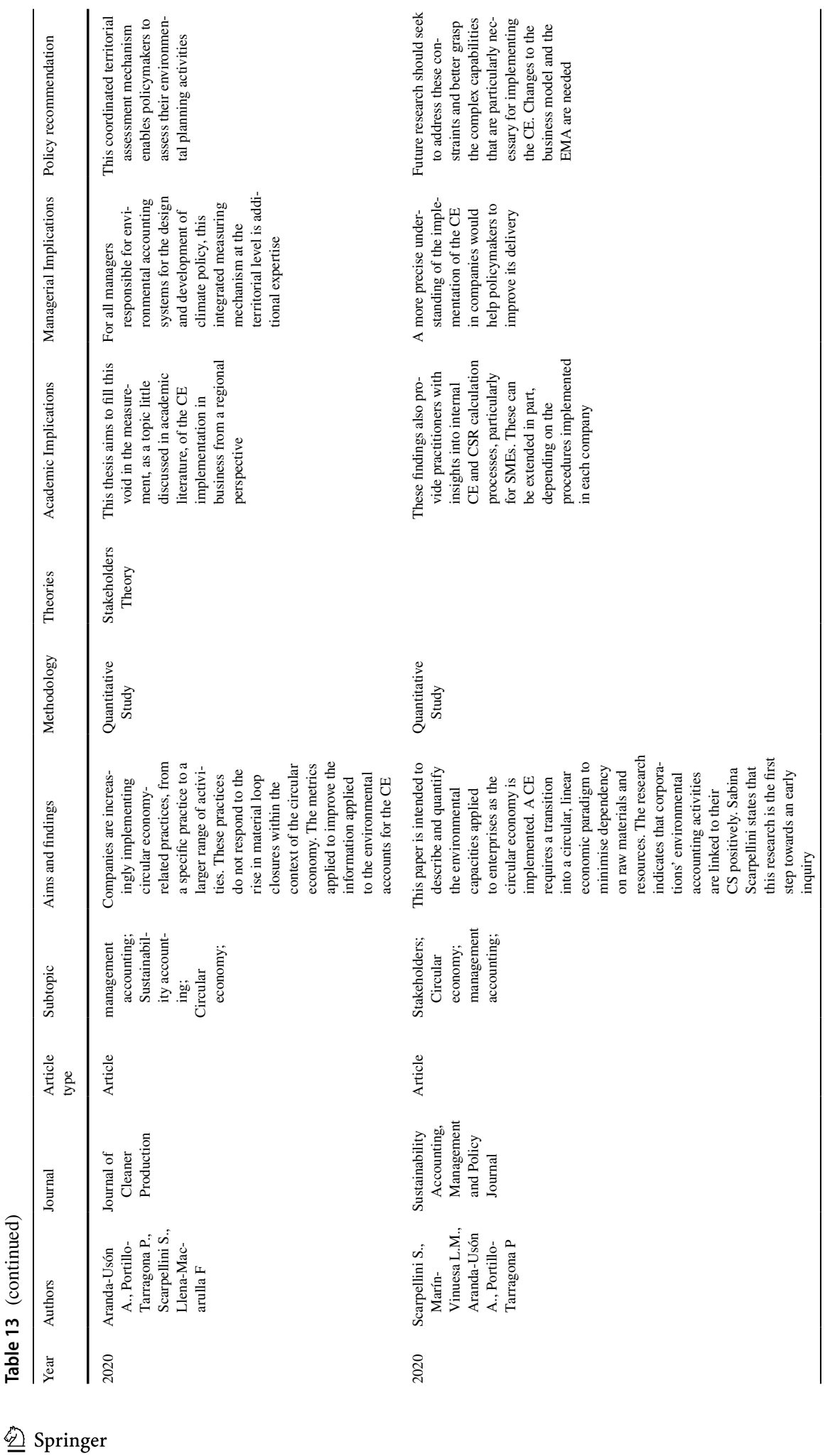




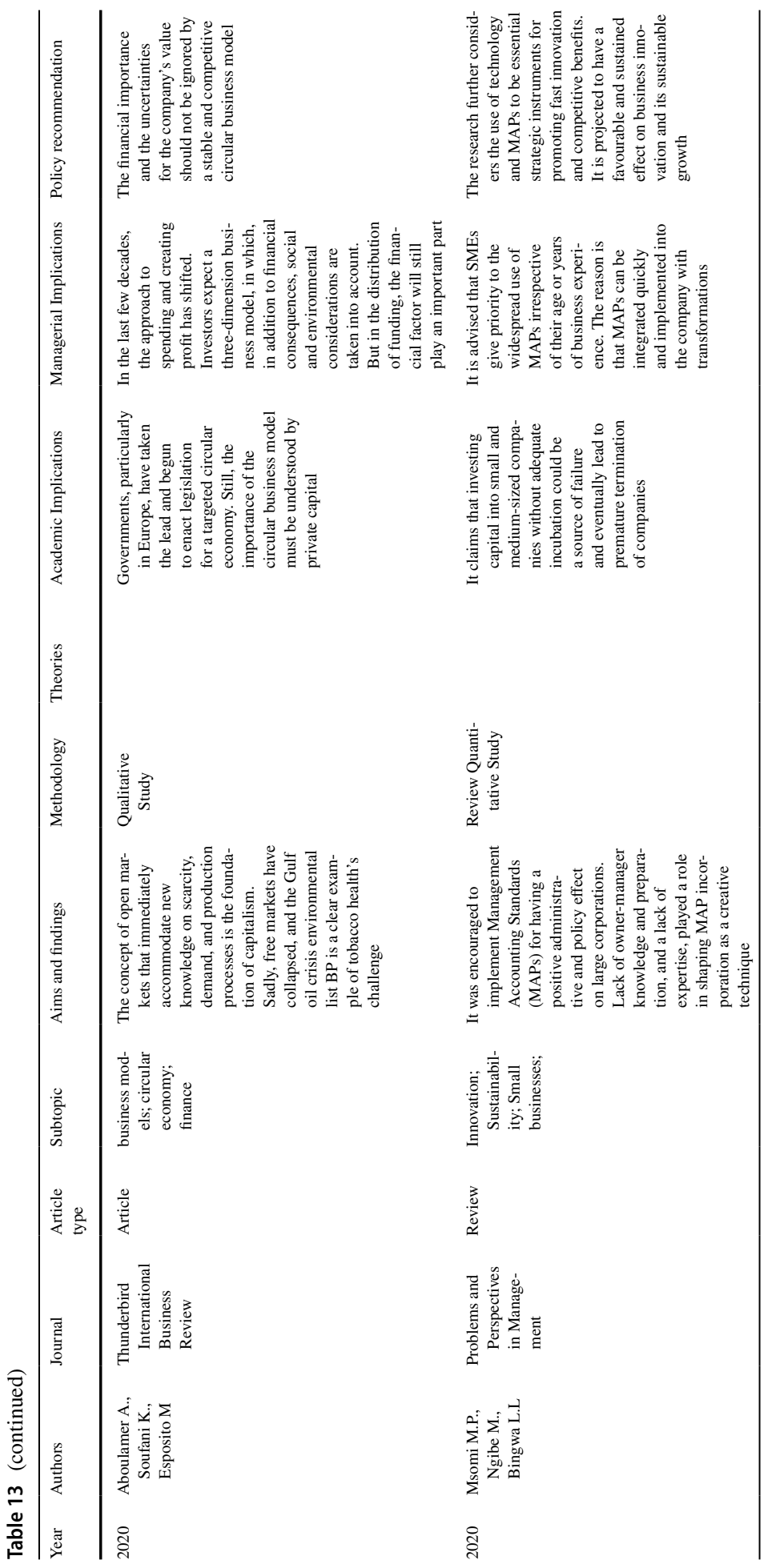




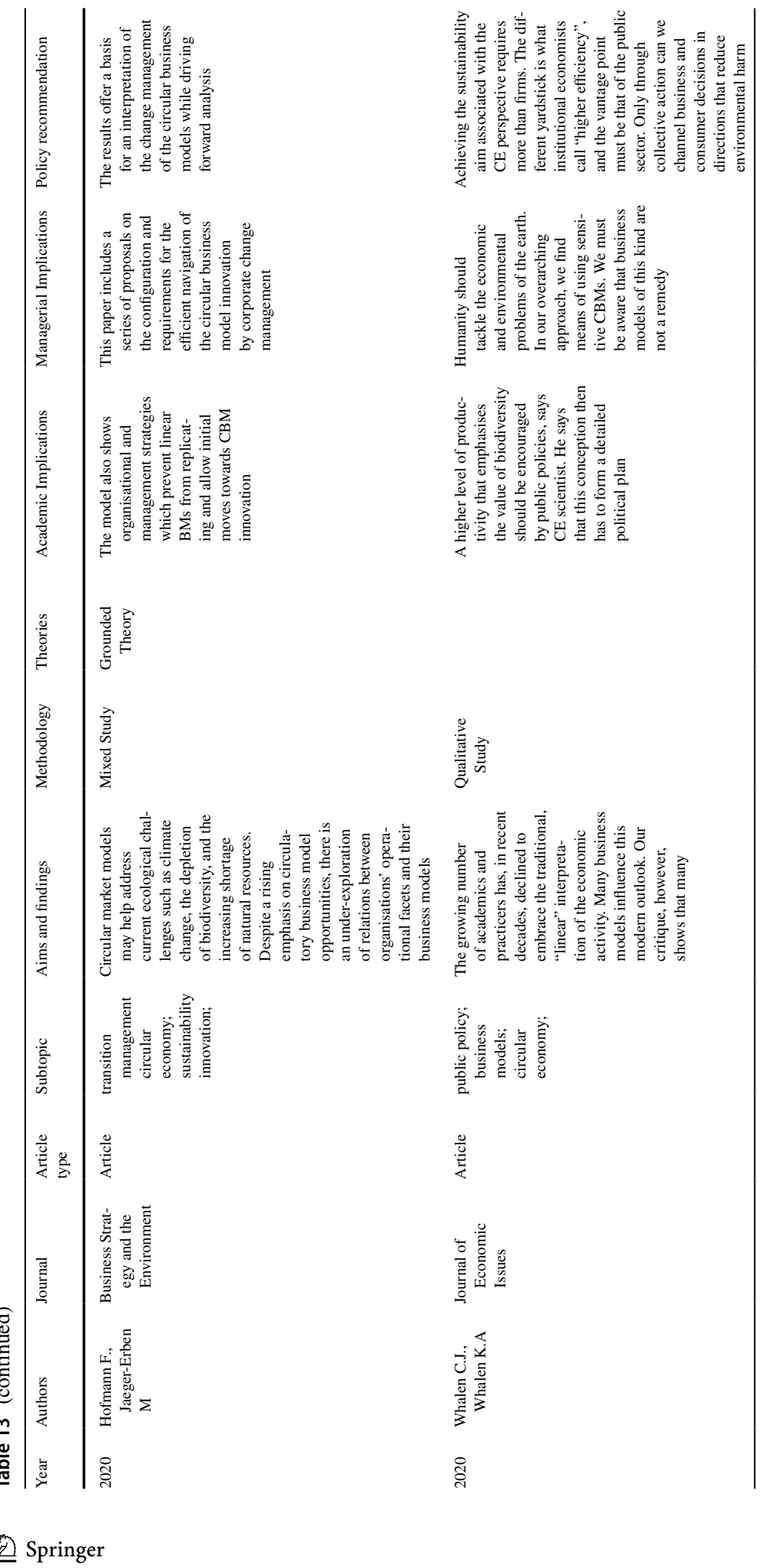




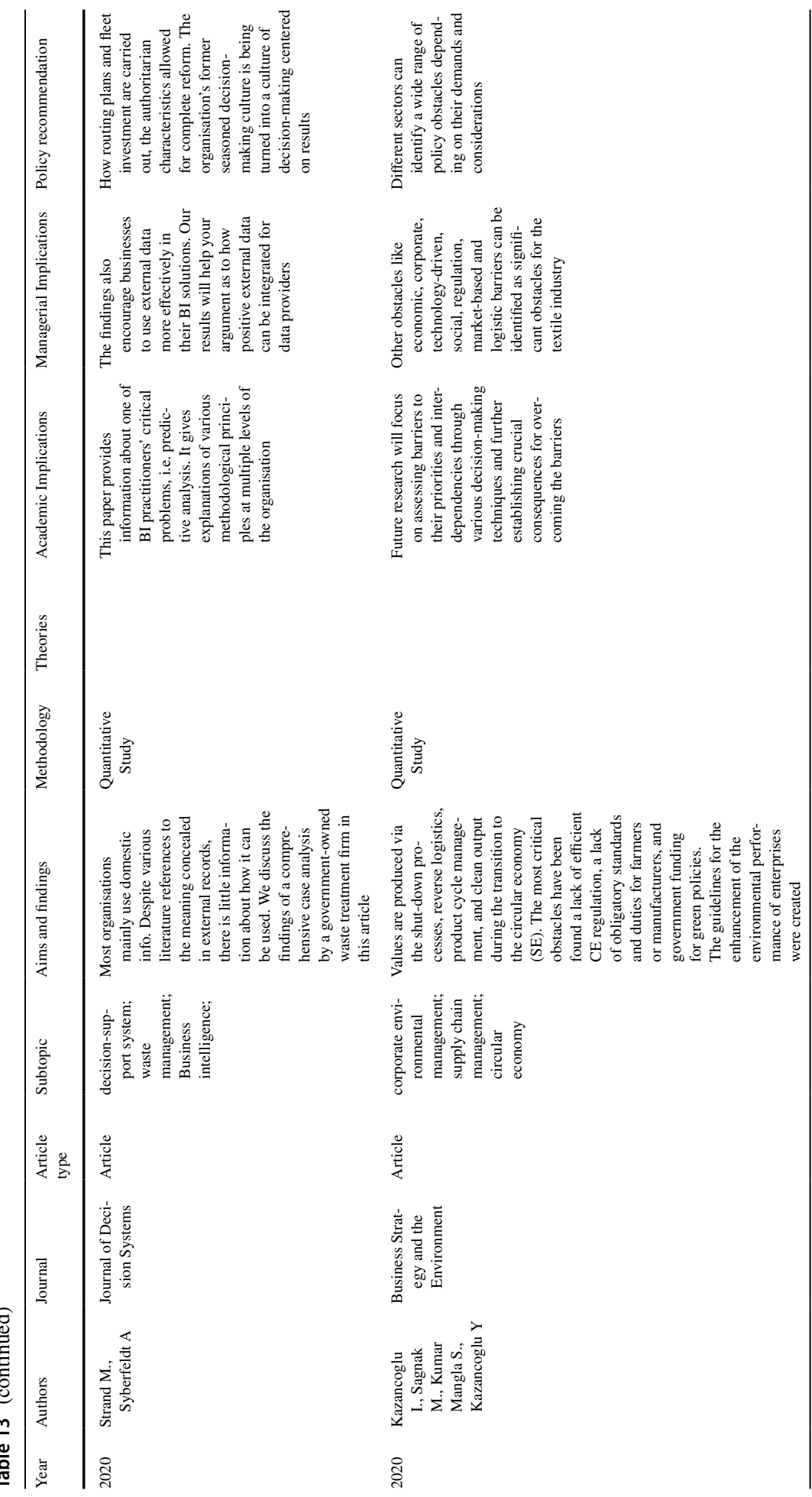




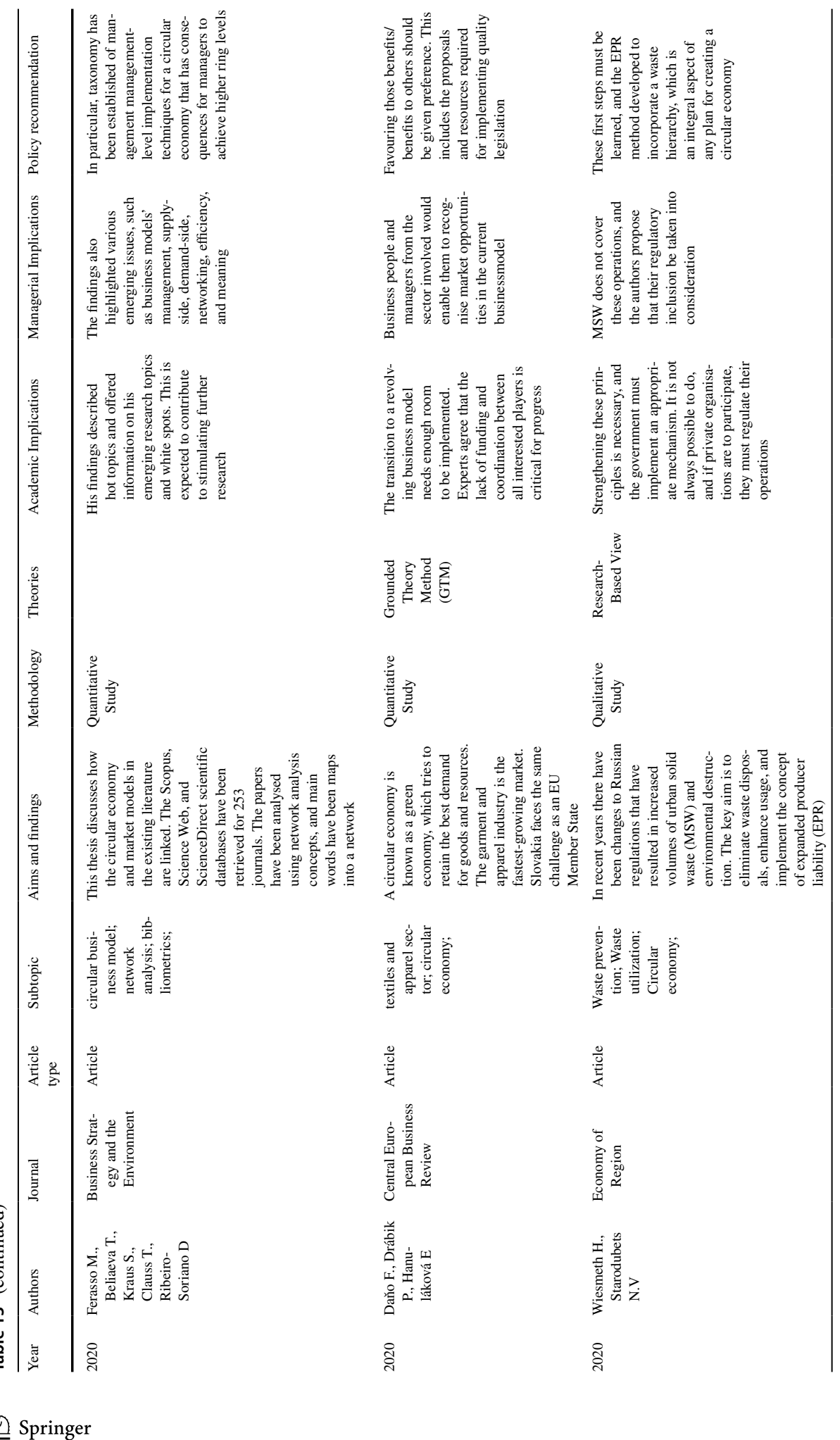




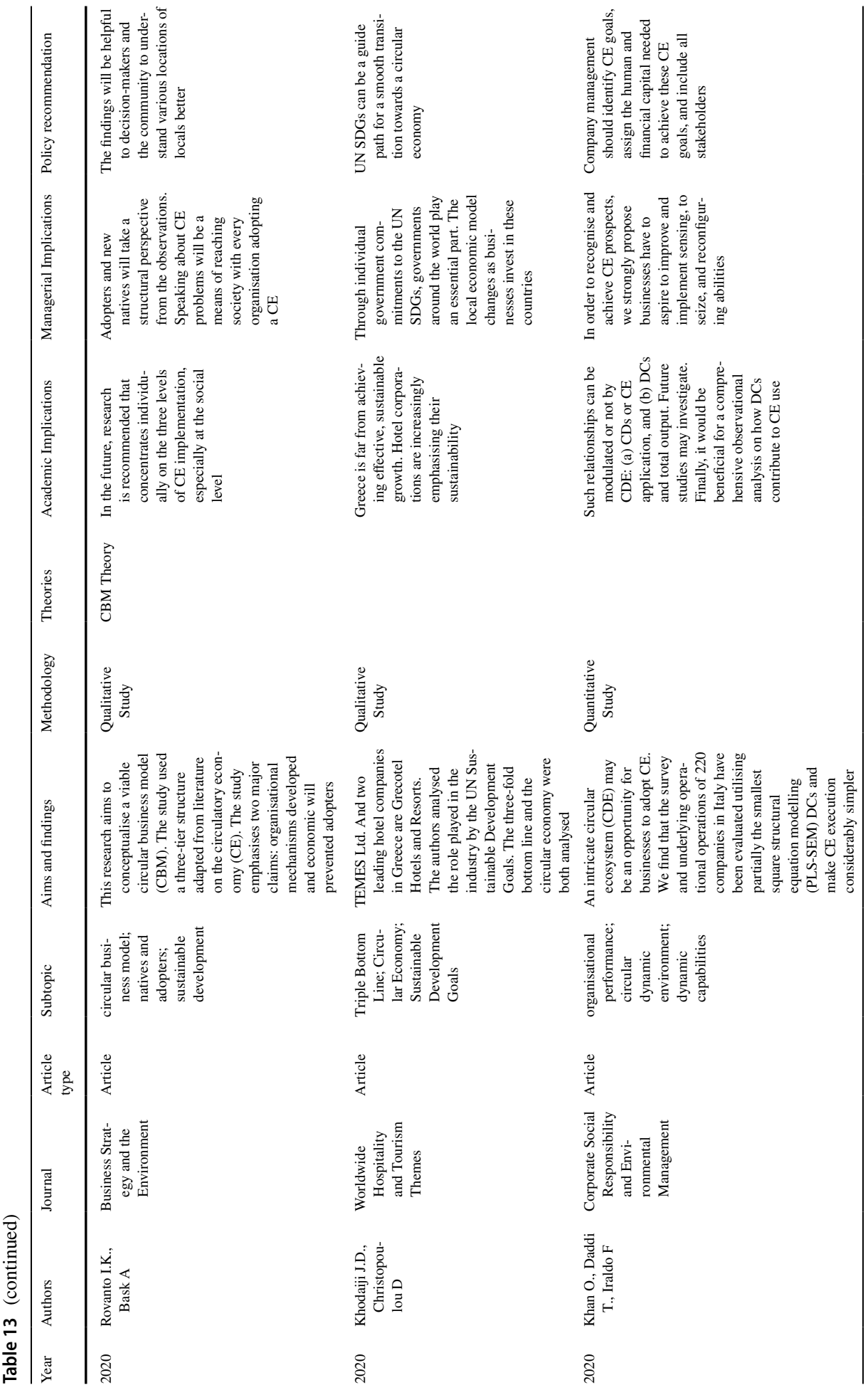




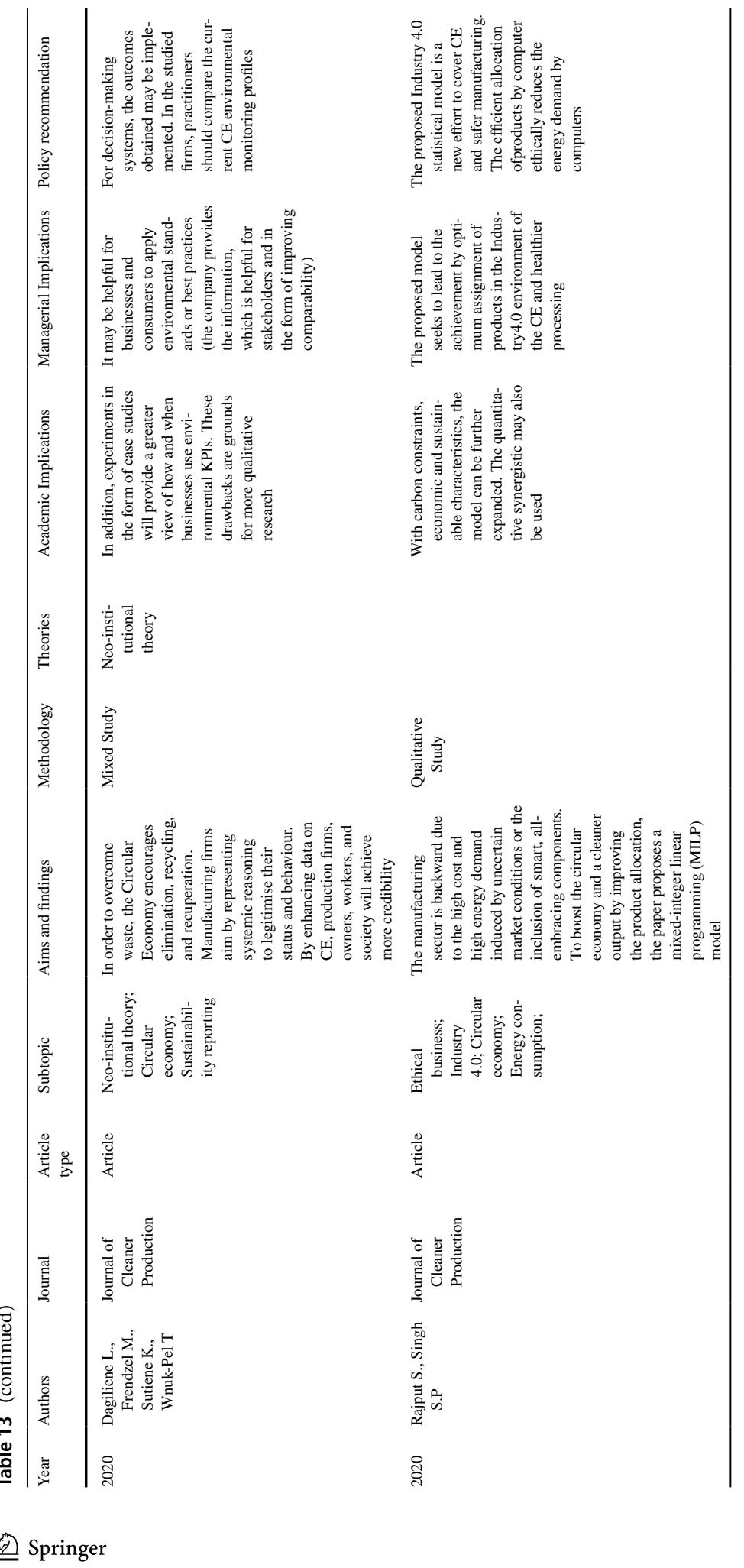




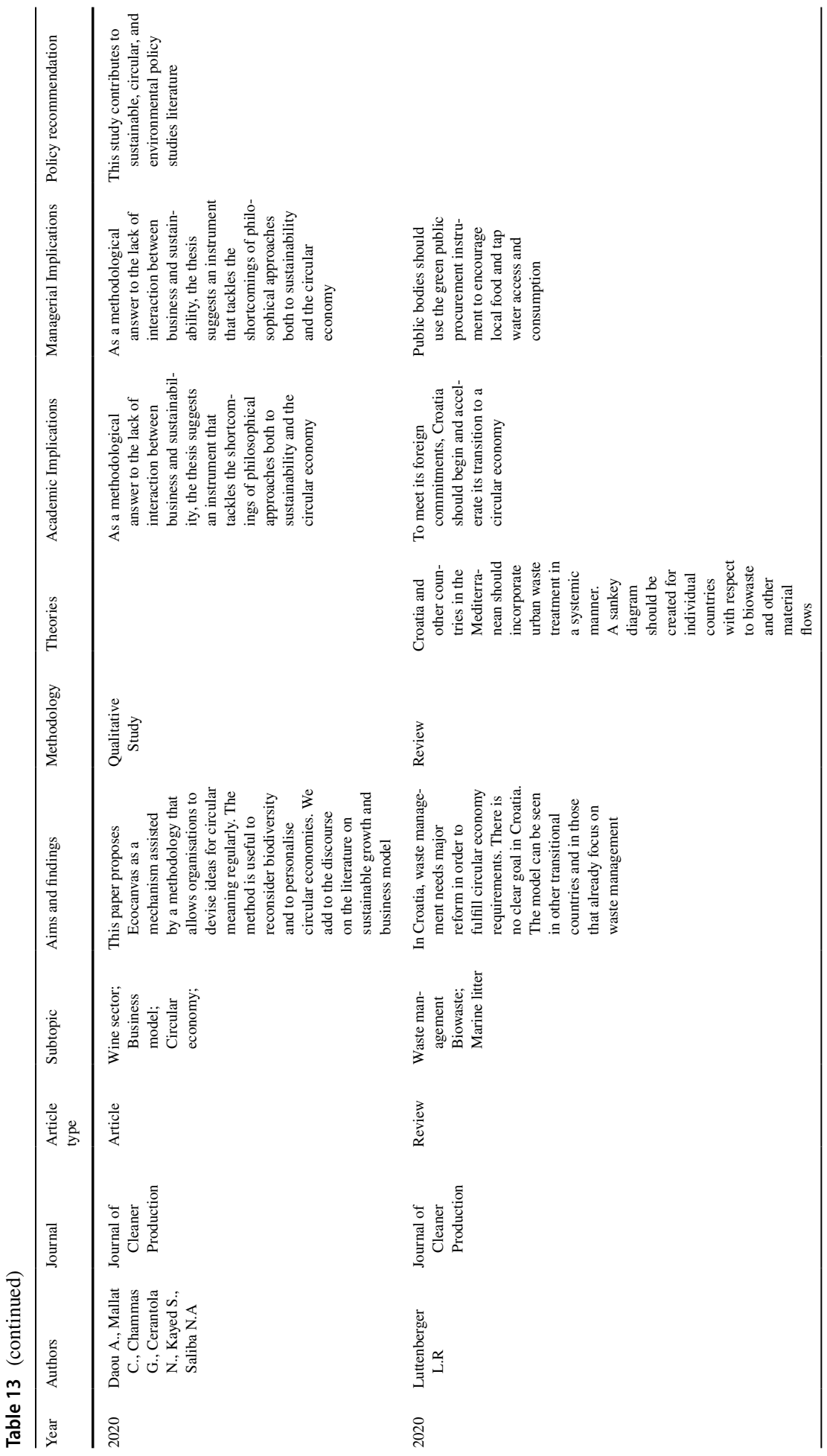




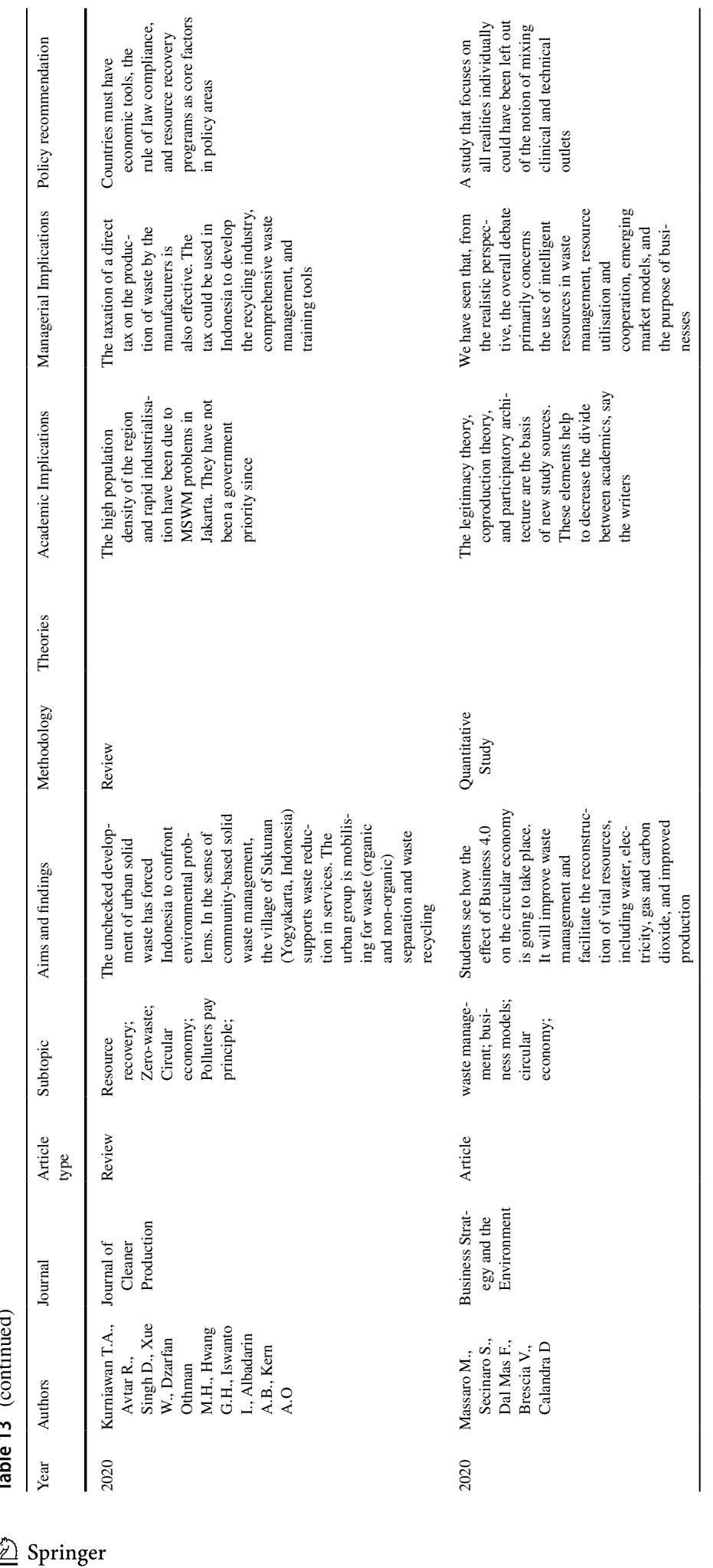




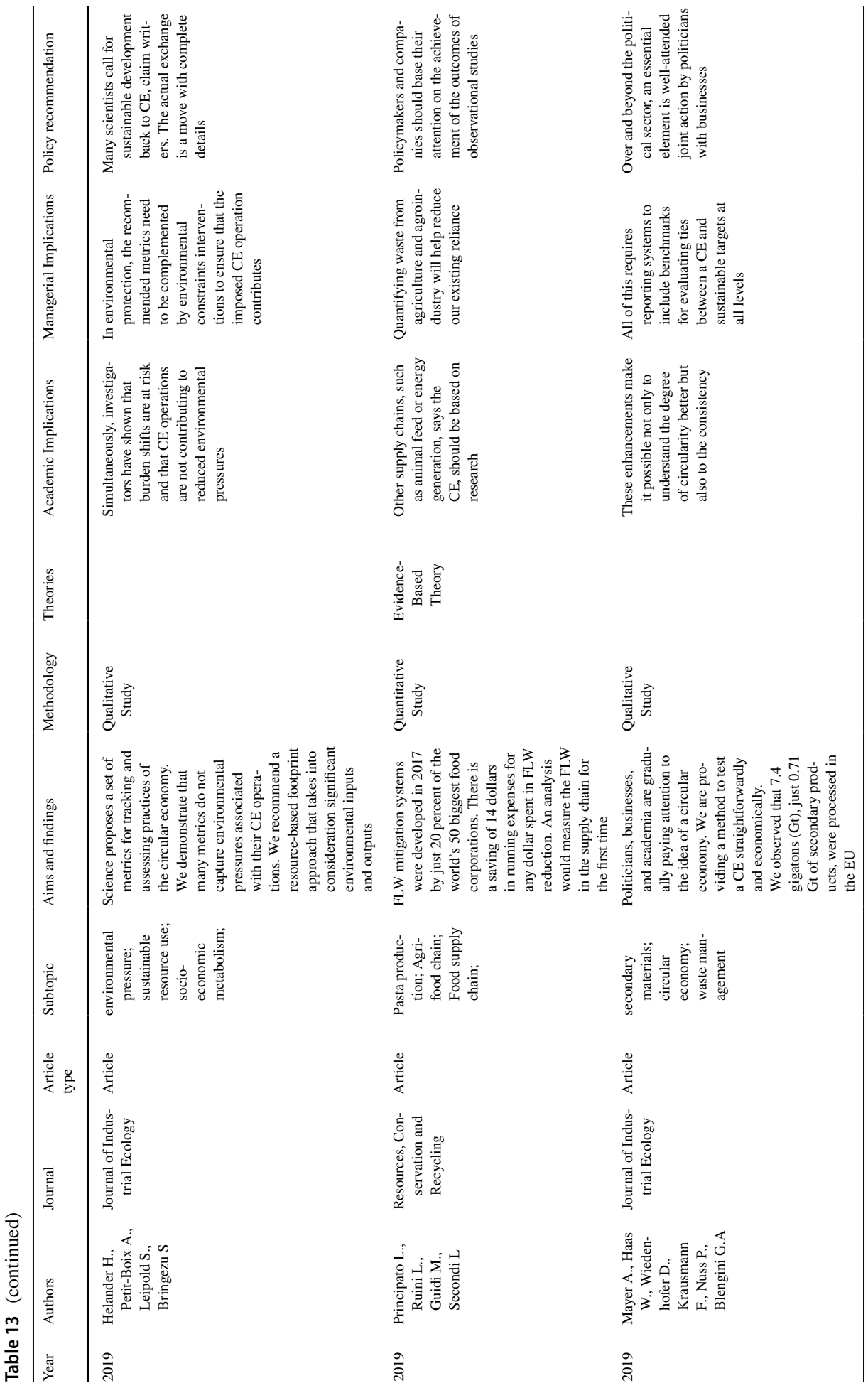




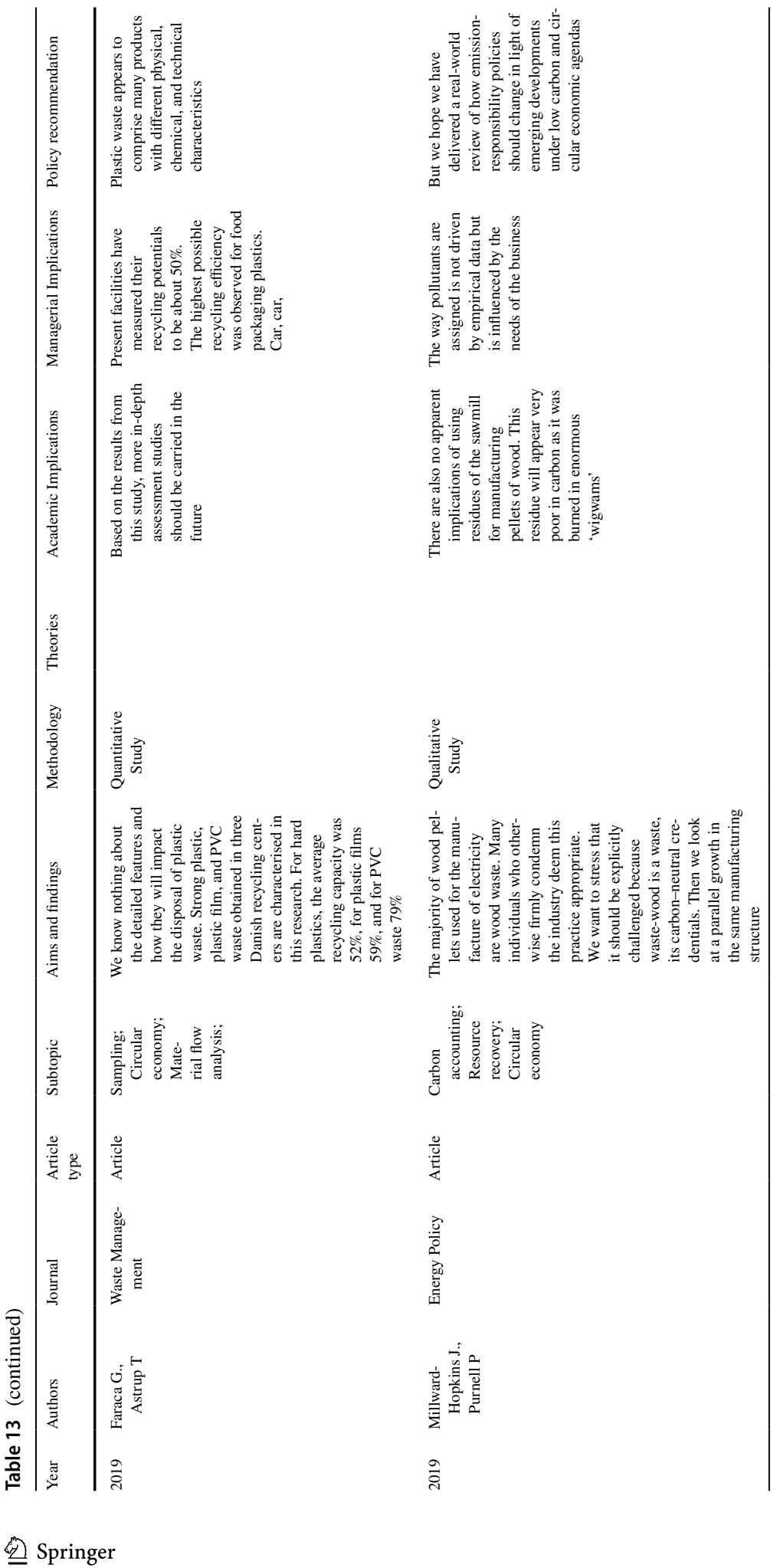




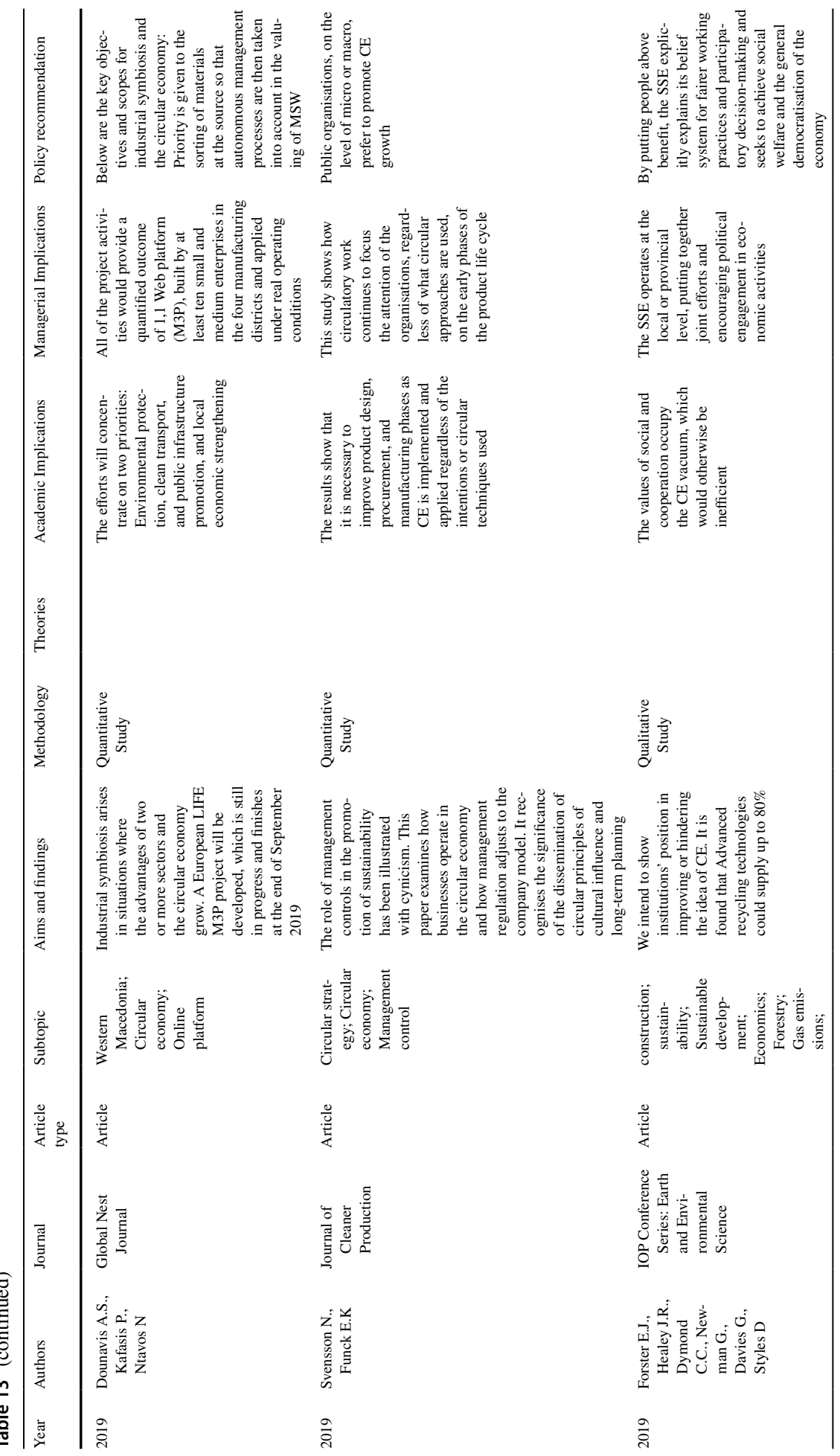




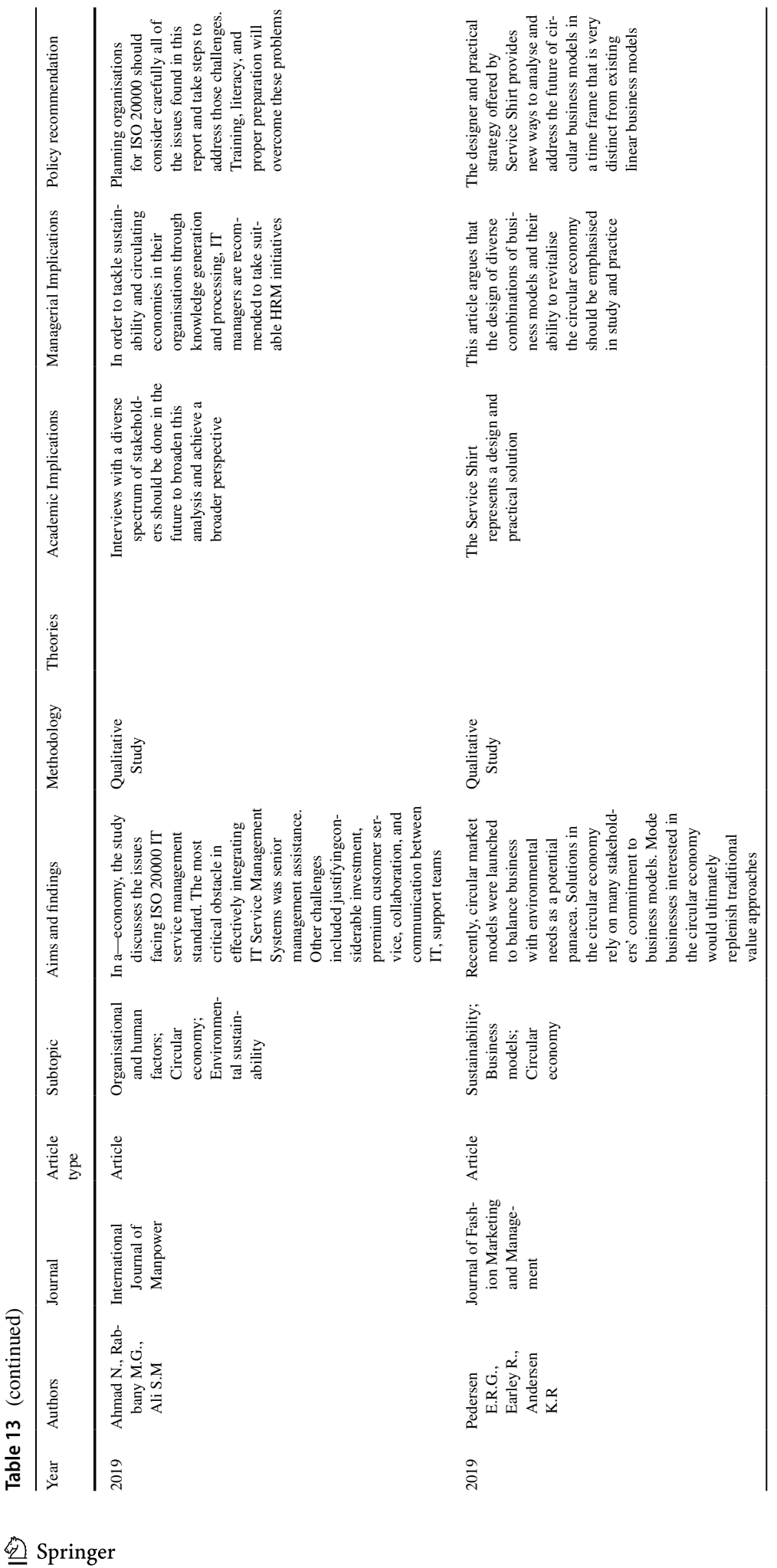




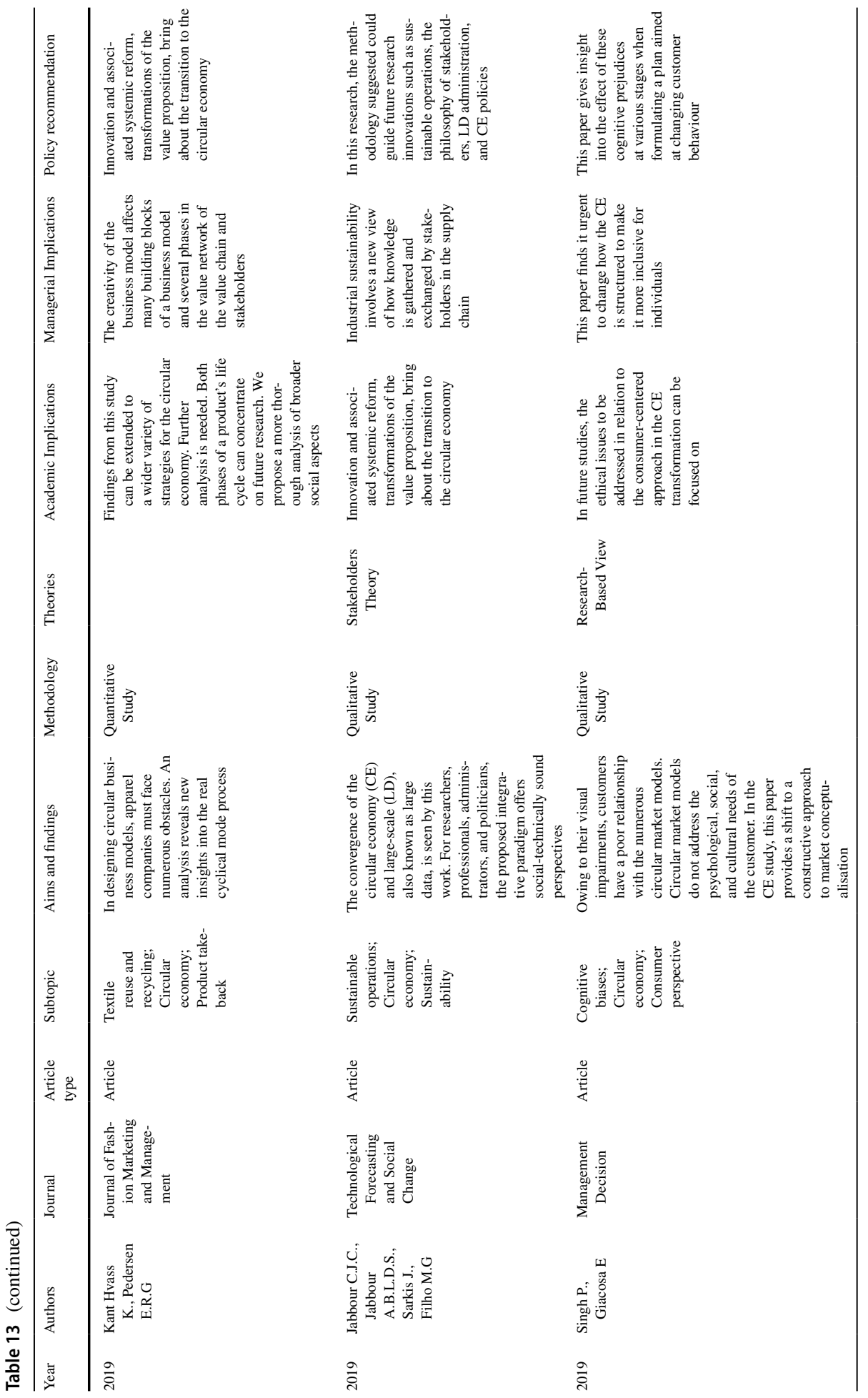




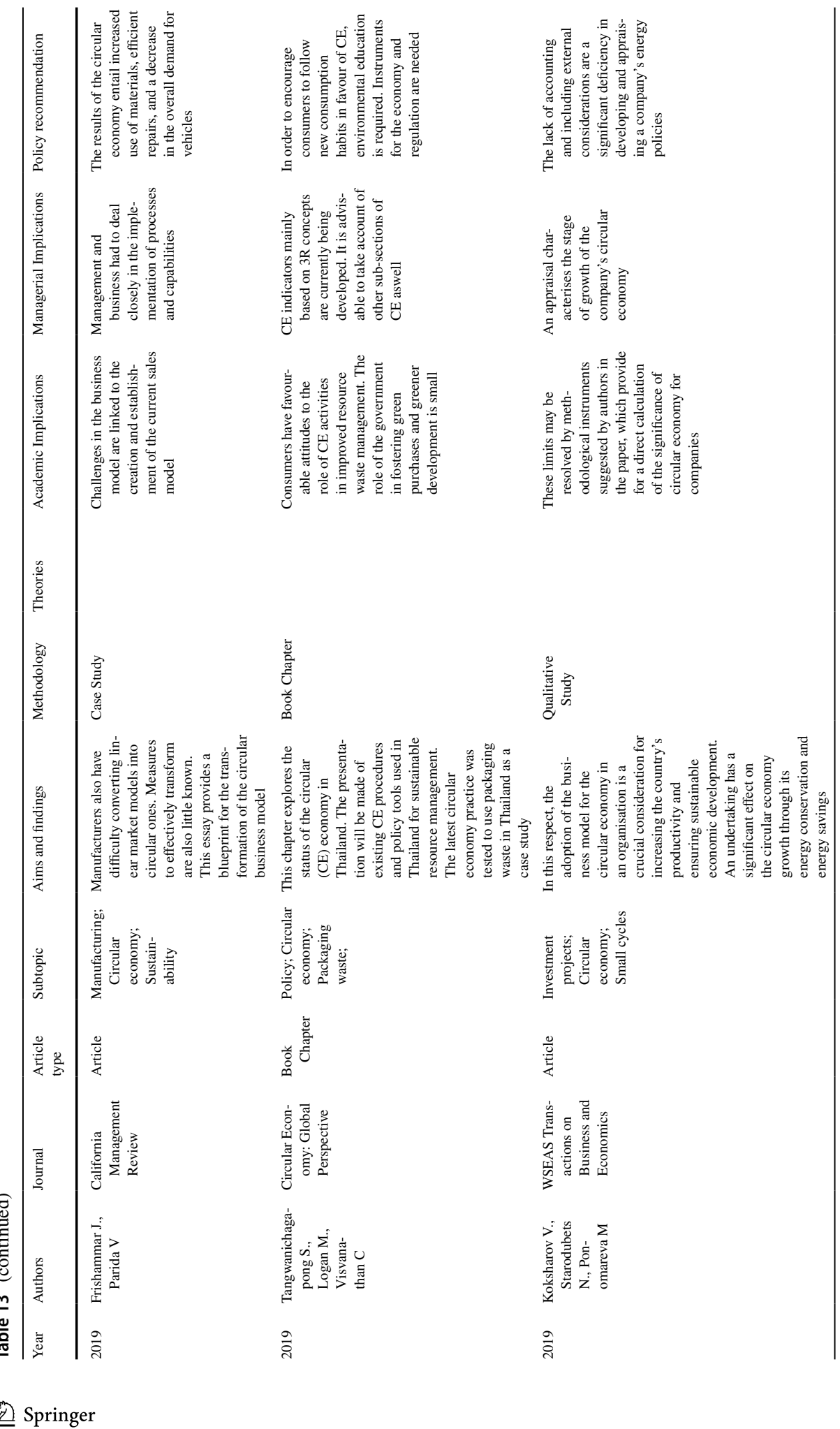




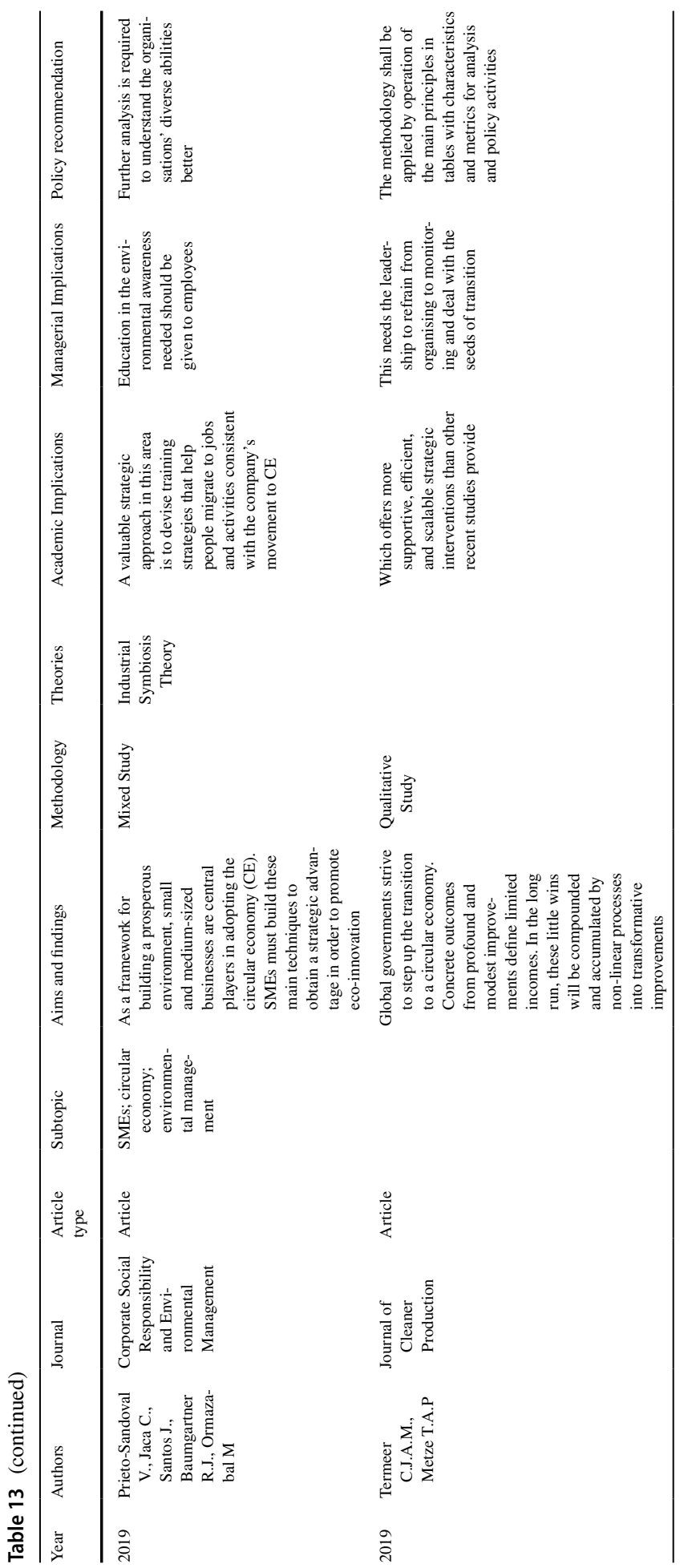




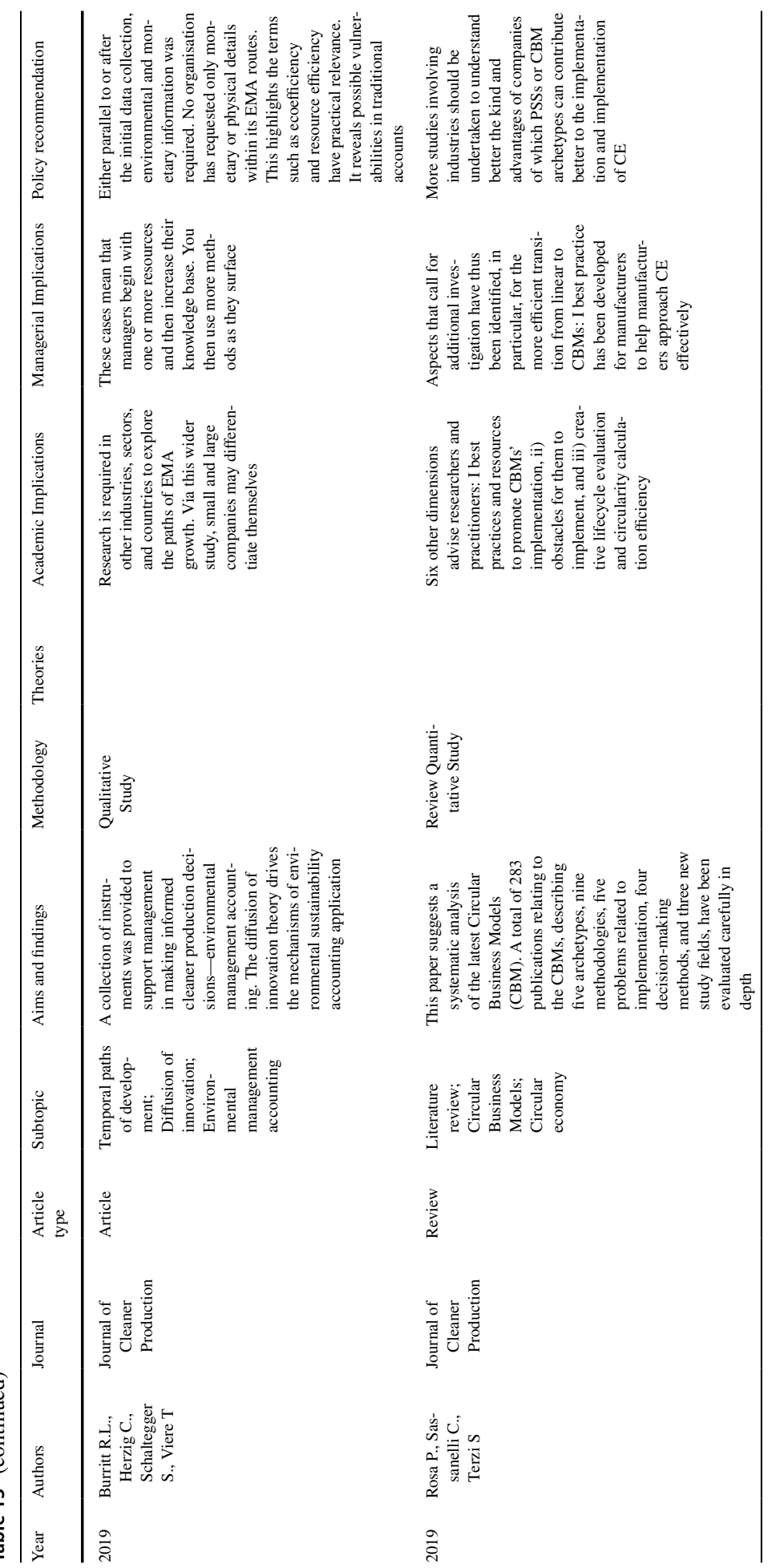




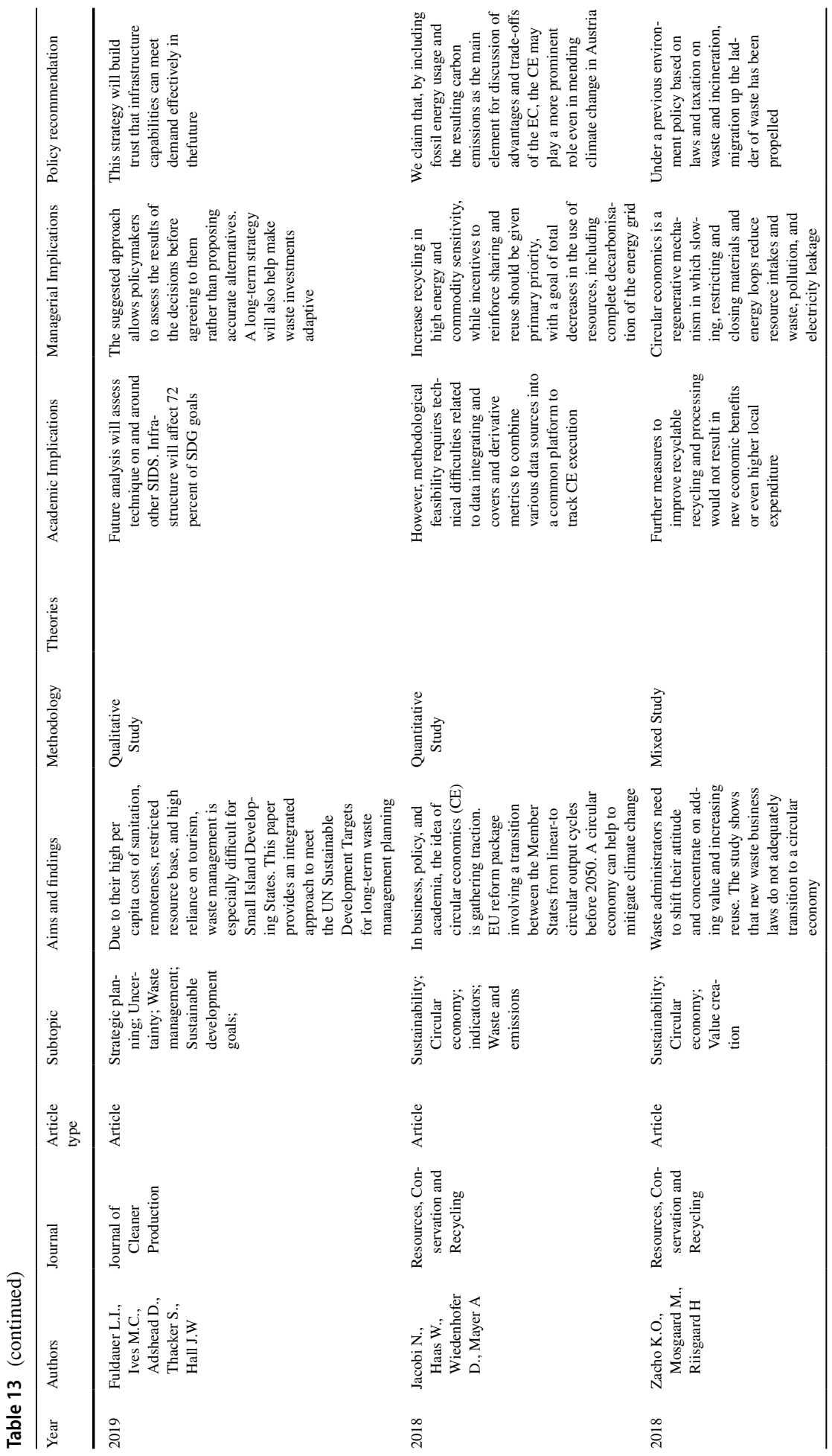




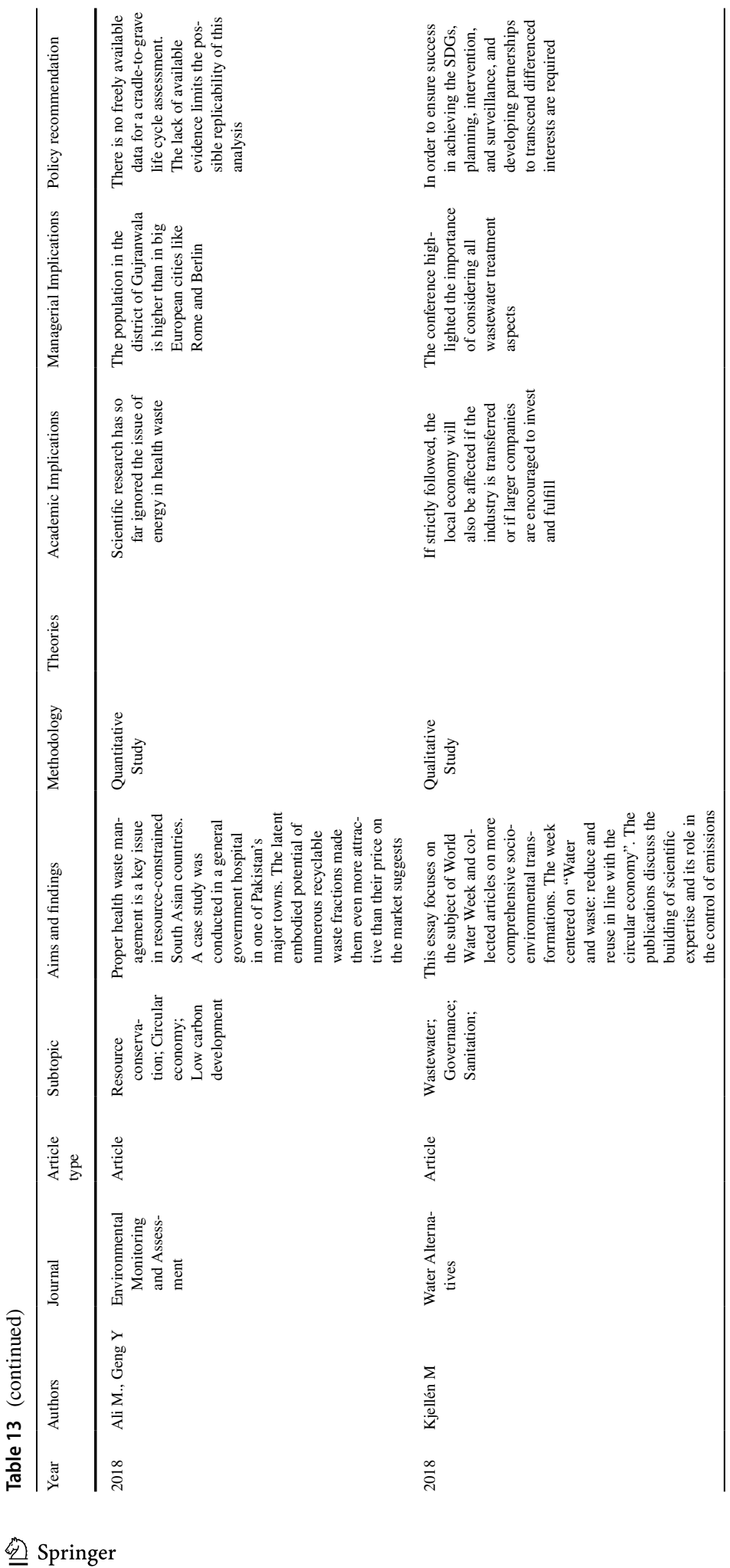




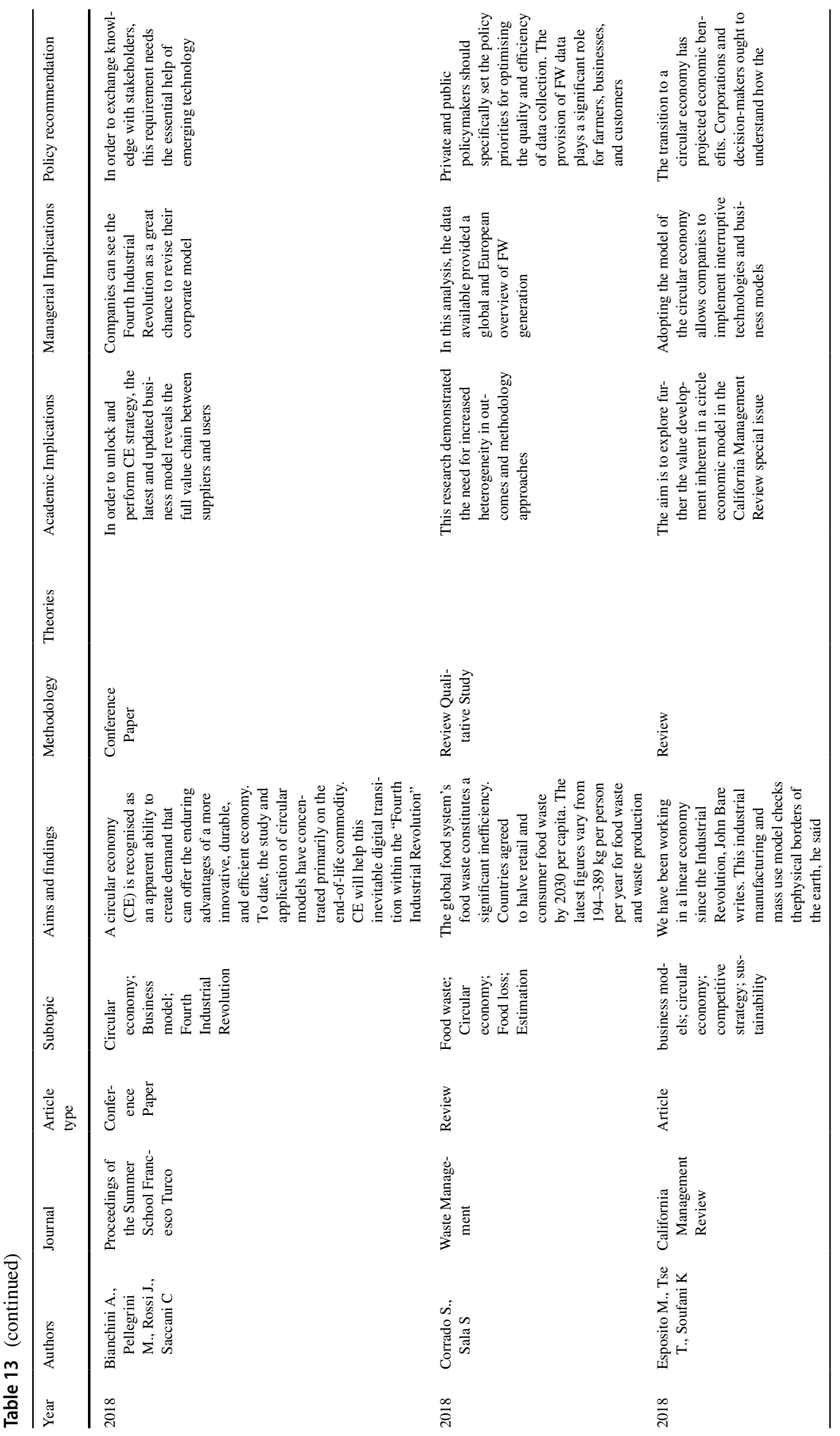




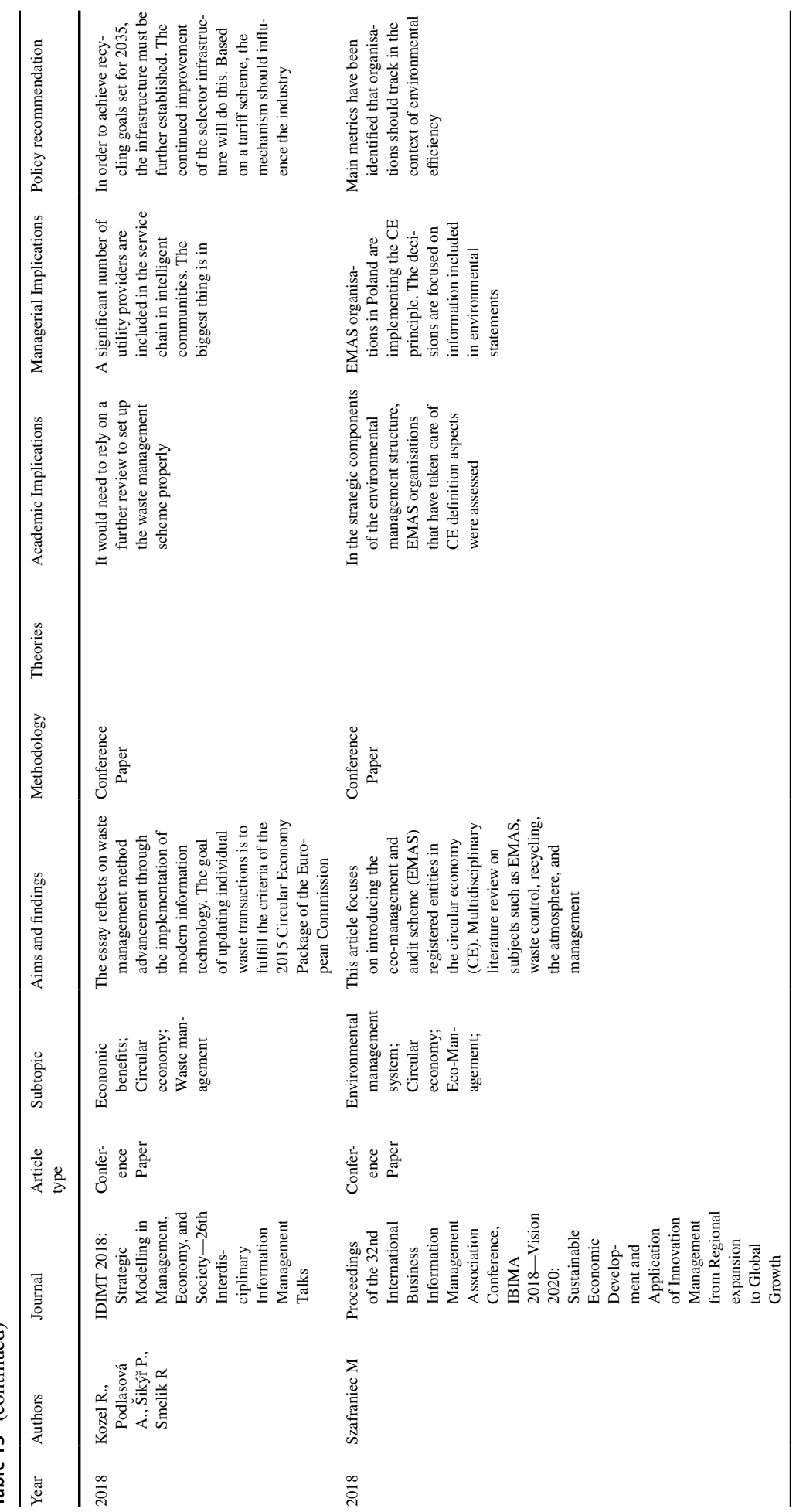




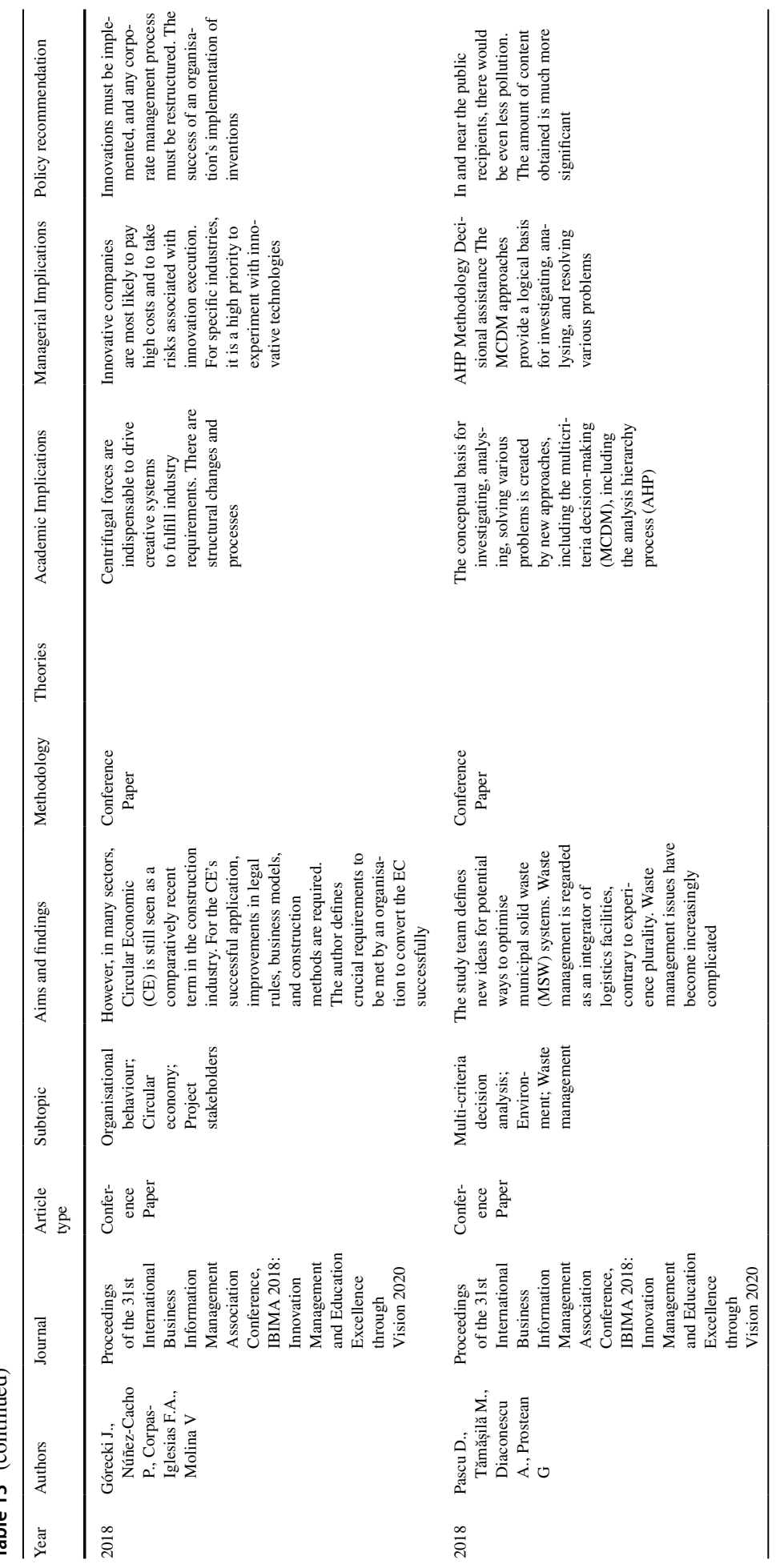




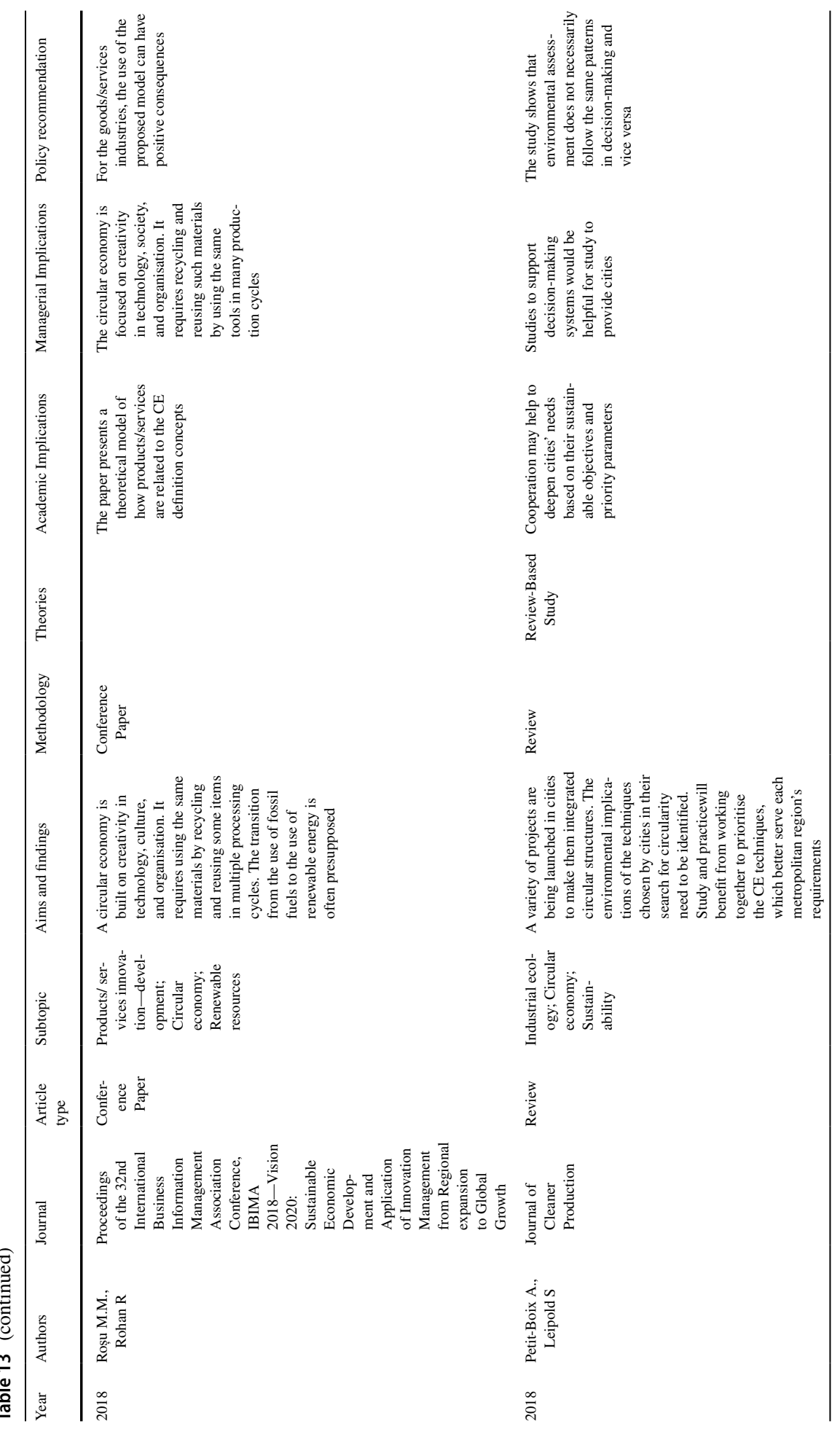




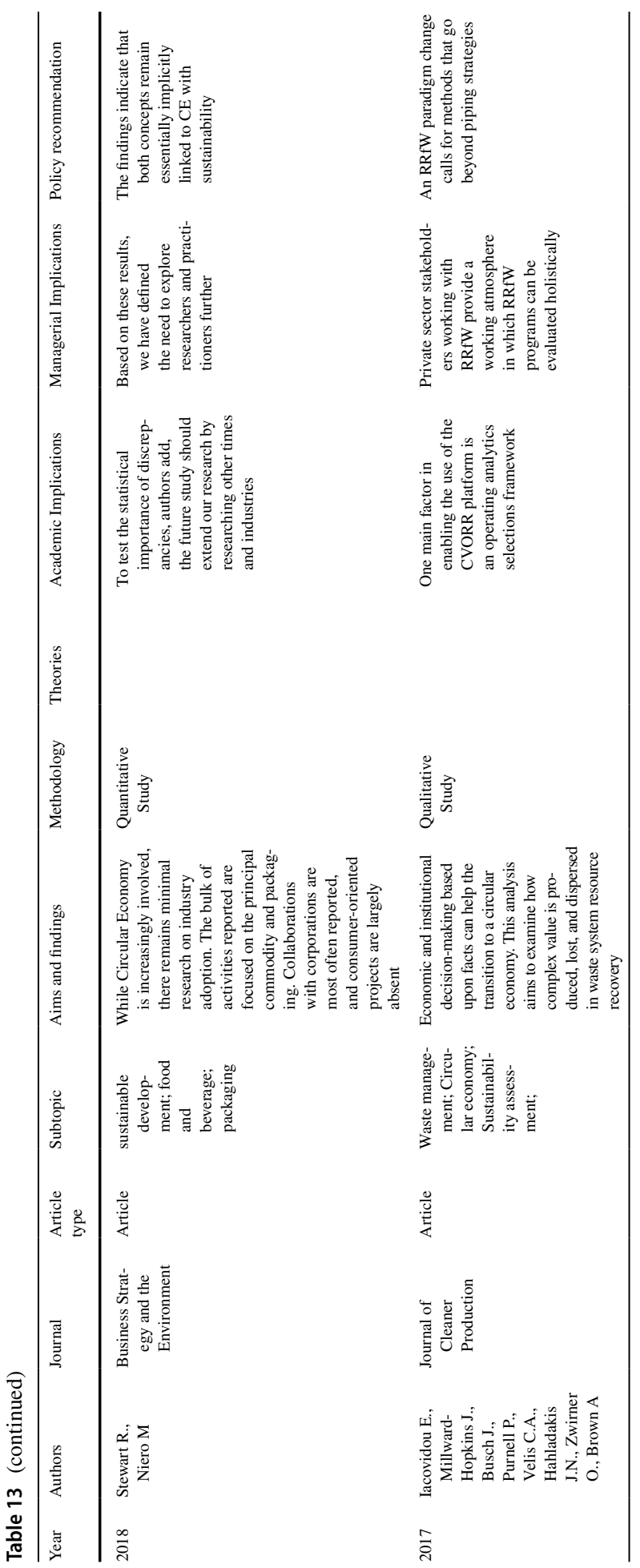




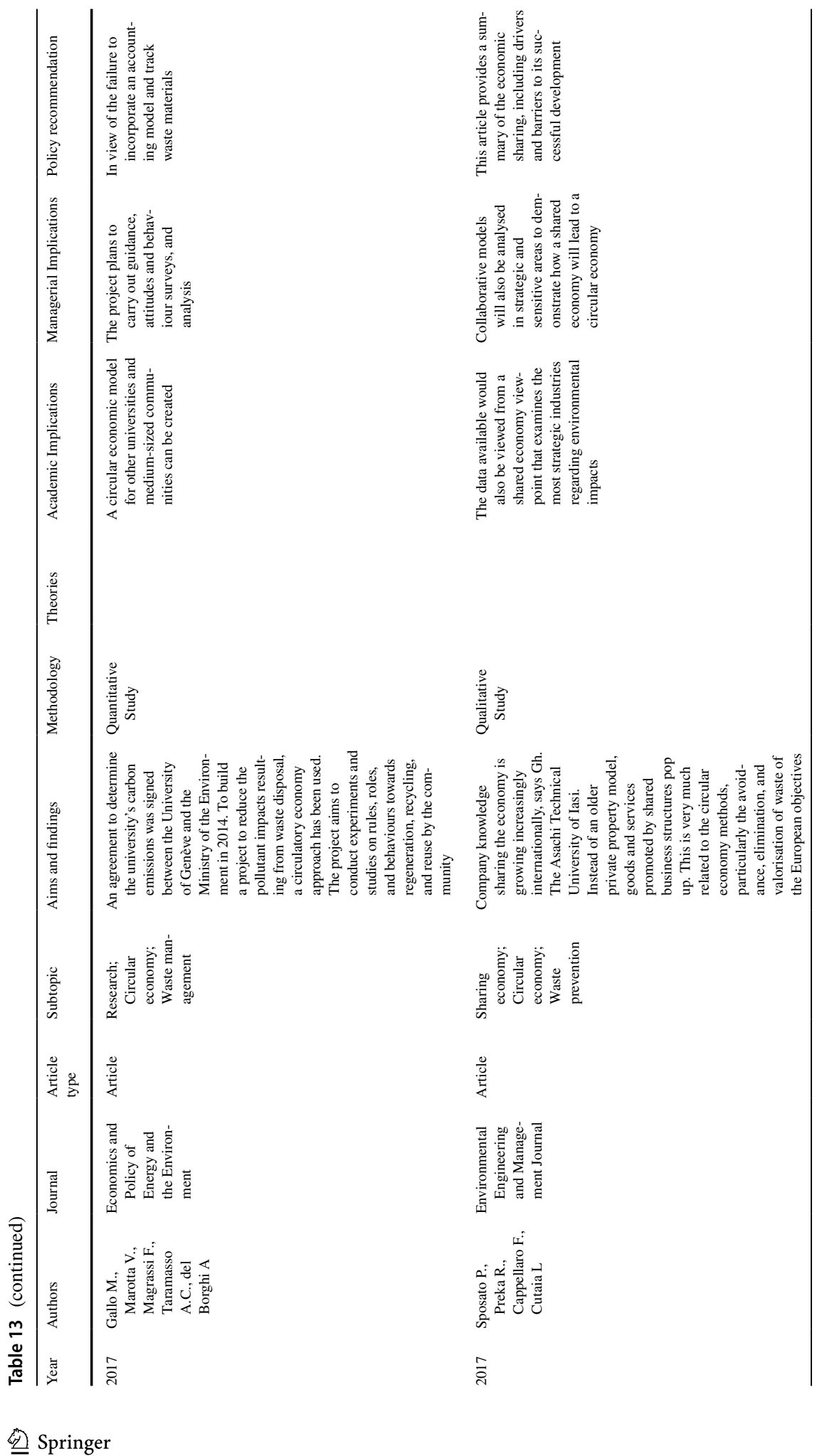




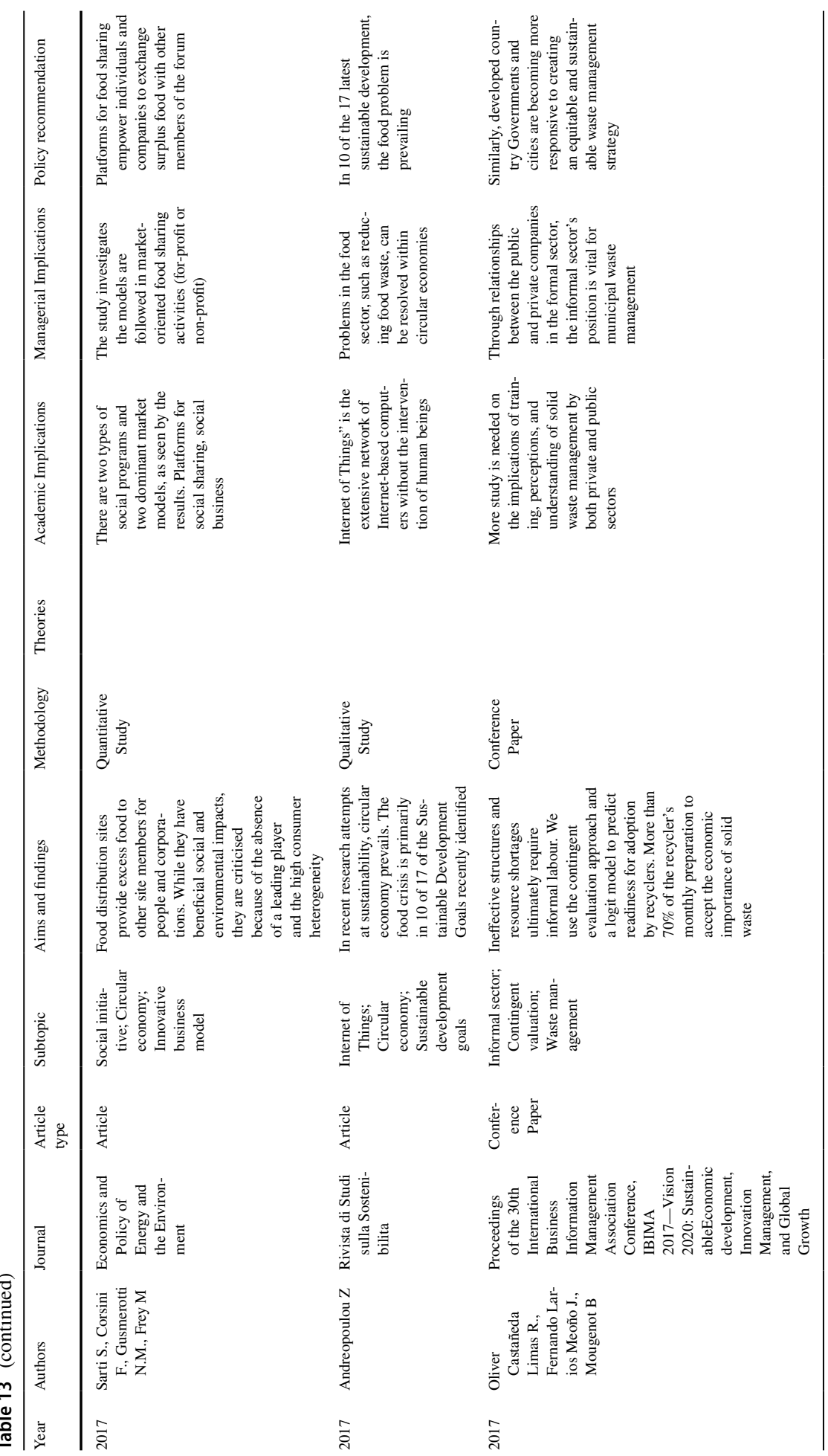




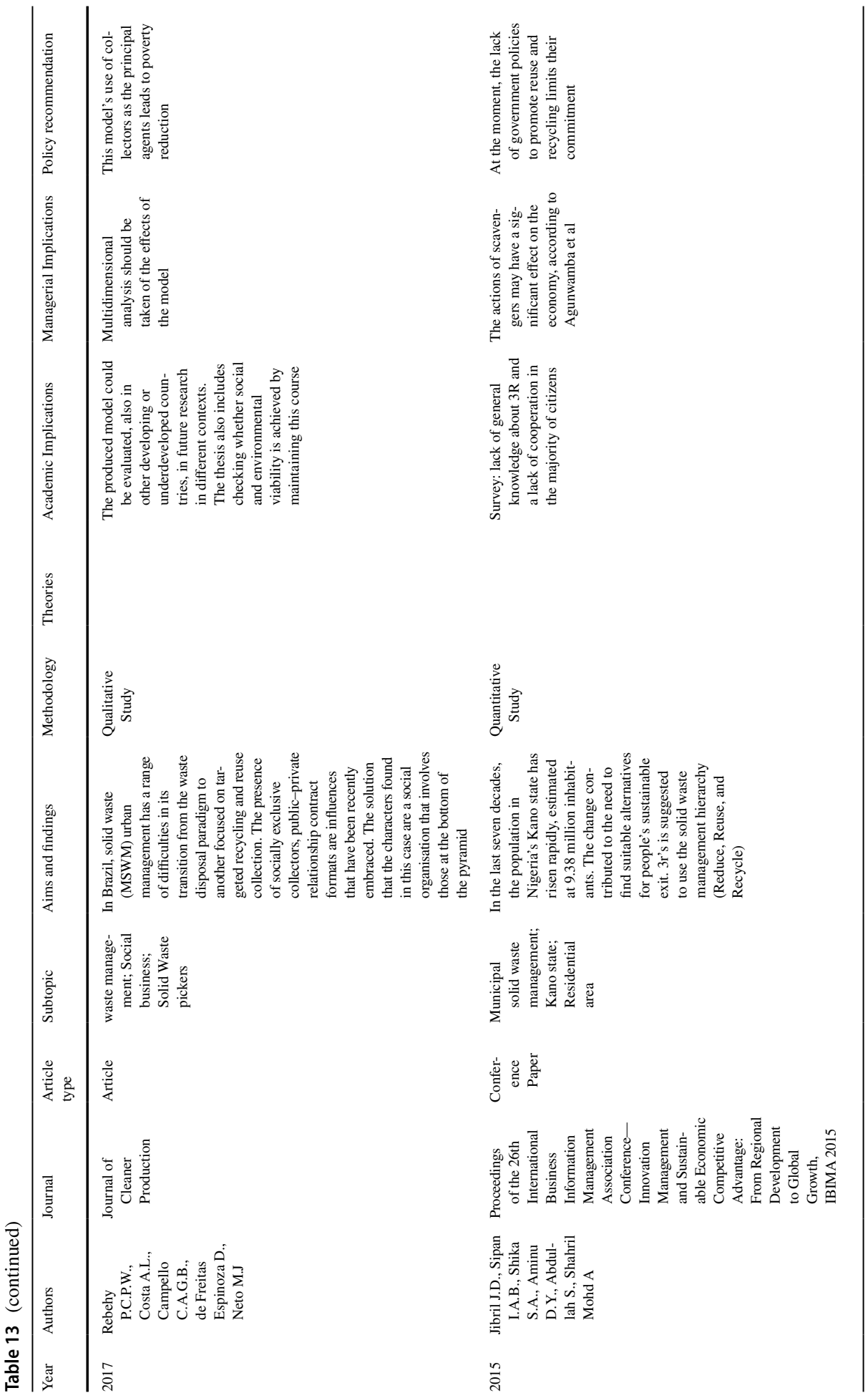




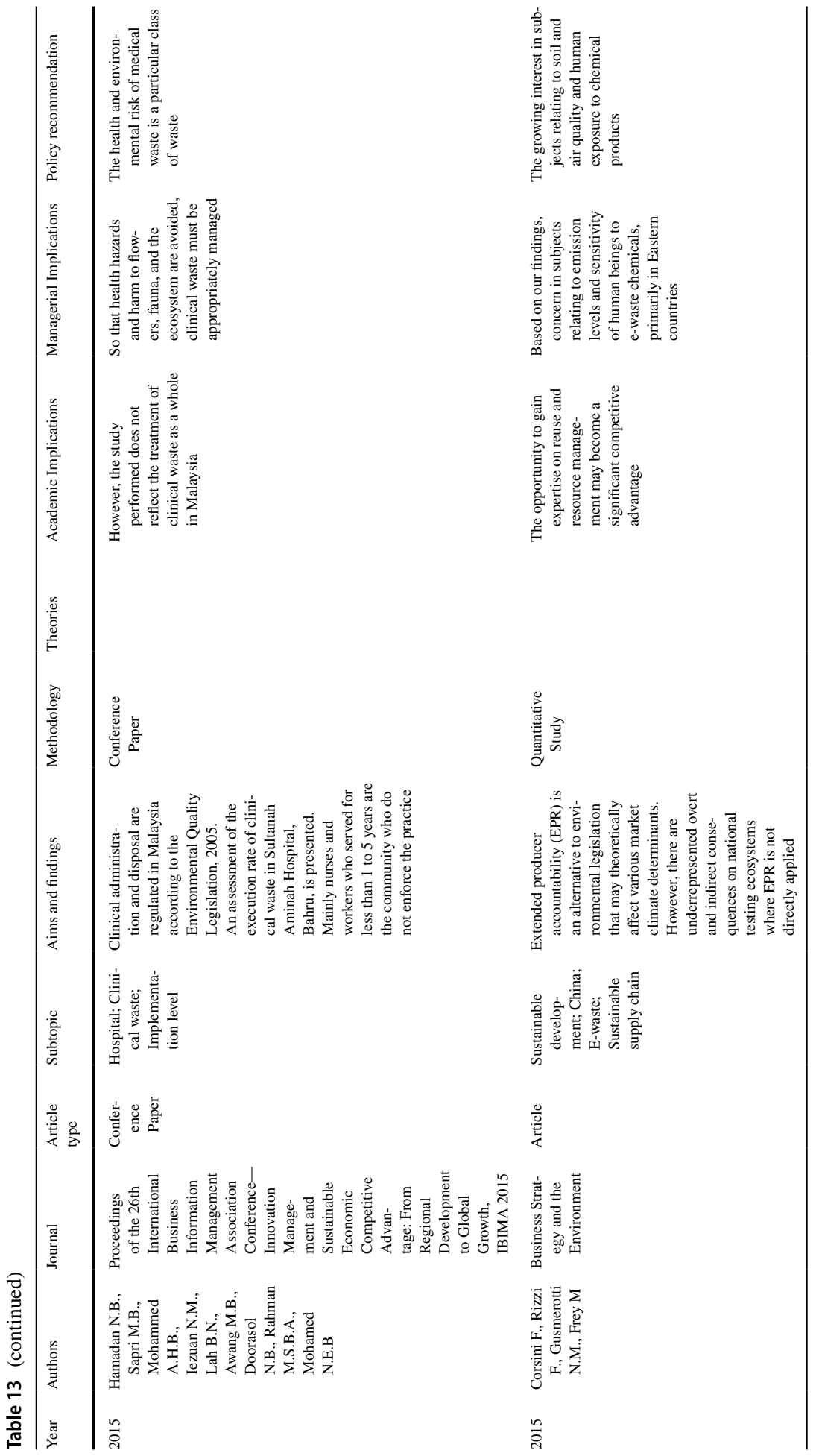




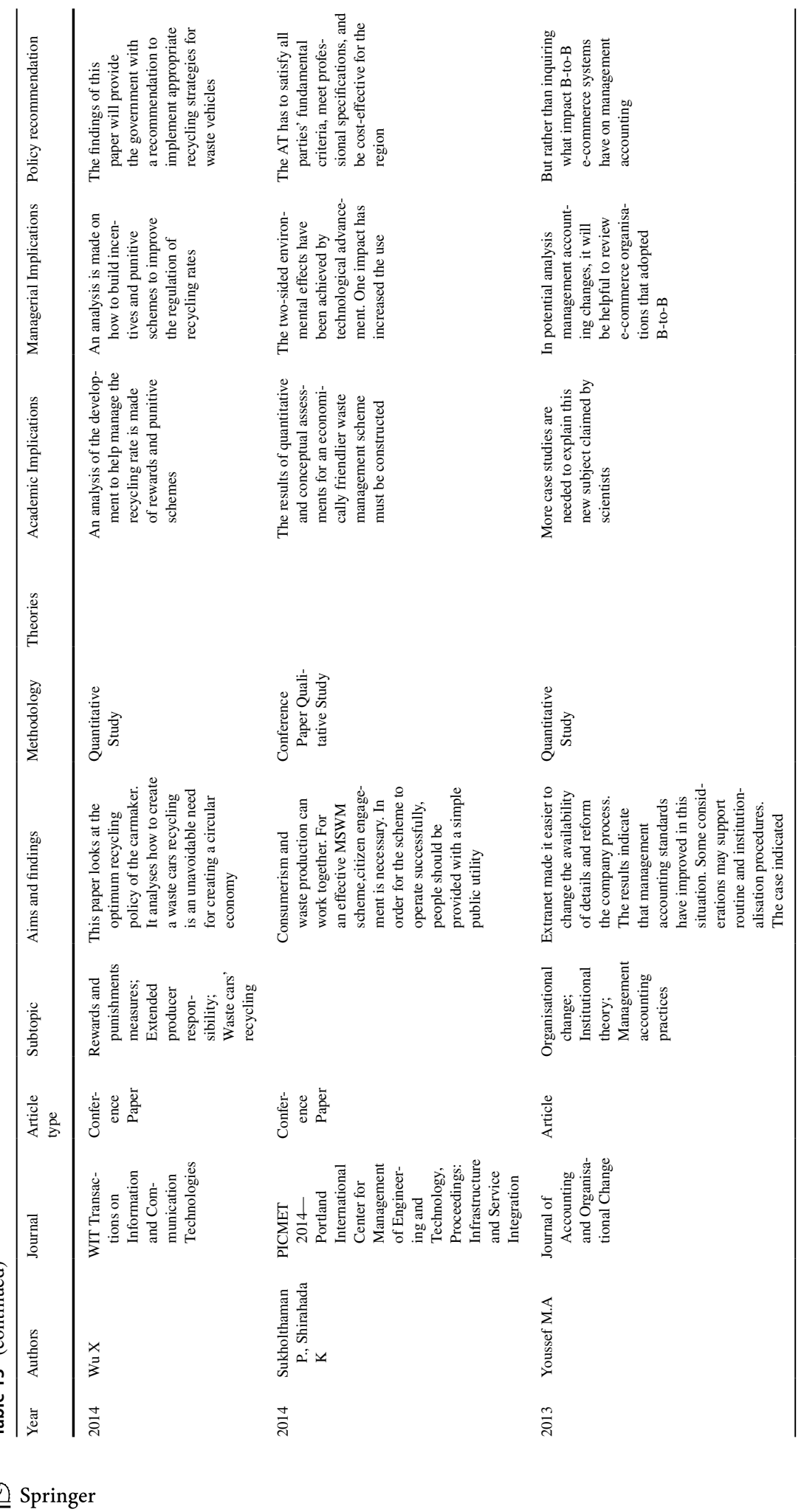




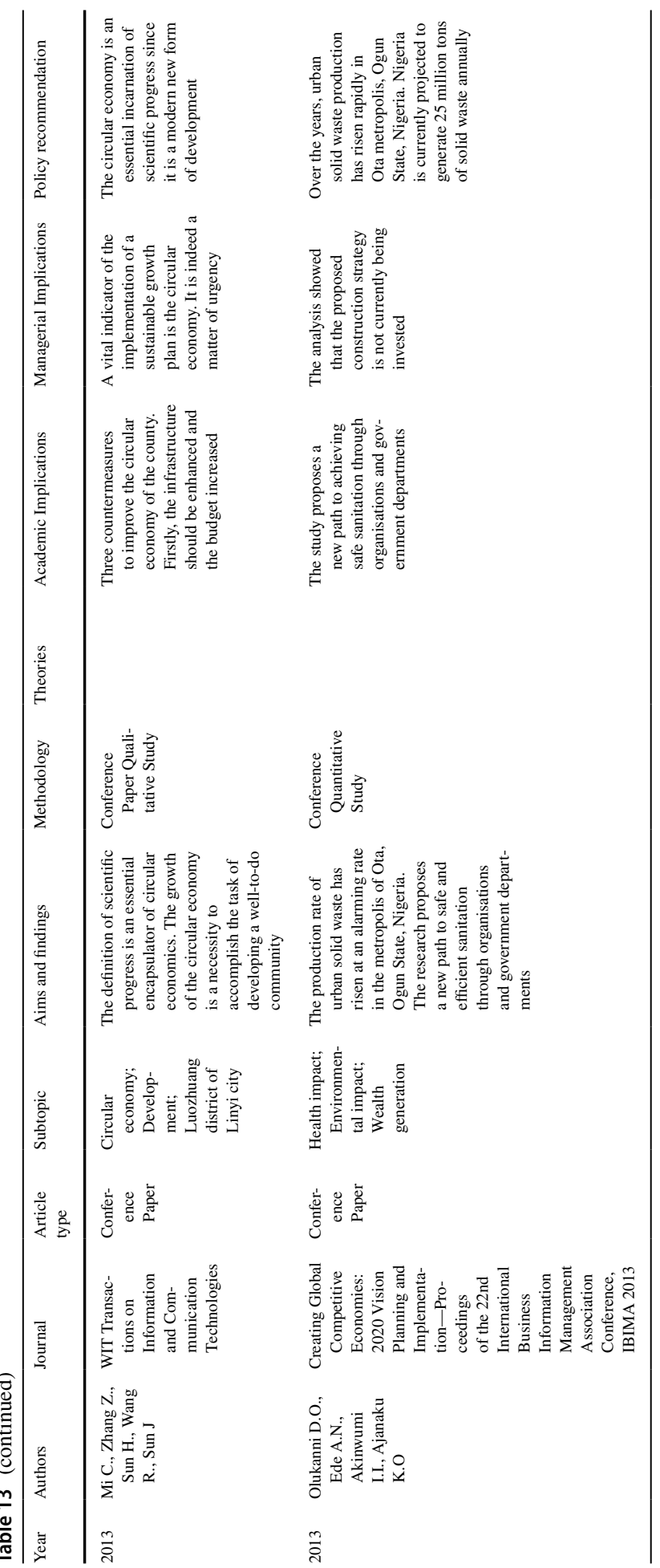




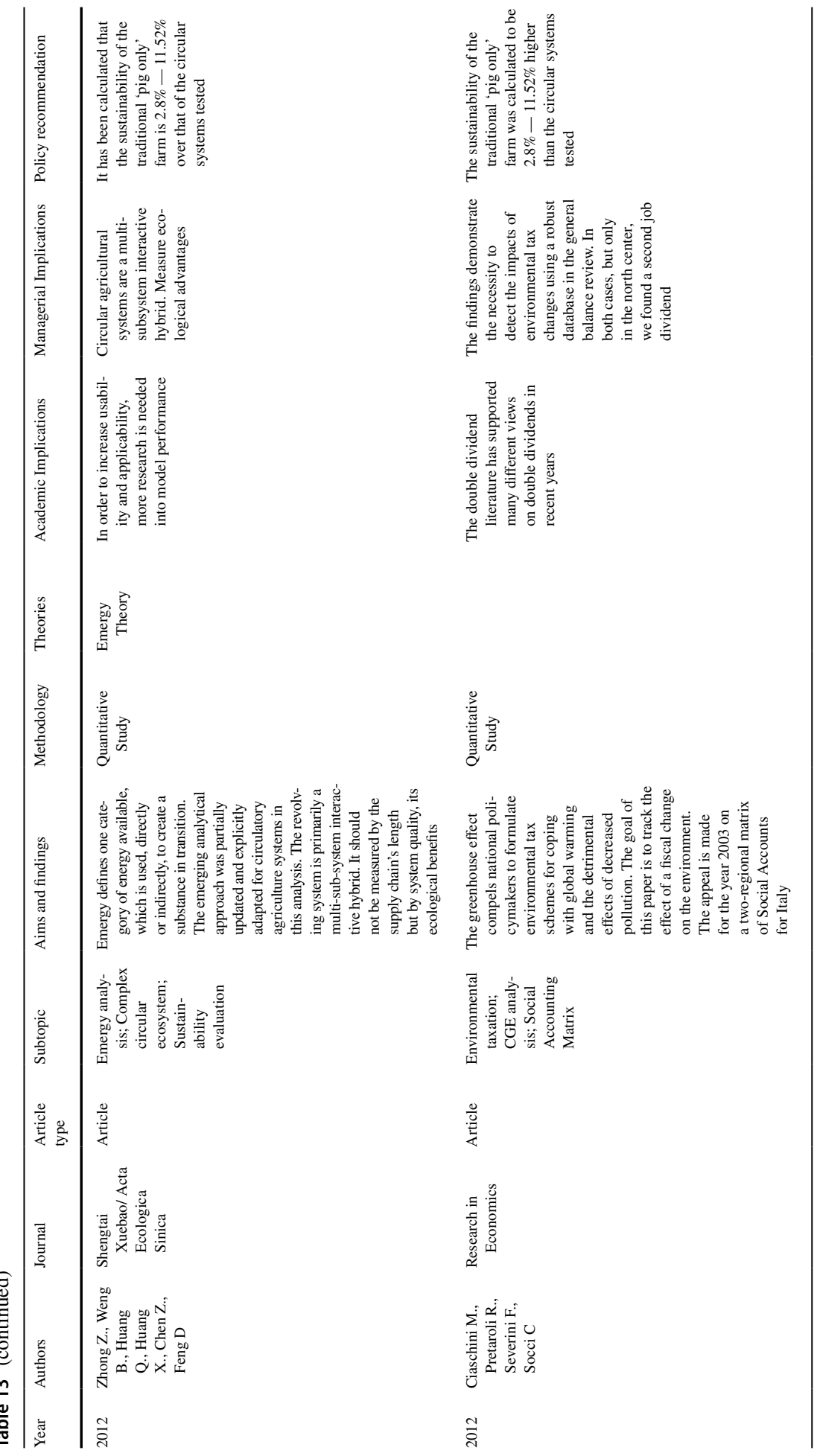




\section{References}

Adams, C. A., \& Larrinaga, C. (2019). Progress: Engaging with organisations in pursuit of improved sustainability accounting and performance. Accounting, Auditing \& Accountability Journal. https://doi. org/10.1108/AAAJ-03-2018-3399

Adams, C. A., \& Larrinaga-González, C. (2007). Engaging with organisations in pursuit of improved sustainability accounting and performance. Accounting, Auditing \& Accountability Journal. https://doi. org/10.1108/09513570710748535

Agovino, M., Ferrara, M., Marchesano, K., \& Garofalo, A. (2020). The separate collection of recyclable waste materials as a flywheel for the circular economy: The role of institutional quality and socioeconomic factors. Economia Politica, 37(2), 659-681.

Ajwani-Ramchandani, R., Figueira, S., de Oliveira, R. T., Jha, S., Ramchandani, A., \& Schuricht, L. (2021). Towards a circular economy for packaging waste by using new technologies: The case of large multinationals in emerging economies. Journal of Cleaner Production, 281, 125139. https://doi.org/10. 1016/j.jclepro.2020.125139

Andrews, D. (2015). The circular economy, design thinking and education for sustainability. Local Economy, 30(3), 305-315. https://doi.org/10.1177/0269094215578226

Arjaliès, D. L., \& Mundy, J. (2013). The use of management control systems to manage CSR strategy: A levers of control perspective. Management Accounting Research, 24(4), 284-300. https://doi.org/10. 1016/j.mar.2013.06.003

Ball, A., \& Craig, R. (2010). Using neo-institutionalism to advance social and environmental accounting. Critical Perspectives on Accounting, 21(4), 283-293. https://doi.org/10.1016/j.cpa.2009.11.006

Böckel, A., Nuzum, A. K., \& Weissbrod, I. (2020). Blockchain for the circular economy: Analysis of the research-practice gap. Sustainable Production and Consumption. https://doi.org/10.1016/j.spc.2020. 12.006

Bocken, N. M., Short, S. W., Rana, P., \& Evans, S. (2014). A literature and practice review to develop sustainable business model archetypes. Journal of Cleaner Production, 65, 42-56. https://doi.org/10. 1016/j.jclepro.2013.11.039

Bohringer, C., \& Rutherford, T. (2015). The circular economy-an economic impact assessment. Report to SUN-iza, 1-33. Report is available at https://www.sun-institute.org/wc/files/report-circular-economy. pdf

Bonilla, C. A., Merigó, J. M., \& Torres-Abad, C. (2015). Economics in Latin America: A bibliometric analysis. Scientometrics, 105(2), 1239-1252. https://doi.org/10.1007/s11192-015-1747-7

Boons, F., Montalvo, C., Quist, J., \& Wagner, M. (2013). Sustainable innovation, business models and economic performance: An overview. Journal of Cleaner Production, 45, 1-8. https://doi.org/10.1016/j. jclepro.2012.08.013

Bornmann, L., \& Daniel, H. D. (2007). What do we know about the h index? Journal of the American Society for Information Science and Technology, 58(9), 1381-1385. https://doi.org/10.1002/asi.20609

Bornmann, L., Mutz, R., Neuhaus, C., \& Daniel, H. D. (2008). Citation counts for research evaluation: Standards of good practice for analysing bibliometric data and presenting and interpreting results. Ethics in Science and Environmental Politics, 8(1), 93-102. https://doi.org/10.3354/esep00084

Bouten, L., \& Hoozée, S. (2021). Designing eco-controls for multi-objective organisations 1. In Routledge Handbook of Environmental Accounting (pp. 194-206). Routledge. https://doi.org/10.4324/97803 67152369.

Carmona, S., \& Ezzamel, M. (2007). Accounting and accountability in ancient civilisations: Mesopotamia and ancient Egypt. Accounting, Auditing \& Accountability Journal. https://doi.org/10.1108/09513 570710740993

Casino, F., Dasaklis, T. K., \& Patsakis, C. (2019). A systematic literature review of blockchain-based applications: Current status, classification and open issues. Telematics and Informatics, 36, 55-81. https:// doi.org/10.1016/j.tele.2018.11.006

Cho, C. H., Kim, A., Rodrigue, M., \& Schneider, T. (2020). Towards a better understanding of sustainability accounting and management research and teaching in North America: A look at the community. Sustainability Accounting, Management and Policy Journal. https://doi.org/10.1108/ SAMPJ-08-2019-0311

Ciulli, F., Kolk, A., \& Boe-Lillegraven, S. (2020). Circularity brokers: Digital platform organisations and waste recovery in food supply chains. Journal of Business Ethics, 167(2), 299-331. https://doi.org/10. 1007/s10551-019-04160-5

Collier, P. M. (2001). The power of accounting: A field study of local financial management in a police force. Management Accounting Research, 12(4), 465-486. https://doi.org/10.1006/mare.2001.0157 
European Commission (2011). Roadmap to a resource efficient Europe. https://eur-lex.europa.eu/legal-conte nt/EN/TXT/?uri=CELEX:52011DC0571.

European Commission (2015). Communication from the Commission to the European Parliament, the Council, the European Economic and Social Committee and the Committee of the Regions: Closing the loop-An EU action plan for the circular economy. Brussels. https://ec.europa.eu/transparency/ regdoc/rep/1/2015/EN/1-2015-614-EN-F1-1.PDF.

European Commission (2017). Report on the Implementation of the Circular Economy Action Plan. Available at http://www.astrid-online.it/static/upload/impl/implementation_report_annex.pdf.

European Commission (2019). Circular economy: Implementation of the circular economy action plan. Retrieved from https://ec.europa.eu/info/sites/default/files/report_implementation_circular_economy_ action_plan.pdf.

Contrafatto, M. (2014). The institutionalisation of social and environmental reporting: An Italian narrative. Accounting, Organisations and Society, 39(6), 414-432. https://doi.org/10.1016/j.aos.2014.01.002

Crosby, M., Pattanayak, P., Verma, S., \& Kalyanaraman, V. (2016). Blockchain technology: Beyond bitcoin. Applied Innovation, 2(6-10), 71. https://https://doi.org/10.4236/jmp.2019.103020

D’Adamo, I. (2019). Adopting a Circular Economy: Current Practices and Future Perspectives. https://doi. org/10.3390/socsci8120328

De-Juan-Vigaray, M. D., \& Seguí, A. I. E. (2019). Retailing, Consumers, and Territory: Trends of an Incipient Circular Model. Social Sciences, 8(11), 300. https://doi.org/10.3390/socsci8110300

Dubnick, M. J. (2007). Sarbanes-Oxley and the search for accountable corporate governance. GovNet ejournal. Available at: http://www.griffith.edu.au/epress/govnet.

Durand, R., Paugam, L., \& Stolowy, H. (2019). Do investors actually value sustainability indices? Replication, development, and new evidence on CSR visibility. Strategic Management Journal, 40(9), 1471-1490. https://doi.org/10.1002/smj.3035

Eckelman, M. J., Ashton, W., Arakaki, Y., Hanaki, K., Nagashima, S., \& Malone-Lee, L. C. (2014). Island waste management systems: Statistics, challenges, and opportunities for applied industrial ecology. Journal of Industrial Ecology, 18(2), 306-317. https://doi.org/10.1111/jiec.12113

Elgie, A. R., Singh, S. J., \& Telesford, J. N. (2021). You can't manage what you can't measure: The potential for circularity in Grenada's waste management system. Resources, Conservation and Recycling, 164, 105170. https://doi.org/10.1016/j.resconrec.2020.105170

Esposito, M., Tse, T., \& Soufani, K. (2018). Introducing a circular economy: new thinking with new managerial and policy implications. California Management Review, 60(3), 5-19. https://doi.org/10.1177/ 0008125618764691.

FAO. (2017). Food loss and food waste. Retrieved December 20, 2020 from http://www.fao.org/food-lossand-food-waste/en/.

Fink, A. (2014). Conducting research literature reviews: From the internet to paper. Sage publications. 4th Edition available at https://books.google.com.pk/books?id=edTeAQAAQBAJ\&printsec=frontcover $\& d q=$ conducting + research+literature +reviews +fink + pdf $\& h l=e n \& s a=X \& v e d=2 a h U K E w j l k K$ Z5pXuAhWZQkEAHW1nBxUQ6AEwAnoECAEQAg.

Fink, A. (2019). Conducting research literature reviews: From the internet to paper. Sage publications. $5^{\text {th }}$ Edition available at https://books.google.it/books?hl=en\&lr=\&id=0z1_DwAAQBAJ\&oi=fnd\& $\mathrm{pg}=\mathrm{PP} 1 \& \mathrm{dq}=$ Fink, + Arlene.+ Conducting+research+literature+reviews:+From +the+internet+to+ paper.+Sage+publications, $+2019 .+5$ th+Edition. $\&$ ots $=15$ Huh 1 UTfA\&sig $=x x 1 \mathrm{kNmChRcHtLq}$ namRS4MSUkWQ\&redir_esc $=\mathrm{y} \# \mathrm{v}=$ onepage $\& \mathrm{q}=$ Fink $\% 2 \mathrm{C} \% 20$ Arlene. $\% 20$ Conducting $\% 20$ res earch $\% 20$ literature $\% 20$ reviews $\% 3$ A $\% 20$ From $\% 20$ the $\% 20$ internet $\% 20$ to $\% 20$ paper.\%20Sage $\% 20$ pub lications $\% 2$ C $\% 202019 . \% 205$ th\%20Edition. $\& \mathrm{f}=$ false.

Frishammar J, Parida, V. (2019). Circular business model transformation: A roadmap for incumbent firms. California Management Review, 61(2):5-29. https://doi.org/10.1177/0008125618811926.

Fuldauer, L. I., Ives, M. C., Adshead, D., Thacker, S., \& Hall, J. W. (2019). Participatory planning of the future of waste management in small island developing states to deliver on the Sustainable Development Goals. Journal of Cleaner Production, 223, 147-162. https://doi.org/10.1016/j.jclepro.2019.02. 269

Geissdoerfer, M., Savaget, P., Bocken, N. M., \& Hultink, E. J. (2017). The Circular Economy-A new sustainability paradigm? Journal of Cleaner Production, 143, 757-768. https://doi.org/10.1016/j.jclepro. 2016.12.048

Ghisellini, P., Cialani, C., \& Ulgiati, S. (2016). A review on circular economy: The expected transition to a balanced interplay of environmental and economic systems. Journal of Cleaner Production, 114, 11-32. https://doi.org/10.1016/j.jclepro.2015.09.007 
Gregson, N., Crang, M., Fuller, S., \& Holmes, H. (2015). Interrogating the circular economy: The moral economy of resource recovery in the EU. Economy and Society, 44(2), 218-243. https://doi.org/10. 1080/03085147.2015.1013353

Guinée, J. B., Heijungs, R., \& Van Der Voet, E. (2009). A greenhouse gas indicator for bioenergy: Some theoretical issues with practical implications. The International Journal of Life Cycle Assessment, 14(4), 328-339. https://doi.org/10.1007/s11367-009-0080-x

Helander, H., Petit-Boix, A., Leipold, S., \& Bringezu, S. (2019). How to monitor environmental pressures of a circular economy: An assessment of indicators. Journal of Industrial Ecology, 23(5), 1278-1291. https://doi.org/10.1111/jiec.12924

Hirsch, J. E. (2005). An index to quantify an individual's scientific research output. Proceedings of the National Academy of Sciences, 102(46), 16569-16572. https://doi.org/10.1073/pnas.0507655102

Hofmann, F., \& Jaeger-Erben, M. (2020). Organizational transition management of circular business model innovations. Business Strategy and the Environment, 29(6), 2770-2788. https://doi.org/10.1002/bse. 2542

Hu, Z., Tian, W., Xu, S., Zhang, C., \& Wang, X. (2018). Four pitfalls in normalising citation indicators: An investigation of ESI's selection of highly cited papers. Journal of Informetrics, 12(4), 1133-1145. https://doi.org/10.1016/j.joi.2018.09.006

Hughes, L., Dwivedi, Y. K., Misra, S. K., Rana, N. P., Raghavan, V., \& Akella, V. (2019). Blockchain research, practice and policy: Applications, benefits, limitations, emerging research themes and research agenda. International Journal of Information Management, 49, 114-129. https://doi.org/10. 1016/j.ijinfomgt.2019.02.005

Iacovidou, E., Hahladakis, J., Deans, I., Velis, C., \& Purnell, P. (2018). Technical properties of biomass and solid recovered fuel (SRF) co-fired with coal: Impact on multi-dimensional resource recovery value. Waste Management, 73, 535-545. https://doi.org/10.1016/j.wasman.2017.07.001

Iacovidou, E., Hahladakis, J. N., \& Purnell, P. (2021). A systems thinking approach to understanding the challenges of achieving the circular economy. Environmental Science and Pollution Research, 28(19), 24785-24806.

Iacovidou, E., Millward-Hopkins, J., Busch, J., Purnell, P., Velis, C. A., Hahladakis, J. N., Zwirner, O., \& Brown, A. (2017). A pathway to circular economy: Developing a conceptual framework for complex value assessment of resources recovered from waste. Journal of Cleaner Production, 168, 12791288. https://doi.org/10.1016/j.jclepro.2017.09.002

Imoniana, J. O., Silva, W. L., Reginato, L., Slomski, V., \& Slomski, V. G. (2020). Sustainable technologies for the transition of auditing towards a circular economy. Sustainability, 2021(13), 218. https://doi. org/10.3390/su13010218

Imperatives, S. (1987). Report of the World Commission on Environment and Development: Our common future. Available at http://www.ask-force.org/web/Sustainability/Brundtland-Our-Common-Future1987-2008.pdf.

Jabbour, C. J. C., de Sousa Jabbour, A. B. L., Sarkis, J., \& Godinho Filho, M. (2019). Unlocking the circular economy through new business models based on large-scale data: An integrative framework and research agenda. Technological Forecasting and Social Change, 144, 546-552. https://doi.org/10. 1016/j.techfore.2017.09.010

Jacobi, N., Haas, W., Wiedenhofer, D., \& Mayer, A. (2018). Providing an economy-wide monitoring framework for the circular economy in Austria: Status quo and challenges. Resources, Conservation and Recycling, 137, 156-166. https://doi.org/10.1016/j.resconrec.2018.05.022

Jacso, P. (2018). The scientometric portrait of Eugene Garfield through the free ResearcherID service from the Web of Science Core Collection of 67 million master records and 1.3 billion references. Scientometrics, 114(2), 545-555. https://doi.org/10.1007/s11192-017-2624-3.

Jamali, D. (2010). MNCs and international accountability standards through an institutional lens: Evidence of symbolic conformity or decoupling. Journal of Business Ethics, 95(4), 617-640.

Kauflin, J. (2017). The world's most sustainable companies 2017. Forbes,(online) Available at: https://www. forbes.com/sites/jeffkauflin/2017/01/17/theworlds-most-sustainable-companies-2017.

Kazancoglu, I., Sagnak, M., Kumar Mangla, S., \& Kazancoglu, Y. (2021). Circular economy and the policy: A framework for improving the corporate environmental management in supply chains. Business Strategy and the Environment, 30(1), 590-608. https://doi.org/10.1002/bse.2641

Kirchherr, J., Reike, D., \& Hekkert, M. (2017). Conceptualising the circular economy: An analysis of 114 definitions. Resources, Conservation and Recycling, 127, 221-232. https://doi.org/10.1016/j.resco nrec.2017.09.005

Koksharov, S. A., Aleeva, S. V., \& Lepilova, O. V. (2019). Description of adsorption interactions of lead ions with functional groups of pectin-containing substances. Journal of Molecular Liquids, 283, 606616. https://doi.org/10.1016/j.molliq.2019.03.109 
Kolk, A., Van Tulder, R., \& Welters, C. (1999). International codes of conduct and corporate social responsibility: can transnational corporations regulate themselves?. Transnational Corporations, 8(1), 143180. Available at https://www.researchgate.net/profile/Roger-Strange/publication/232128530_Where_ Do_Japanese_Manufacturing_Firms_Invest_within_Europe_and_Why/links/578e080608ae35e97c3f 5d90/Where-Do-Japanese-Manufacturing-Firms-Invest-within-Europe-and-Why.pdf\#page=151.

Korhonen, J., Honkasalo, A., \& Seppälä, J. (2018). Circular economy: The concept and its limitations. Ecological Economics, 143, 37-46. https://doi.org/10.1016/j.ecolecon.2017.06.041

Krippendorff, K. (2004). Reliability in content analysis: Some common misconceptions and recommendations. Human Communication Research, 30(3), 411-433. https://doi.org/10.1111/j.1468-2958.2004. tb00738.x

Langley, A., \& Abdallah, C. (2011). Templates and turns in qualitative studies of strategy and management. Emerald Group Publishing Limited. https://doi.org/10.1108/S1479-8387(2011)0000006007

Latour, B. (2018). Down to earth: Politics in the new climatic regime. John Wiley \& Sons. Available at: https://books.google.it/books?hl=en\&lr=\&id=-md-DwAAQBAJ\&oi=fnd\&pg=PT4\&dq=Latour,+ 2018\&ots=X0i-_RnzjE\&sig=LtowAJv6K42jiTULPsw5LKRsnaU\&redir_esc $=y \# v=$ onepage \&q= Latour\%2C\%202018\&f=false.

Lenkiewicz, Z. (2016). Waste and the sustainable development goals. Wasteaid. Wasteaid URL. https:// wasteaid.org/waste-sustainable-development-goals/.

Li, K., Rollins, J., \& Yan, E. (2018). Web of Science use in published research and review papers 19972017: A selective, dynamic, cross-domain, content-based analysis. Scientometrics, 115(1), 1-20. https://doi.org/10.1007/s11192-017-2622-5

Liu, W., Tang, L., \& Hu, G. (2020). Funding information in Web of Science: An updated overview. Scientometrics, in Press. https://doi.org/10.1007/s11192-020-03362-3

MacArthur, E. (2013). Towards the circular economy, economic and business rationale for an accelerated transition. Ellen MacArthur Foundation: Cowes, UK, 21-34. Available online:https://ellenmacarthurf oundation.org/towards-the-circular-economy-vol-1-an-economic-and-business-rationale-for-an.

Maina, S., Kachrimanidou, V., \& Koutinas, A. (2017). A roadmap towards a circular and sustainable bioeconomy through waste valorisation. Current Opinion in Green and Sustainable Chemistry, 8, 18-23. https://doi.org/10.1016/j.cogsc.2017.07.007

Martens, M. L., Brones, F., \& Carvalho, M. M. (2013). Lacunas e tendências na literatura de sustentabilidade no gerenciamento de projetos: uma revisão sistemática mesclando bibliometria e análise de conteúdo. Revista De Gestão e Projetos, 4(1), 165-195. https://doi.org/10.5585/gep.v4i1.123

Massaro, M., Dumay, J., \& Guthrie, J. (2016). On the shoulders of giants: Undertaking a structured literature review in accounting. Accounting, Auditing \& Accountability Journal, 29(5), 767-801. https:// doi.org/10.1108/AAAJ-01-2015-1939

Mathews, J. A., \& Tan, H. (2011). Progress toward a circular economy in China: The drivers (and inhibitors) of eco-industrial initiative. Journal of Industrial Ecology, 15(3), 435-457. https://doi.org/10.1111/j. 1530-9290.2011.00332.x

Mathews, J. A., \& Tan, H. (2016). Circular economy: Lessons from China. Nature News, 531(7595), 440. https://doi.org/10.1038/531440a

Mayer, A., Haas, W., Wiedenhofer, D., Krausmann, F., Nuss, P., \& Blengini, G. A. (2019). Measuring progress towards a circular economy: A monitoring framework for economy-wide material loop closing in the EU28. Journal of Industrial Ecology, 23(1), 62-76. https://doi.org/10.1111/jiec. 12809

Michelon, G., Patten, D. M., \& Romi, A. M. (2019). Creating legitimacy for sustainability assurance practices: Evidence from sustainability restatements. European Accounting Review, 28(2), 395-422. https://doi.org/10.1080/09638180.2018.1469424

Millette, S., Williams, E., \& Hull, C. E. (2019). Materials flow analysis in support of circular economy development: Plastics in Trinidad and Tobago. Resources, Conservation and Recycling, 150, 104436. https://doi.org/10.1016/j.resconrec.2019.104436

Millward-Hopkins, J., \& Purnell, P. (2019). Circulating blame in the circular economy: The case of woodwaste biofuels and coal ash. Energy Policy, 129, 168-172. https://doi.org/10.1016/j.enpol.2019.02. 019

Murray, A., Skene, K., \& Haynes, K. (2017). The circular economy: An interdisciplinary exploration of the concept and application in a global context. Journal of Business Ethics, 140(3), 369-380. https://doi. org/10.1007/s10551-015-2693-2

Nadae, J., \& Carvalho, M. M. (2019). Integrated manaement systems as a driver for sustainability: the greview and analysis of the literature and the proposition of the conceptual framework. Production, v28, e20180048. https://doi.org/10.1590/0103-6513.201. 
Okoli, C., \& Schabram, K. (2010). A guide to conducting a systematic literature review of information systems research. Sprouts: Working Papers on Information Systems, 10(26). http://sprouts.aisnet.org/ $10-26$.

Pagoropoulos, A., Pigosso, D. C., \& McAloone, T. C. (2017). The emergent role of digital technologies in the Circular Economy: A review. Procedia CIRP, 64, 19-24. https://doi.org/10.1016/j.procir.2017.02. 047

Principato, L., (2018). Food Waste at the Consumer Level. A Comprehensive Literature Review. Springer International Publishing, Cham (ZG)Switzerland. https://doi.org/10.1007/978-3-319-78887-6_1.

Qian, W., Burritt, R., \& Monroe, G. (2011). Environmental management accounting in local government: A case of waste management. Accounting, Auditing \& Accountability Journal. https://doi.org/10.1108/ 09513571111098072

Queeny, D. S. (2000). Handbook of Adult and Continuing Education, 2000, 141.

Rajput, S., \& Singh, S. P. (2019). Industry 4.0- challenges to implement circular economy. Benchmarking: An International Journal. https://doi.org/10.1108/BIJ-12-2018-0430.

Rajput, S., \& Singh, S. P. (2019a). Connecting circular economy and industry 4.0. International Journal of Information Management, 49, 98-113. https://doi.org/10.1016/j.ijinfomgt.2019.03.002

Reike, D., Vermeulen, W. J. V., \& Witjes, S. (2018). The circular economy: new or refurbished as CE 3.0? - exploring controversies in the conceptualisation of the circular economy through a focus on history and resource value retention. Resources, Conservation \& Recycling, 135, 246-264. https://doi. org/10.1016/j.resconrec.2017.08.027

Ribeiro, I., Sobral, P., Peças, P., \& Henriques, E. (2018). A sustainable business model to fight food waste. Journal of Cleaner Production, 177, 262-275. https://doi.org/10.1016/j.jclepro.2017.12.200

Ribeiro, J. A., \& Scapens, R. W. (2006). Institutional theories in management accounting change: Contributions, issues and paths for development. Qualitative Research in Accounting \& Management. https:// doi.org/10.1108/11766090610670640

RLI (2015). Circulaire Economie: Van Wens Naar Uitvoering. Available at https://www.rli.nl/sites/default/ files/advice_rli_circular_economy_interactive_def.pdf.

Rogers, E. M. (2003). "Diffusion of Innovations," Book available online at https://teddykw2.files.wordpress. com/2012/07/everett-m-rogers-diffusion-of-innovations.pdf.

Rosa, P., Sassanelli, C., \& Terzi, S. (2019). Towards Circular Business Models: A systematic literature review on classification frameworks and archetypes. Journal of Cleaner Production, 236, 117696. https://doi.org/10.1016/j.jclepro.2019.117696

Scarpellini, S., Marín-Vinuesa, L. M., Aranda-Usón, A., \& Portillo-Tarragona, P. (2020)b. Dynamic capabilities and environmental accounting for the circular economy in businesses. Sustainability Accounting, Management and Policy Journal. https://doi.org/10.1108/SAMPJ-04-2019-0150.

Scarpellini, S., Valero-Gil, J., Moneva, J. M., \& Andreaus, M. (2020)a. Environmental management capabilities for a "circular eco-innovation". Business Strategy and the Environment, 29(5), 1850-1864. https://doi.org/10.1002/bse.2472.

Schaltegger, S., Lüdeke-Freund, F., \& Hansen, E. G. (2016). Business models for sustainability: A co-evolutionary analysis of sustainable entrepreneurship, innovation, and transformation. Organization \& Environment, 29(3), 264-289. https://doi.org/10.1177/1086026616633272.

Schroeder, P., Anggraeni, K., \& Weber, U. (2019). The relevance of circular economy practices to the sustainable development goals. Journal of Industrial Ecology, 23(1), 77-95. https://doi.org/10.1111/jiec. 12732

Schubert, A., \& Schubert, G. (2020). Internationality at university level. Scientometrics, 123(3), 1341-1364. https://doi.org/10.1007/s11192-020-03443-3

Scopus (2020). Scopus Roadmap: What's coming up in 2020 \& 2021? Recovered from https://blog.scopus. com/posts/scopus-roadmap-whats-coming-up-in-2020-2021.

Selçuk, A. A. (2019). A guide for systematic reviews: PRISMA. Turkish Archives of Otorhinolaryngology, 57(1), 57. https://doi.org/10.5152/tao.2019.4058

SER (2016). Werken aan een circulaire economie: geen tijd te verliezen. The Hague, The Netherlands: Sociaal-Economische Raad. Available at https://www.mk-bedrijfsoverdrachten.nl/wp-content/uploa ds/2016/08/circulaire-economie.pdf.

Shamir, R. (2004). Between self-regulation and the Alien Tort Claims Act: on the contested concept of corporate social responsibility. Law \& Society Review, 38(4), 635-664.https://doi.org/10.1111/j.00239216.2004.00062.x.

Sikdar, S. (2019). Circular economy: Is there anything new in this concept?. https://doi.org/10.1007/ s10098-019-01722-z.

Strand, M., \& Syberfeldt, A. (2020). Using external data in a BI solution to optimise waste management. Journal of Decision Systems, 29(1), 53-68. https://doi.org/10.1080/12460125.2020.1732174. 
Tang, L., \& Shapira, P. (2011). China-US scientific collaboration in nanotechnology: Patterns and dynamics. Scientometrics, 88(1), 1-16. https://doi.org/10.1007/s11192-011-0376-Z

Tuladhar, S., Yuan, M., \& Montgomery, W. D. (2016). An Economic Analysis of The Circular Economy. Available at https://www.gtap.agecon.purdue.edu/resources/res_display.asp?RecordID=4937.

Turner, J. R., \& Baker, R. (2020). Collaborative research: Techniques for conducting collaborative research from the science of team science (SciTS). Advances in Developing Human Resources, 22(1), 72-86. https://doi.org/10.1177/1523422319886300

Tweede K. (2012). Bruggen slaan. Regeerakkoord VVD - PvdA. 29 oktober 2012. Regeerakkoord voor de periode 2012 - 2015. Available at http://www.rijksoverheid.nl/documentenen-publicaties/rapporten/ 2012/10/29/regeerakkoord.html Accessed on May 23rd, 2018.

Upward, A., \& Jones, P. (2016). An ontology for strongly sustainable business models: Defining an enterprise framework compatible with natural and social science. Organization \& Environment, 29(1), 97-123. https://doi.org/10.1177/1086026615592933.

Valenzuela-Fernandez, L., Merigó, J. M., Lichtenthal, J. D., \& Nicolas, C. (2019). A bibliometric analysis of the first 25 years of the Journal of Business-to-Business Marketing. Journal of Business-to-Business Marketing, 26(1), 75-94. https://doi.org/10.1080/1051712X.2019.1565142

Vallero, D. A. (2019). Waste Management Accountability: Risk, Reliability, and Resilience. In waste (pp. 693-740). Academic Press. https://doi.org/10.1016/B978-0-12-815060-3.00035-9.

Van Eck, N. J., \& Waltman, L. (2007). VOS: A new method for visualising similarities between objects. In Advances in data analysis (pp. 299-306). Springer, Berlin, Heidelberg. https://doi.org/10.1007/ 978-3-540-70981-7_34.

Van Eck, N. J., \& Waltman, L. (2014). Visualising bibliometric networks. In Measuring scholarly impact (pp. 285-320). Springer, Cham. https://doi.org/10.1007/978-3-319-10377-8_13.

Waddock, S. (2004). Parallel universes: Companies, academics, and the progress of corporate citizenship. Business and Society Review, 109(1), 5-42. https://doi.org/10.1111/j.0045-3609.2004.00002.x

Warren, C. S., Reeve, J. M., \& Duchac, J. (2012). Accounting. Cengage Learning. Available at: https:// books.google.it/books?hl=en \&lr=\&id=waEWAAAAQBAJ\&oi=fnd \&pg=PP1\&dq=what + is + accou nting \&ots=UC54AZP4Wj\&sig=Xn4bBFRYmFfpUqMeR2L8IZKcNJ4\&redir_esc=y\#v=onepa ge $\& \mathrm{q}=$ what $\% 20$ is $\% 20$ accounting $\& \mathrm{f}=$ false.

Williams, O. F. (2004). The UN Global Compact: The challenge and the promise. Business Ethics Quarterly, 14(4), 755-774. https://doi.org/10.5840/beq200414432

World Bank. (2014). Food loss and waste a barrier to poverty reduction. Retrieved from https://www.world bank.org/en/news/press-release/2014/02/27/food-loss-waste-barrier-poverty-reduction.

Zacho, K. O., Mosgaard, M., \& Riisgaard, H. (2018). Capturing uncaptured values-A Danish case study on municipal preparation for reuse and recycling of waste. Resources, Conservation and Recycling, 136, 297-305. https://doi.org/10.1016/j.resconrec.2018.04.031

Publisher's Note Springer Nature remains neutral with regard to jurisdictional claims in published maps and institutional affiliations.

\section{Authors and Affiliations}

\section{Assunta Di Vaio ${ }^{1}(\mathbb{D})$ Sohail Hasan ${ }^{1}\left(\mathbb{D} \cdot\right.$ Rosa Palladino $^{2}(\mathbb{D}) \cdot$ Rohail Hassan $^{3}$}

Sohail Hasan

sohailhassanias.pu@kdis.ac.kr

Rosa Palladino

rosa.palladino@unimib.it

Rohail Hassan

rohail.hassan@uum.edu.my

1 Department of Law, University of Naples "Parthenope", Via G. Parisi, No. 13, 80132 Naples, Italy

2 Department of Economics, Quantitative Methods and Business Strategies, University of Milano "Bicocca", Piazza dell'Ateneo Nuovo, No. 1, 20126 Milan, Italy

3 Othman Yeop Abdullah Graduate School of Business (OYAGSB), Universiti Utara Malaysia (UUM), 50300 Kuala Lumpur, Malaysia 